\title{
TOLERÂNCIA DO TOMATEIRO À SALINIDADE SOB FERTIRRIGAÇÃO E CALIBRAÇÃO DE MEDIDORES DE ÍONS ESPECÍFICOS PARA DETERMINAÇÃO DE NUTRIENTES NA SOLUÇÃO DO SOLO E NA PLANTA
}

FLÁVIO FAVARO BLANCO

Tese apresentada à Escola Superior de Agricultura "Luiz de Queiroz", Universidade de São Paulo, para obtenção do título de Doutor em Agronomia, Área de Concentração: Irrigação e Drenagem.

PIR A C I C A B A

Estado de São Paulo - Brasil

Janeiro - 2004 


\title{
TOLERÂNCIA DO TOMATEIRO À SALINIDADE SOB FERTIRRIGAÇÃO E CALIBRAÇÃO DE MEDIDORES DE ÍONS ESPECÍFICOS PARA DETERMINAÇÃO DE NUTRIENTES NA SOLUÇÃO DO SOLO E NA PLANTA
}

\author{
FLÁVIO FAVARO BLANCO
}

Engenheiro Agrônomo

Orientador: Prof. Dr. MARCOS VINÍCIUS FOLEGATTI

Tese apresentada à Escola Superior de Agricultura "Luiz de Queiroz", Universidade de São Paulo, para obtenção do título de Doutor em Agronomia, Área de Concentração: Irrigação e Drenagem.

P I R A C I C A B A

Estado de São Paulo - Brasil

Janeiro - 2004 
Dados Internacionais de Catalogação na Publicação (CIP)
DIVISÃO DE BIBLIOTECA E DOCUMENTAÇÃO - ESALQ/USP

\section{Blanco, Flávio Favaro}

Tolerância do tomateiro à salinidade sob fertirrigação e calibração de medidores de íons específicos para determinação de nutrientes na solução do solo e na planta / Flávio Favaro Blanco. - - Piracicaba, 2004.

$115 \mathrm{p}$.

Tese (doutorado) - Escola Superior de Agricultura Luiz de Queiroz, 2004.

Bibliografia.

1. Condutividade elétrica 2. Fertirrigação 3 . Salinidade do solo 4. Tolerância a salinidade 5 . Tomate I. Título

CDD 635.642

\section{"Permitida a cópia total ou parcial deste documento, desde que citada a fonte - $\mathrm{O}$ autor"}


Aos meus pais, Luiz e Dair, que com muito amor se dedicaram e se esforçaram para que eu pudesse alcançar os meus objetivos.

\section{DEDICO}

Ao agricultor que busca o aprimoramento das técnicas de cultivo à luz dos conhecimentos gerados em trabalhos como este. MINHA HOMENAGEM

À minha amada esposa, Alessandra, pelo amor, carinho e paciência nos momentos mais difíceis. 


\section{AGRADECIMENTOS}

À Deus e à sagrada família, pela luz que me guia em todos os momentos da minha vida.

Ao Departamento de Engenharia Rural da ESALQ/USP, pela possibilidade de realização do curso.

À FAPESP, pela bolsa de estudos e pelos recursos financeiros concedidos para o desenvolvimento do projeto de pesquisa.

Ao prof. Dr. Marcos Vinícius Folegatti, pela orientação, amizade e, principalmente, pela total confiança que sempre depositou na minha pessoa e no meu trabalho.

À empresa de sementes Tomatec, pela doação das sementes do híbrido de tomateiro utilizado neste estudo.

Aos professores Antonio Enedi Boaretto (CENA/USP) e Murilo Melo (CBTEC - ESALQ/USP), pelos ensinamentos e pelo apoio nas análises laboratoriais.

Aos funcionários do Departamento de Engenharia Rural, pela amizade, auxílio nos trabalhos e convivência harmoniosa.

A todos os colegas do curso de Pós-Graduação em Irrigação e Drenagem (CPGID), pela amizade e companheirismo durante o período de realização do curso.

A todos que contribuíram para minha formação e para a realização deste trabalho. 


\section{SUMÁRIO}

Página

LISTA DE FIGURAS .......................................................................... viii

LISTA DE TABELAS ......................................................................

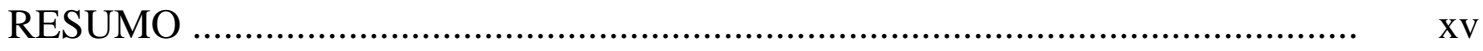

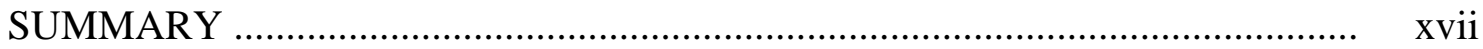

1 INTRODUÇÃ

2 REVISÃO DE LITERATURA ….......................................................... 4

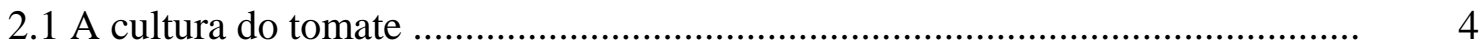

2.2 Métodos de irrigação e manejo para o tomateiro ............................................ 7

2.3 Aspectos nutricionais e fertirrigação do tomateiro ......................................... 10

2.4 A solução do solo ................................................................................. 12

2.5 Análise da solução do solo e da seiva ........................................................... 16

2.6 Salinidade e tolerância do tomateiro aos sais .................................................. 18

2.7 Interação entre a nutrição mineral e a tolerância das culturas à salinidade ...... 20

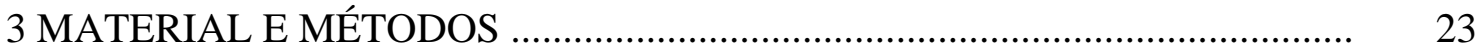

3.1 Localização e características da área experimental ....................................... 23

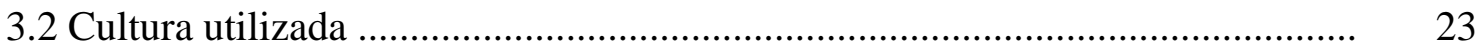

3.3 Descrição da estrutura experimental ............................................................. 24

3.4 Características físico-hídricas do solo ..................................................... 24

3.5 Características químicas do solo e adubação de fundação ............................... 25

3.6 Condução das plantas e tratos culturais ......................................................... 26

3.7 Equipamentos para monitoramento meteorológico ..................................... 27

3.8 Tratamentos e delineamento estatístico ........................................................ 27 
3.9 Sistema de irrigação e manejo ......................................................................... 28

3.10 Preparo das águas de irrigação ................................................................. 31

3.11 Variáveis avaliadas ..................................................................................... 32

3.11.1 Variáveis relacionadas ao solo ............................................................... 32

3.11.1.1 Condutividade elétrica e pH da solução do solo ......................................... 32

3.11.1.2 Concentração iônica na solução do solo ..................................................... 33

3.11.1.3 Relação entre variáveis medidas no extrato de saturação, no extrato 1:2 e na solução do solo ................................................................................

3.11.2 Variáveis relacionadas à cultura ................................................................ 35

3.11.2.1 Altura das plantas e diâmetro da haste ...................................................... 35

3.11.2.2 Área foliar ......................................................................................... 36

3.11.2.3 Florescimento ............................................................................... 36

3.11.2.4 Componentes de produção ......................................................................... 37

3.11.2.5 Produção e porcentagem de matéria seca ..................................................... 37

3.11.2.6 Concentração iônica na seiva ................................................................... 38

3.11.2.7 Teor de prolina nas folhas ..................................................................... 39

3.11.2.8 Teor de macro e micronutrientes nas folhas ................................................ 39

3.11.2.9 Qualidade dos frutos ...................................................................... 39

3.12 Calibração dos medidores de íons específicos ................................................. 40

3.13 Análise estatística .......................................................................................

4 RESULTADOS E DISCUSSÃO ................................................................ 43

4.1 Características físico-hídricas do material de solo .............................................. 43

4.2 Características meteorológicas durante o período de cultivo do tomateiro ........ 44

4.3 Avaliação do sistema de irrigação e equipamentos de manejo ........................... 45

4.4 Condutividade elétrica e pH da água de irrigação .............................................. 46

4.5 Variação do potencial mátrico e freqüência de irrigação ....................................... 47

4.6 Calibração dos medidores de íons específicos ................................................... 49

4.6.1 Solução do solo ..........................................................................................

4.6.2 Folhas das plantas de tomate ………............................................................. 51

4.7 Variáveis relacionadas ao solo ......................................................................... 53 
4.7.1 Características químicas da solução do solo .................................................... 53

4.7.1.1 Condutividade elétrica e $\mathrm{pH}$........................................................................ 53

4.7.1.2 Concentração iônica ................................................................................... 56

4.7.2 Relação entre a condutividade elétrica e a concentração iônica medidas na solução do solo, no extrato de saturação e na solução 1:2 ............................... 64

4.8 Variáveis relacionadas à cultura do tomateiro ................................................... 71

4.8.1 Concentração iônica na seiva do pecíolo ............................................................ 71

4.8.2 Teor de nutrientes e de prolina nas folhas ....................................................... 73

4.8.3 Altura das plantas e diâmetro da haste .......................................................... 78

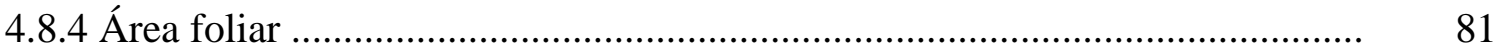

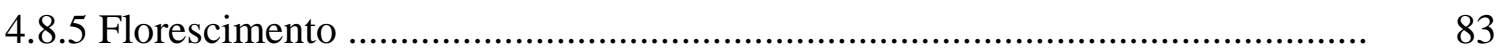

4.8.6 Produtividade e características dos frutos ………………………………....... 85

4.8.7 Produção de matéria seca ................................................................................ 87

4.8.8 Qualidade dos frutos ............................................................................... 91

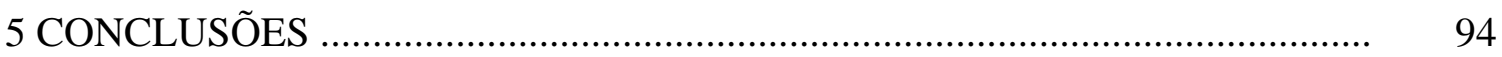

REFERÊNCIAS BIBLIOGRÁFICAS .................................................................. 96 


\section{LISTA DE FIGURAS}

Página

1 Ambiente protegido utilizado no cultivo do tomateiro ……………………..... 24

2 Sistema de irrigação e equipamentos de manejo: (A) Motobombas (MB) e reservatórios; (B) tubulação de irrigação com microtubos e linha lateral de plantas; (C) gotejadores, tensiômetros e extrator da solução do solo .............

3 Quantidades acumuladas de N, K e Ca aplicadas ao longo do ciclo do tomateiro em ambiente protegido ................................................................

4 Esquema da folha do tomateiro demonstrando a parte utilizada nas determinações de concentração de nutrientes na seiva ...................................... 38

5 Curva característica de retenção de água pelo material de solo utilizado ........

6 Variação das temperaturas máxima, média e mínima do ar (A) e umidade relativa média (B) no interior do ambiente protegido durante o período experimental. DAT $=$ dias após o transplantio

7 Variação da evaporação do minitanque no interior do ambiente protegido durante o período experimental. DAT = Dias após o transplantio .....................

8 Variação da condutividade elétrica $\left(\mathrm{CE}_{\mathrm{a}}\right)$ e $\mathrm{pH}\left(\mathrm{pH}_{\mathrm{a}}\right)$ da água de irrigação para cada tratamento ao longo do período de cultivo do tomateiro. DAT = dias após o transplantio

9 Variação do potencial mátrico ( $\Psi \mathrm{m})$ para os diferentes tratamentos ao longo do período de cultivo do tomateiro

10 Intervalo entre as irrigações ao longo do período de cultivo do tomateiro ..... 
11 Relação entre as concentrações de $\mathrm{NO}_{3}$ (A), $\mathrm{K}$ (B) e Na (C) determinadas pelos medidores de íons específicos (MIE) e pelos métodos-padrões (Dest=destilação, $\mathrm{FC}=$ fotometria de chama) na solução do solo

12 Relação entre as concentrações de nitrato, $\mathrm{NO}_{3 \text { seiva }}(\mathrm{A})$, potássio, $\mathrm{K}_{\text {seiva }}(\mathrm{B})$ e sódio, $\mathrm{Na}_{\text {seiva }}(\mathrm{C})$, determinadas pelos medidores de íons específicos na seiva do pecíolo e os teores de N, K e Na na matéria seca, MS, das folhas de tomateiro, híbrido Facundo

13 Variação da condutividade elétrica, $\mathrm{CE}_{\mathrm{s}}\left(\mathrm{A}\right.$ e B), e do $\mathrm{pH}, \mathrm{pH}_{\mathrm{s}}(\mathrm{C}$ e D), da solução do solo ao longo do período de cultivo do tomateiro, para cada nível de $\mathrm{N}$ e K aplicado via fertirrigação. DAT = dias após o transplantio ....

14 Variação da concentração de nitrato, $\mathrm{NO}_{3 \mathrm{~s}}$ (A e B), e potássio, $\mathrm{K}_{\mathrm{s}}$ (C e D), na solução do solo ao longo do período de cultivo do tomateiro, para cada nível de $\mathrm{N}$ e K aplicado via fertirrigação. DAT = dias após o transplantio ....

15 Variação da concentração de sódio na solução do solo, $\mathrm{Na}_{\mathrm{s}}$, ao longo do período de cultivo do tomateiro, para cada nível de N (A) e K (B) aplicado via fertirrigação

16 Relação entre as concentrações de nitrato $\left(\mathrm{NO}_{3 s}\right)$ e potássio $\left(\mathrm{K}_{\mathrm{s}}\right)$ na solução do solo e os níveis de N (A) e K (B) aplicados via fertirrigação, para cada coleta da solução do solo realizada durante o período de cultivo

17 Concentração média de sódio na solução do solo $\left(\mathrm{Na}_{\mathrm{s}}\right)$ dentro dos níveis $\mathrm{K} 1$ e K2 de potássio, na quarta, quinta e sexta amostragens (Am4, Am5 e Am6, respectivamente), em função do nível de $\mathrm{N}$ aplicado via fertirrigação ............

18 Relação entre a condutividade elétrica medida no extrato de saturação, $\mathrm{CE}_{\mathrm{es}}$ (A), e na solução 1:2, $\mathrm{CE}_{1: 2}(\mathrm{~B})$, com a condutividade elétrica medida da solução do solo, $\mathrm{CE}_{\mathrm{s}}$

19 Relação entre as concentrações de nitrato, $\mathrm{NO}_{3 \mathrm{~s}}(\mathrm{~A})$, potássio, $\mathrm{K}_{\mathrm{s}}(\mathrm{B})$, sódio, $\mathrm{Na}_{\mathrm{s}}$ (C) e cálcio, $\mathrm{Ca}_{\mathrm{s}}$ (D), medidas na solução do solo, com as concentrações medidas no extrato de saturação $\left(\mathrm{NO}_{3 \mathrm{es}}, \mathrm{K}_{\mathrm{es}}, \mathrm{Na}_{\mathrm{es}}\right.$ e $\mathrm{Ca}_{\mathrm{es}}$, respectivamente) 
20 Relação entre os valores de condutividade elétrica medida, $\mathrm{CE}_{\mathrm{s}}$, e estimada na solução do solo a partir dos valores medidos: (A) no extrato de saturação

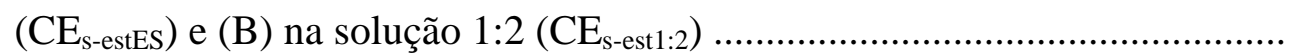

21 Relação entre as concentrações de $\mathrm{NO}_{3}(\mathrm{~A})$, potássio (B), sódio (C) e cálcio (D) medidas ( $\mathrm{NO}_{3 \mathrm{~s}}, \mathrm{~K}_{\mathrm{s}}, \mathrm{Na}_{\mathrm{s}}$ e $\mathrm{Ca}_{\mathrm{s}}$, respectivamente) e estimadas ( $\mathrm{NO}_{3 \mathrm{~s}-\mathrm{estES}}$, $\mathrm{K}_{\text {s-estEs }}, \mathrm{Na}_{\text {s-estEs }}$ e $\mathrm{Ca}_{\text {s-estEs }}$ respectivamente) na solução do solo, a partir das concentrações medidas no extrato de saturação

22 Relação entre o teor de potássio medido na seiva do pecíolo do tomateiro ( $\left.\mathrm{K}_{\text {seiva }}\right)$ por ocasião do florescimento do quinto cacho e os níveis de $\mathrm{K}$ aplicados via fertirrigação

23 Relação entre os teores de nitrogênio (A), fósforo (B), enxofre (C) e boro (D) nas folhas do tomateiro ao final do período de cultivo e os níveis de $\mathrm{N}$ aplicados via fertirrigação .....

24 Relação entre os teores de potássio (A) e prolina (B) nas folhas do tomateiro e os níveis de K aplicados via fertirrigação

25 Variação da altura (A e B) e diâmetro da haste (C e D) das plantas de tomate ao longo do período de cultivo, para cada nível de $\mathrm{N}$ e $\mathrm{K}$ aplicado via fertirrigação. DAT = número de dias após o transplantio

26 Relação entre a área foliar medida e o produto do comprimento (C) pela largura (L) de vinte folhas do tomateiro

27 Padrão de distribuição de área foliar das plantas de tomate para as plantas do tratamento N2K2 em cada bloco experimental

28 Peso médio de frutos de tomate ao longo do período produtivo, para cada nível de $\mathrm{N}$ (A) e K (B) aplicado via fertirrigação

29 Relação entre massa seca de haste+cachos, MSHC (A), e massa seca total, MST (B), e os níveis de K aplicados via fertirrigação

30 Relação entre os teores de nitrogênio (A) e potássio (B) nos frutos do tomateiro ao final do período de cultivo e os níveis de $\mathrm{K}$ aplicados via fertirrigação 


\section{LISTA DE TABELAS}

Página

1 Características químicas do solo antes da adubação de fundação...................... 25

2 Resumo da análise multivariada para condutividade elétrica $\left(\mathrm{CE}_{\mathrm{s}}\right)$ e $\mathrm{pH}$ $\left(\mathrm{pH}_{\mathrm{s}}\right)$ da solução do solo, em função do tempo $(\mathrm{T})$ e dos níveis de $\mathrm{N}$ e $\mathrm{K}$ aplicados via fertirrigação

3 Resumo da análise de variância para condutividade elétrica da solução do solo para cada amostragem realizada ao longo do período de cultivo, em função dos níveis de $\mathrm{N}$ e da interação NxK

4 Resumo da análise de variância para condutividade elétrica da solução do solo para a quinta e sexta amostragens realizadas ao longo do período de cultivo, em função dos níveis de $\mathrm{N}$ dentro dos níveis de $\mathrm{K}$ e dos níveis de $\mathrm{K}$ dentro dos níveis de $\mathrm{N}$

5 Resumo da análise multivariada para concentração de nitrato $\left(\mathrm{NO}_{3 \mathrm{~s}}\right)$, potássio $\left(\mathrm{K}_{\mathrm{s}}\right)$ e sódio $\left(\mathrm{Na}_{\mathrm{s}}\right)$ na solução do solo, em função do tempo $(\mathrm{T})$ e dos níveis de $\mathrm{N}$ e K aplicados via fertirrigação

6 Resumo da análise de variância para concentração de nitrato na solução do solo, para cada amostragem realizada ao longo do período de cultivo, em função dos níveis de $\mathrm{N}$ aplicados via fertirrigação

7 Resumo da análise de variância para concentração de potássio na solução do solo, para cada amostragem realizada ao longo do período de cultivo, em função dos níveis de $\mathrm{K}$ aplicados via fertirrigação 
8 Equações de regressão linear e coeficientes de determinação $\left(r^{2}\right)$ para concentração de nitrato e potássio na solução do solo, em função dos níveis de $\mathrm{N}$ e $\mathrm{K}$, respectivamente, aplicados via fertirrigação

9 Resumo da análise de variância para concentração de sódio na solução do solo, para cada amostragem realizada ao longo do período de cultivo, em função dos níveis de N aplicados via fertirrigação e da interação NxK .........

10 Resumo da análise de variância para concentração de sódio na solução do solo, em função dos níveis de $\mathrm{N}$ dentro dos níveis de $\mathrm{K}$, para a quarta, quinta e sexta amostragens

11 Valores do erro quadrado médio (EQM) e das razões entre o erro quadrado médio sistemático (EQMs) e o erro quadrado médio aleatório (EQMa) e EQM, para cada variável estimada a partir dos valores medidos no extrato de saturação (ES) e na solução 1:2 (1:2)

12 Valores médios da concentração de nitrato, potássio e sódio na seiva do pecíolo do tomateiro $\left(\mathrm{NO}_{3 \text { seiva, }} \mathrm{K}_{\text {seiva }}\right.$ e $\mathrm{Na}_{\text {seiva }}$, respectivamente) por ocasião do florescimento do terceiro e quinto cachos, para cada nível de $\mathrm{N}$ e $\mathrm{K}$ aplicado via fertirrigação

13 Resumo da análise de variância para concentração de nitrato, potássio e sódio na seiva do pecíolo do tomateiro $\left(\mathrm{NO}_{3 \text { seiva, }} \mathrm{K}_{\text {seiva }}\right.$ e $\mathrm{Na}_{\text {seiva }}$, respectivamente) por ocasião do florescimento do terceiro e quinto cachos, em função dos níveis de $\mathrm{N}$ e K aplicados via fertirrigação

14 Valores médios dos teores de macro e micronutrientes e teor de prolina nas folhas do tomateiro, para cada nível de $\mathrm{N}$ e K aplicado via fertirrigação

15 Resumo da análise de variância para teores de macro e micronutrientes e teor de prolina nas folhas do tomateiro, em função dos níveis de $\mathrm{N}$ e $\mathrm{K}$ aplicados via fertirrigação

16 Resumo da análise multivariada para altura e diâmetro da haste das plantas de tomate, em função do tempo (T) e dos níveis de $\mathrm{N}$ e K aplicados via fertirrigação 
17 Resumo da análise de variância para diâmetro da haste das plantas de tomate, para cada medição realizada ao longo do período de cultivo, em função dos níveis de $\mathrm{N}$ aplicados via fertirrigação

18 Valores médios da área foliar média, área foliar total e número de folhas (NF) do tomateiro aos 43 dias após o transplantio, para cada nível de $\mathrm{N}$ e $\mathrm{K}$ aplicado via fertirrigação

19 Resumo da análise de variância para área foliar média (AFM), área foliar total (AFT) e número de folhas por planta (NF) de tomateiro aos 43 dias após o transplantio, em função dos níveis de $\mathrm{N}$ e $\mathrm{K}$ aplicados via fertirrigação .....

20 Valores médios do número de cachos produzidos por planta de tomate e número de dias para o florescimento de cada cacho, para cada nível de $\mathrm{N}$ e K aplicado via fertirrigação

21 Resumo da análise de variância para número de cachos produzidos por planta de tomate e número de dias para o florescimento de cada cacho, em função dos níveis de N e K aplicados via fertirrigação

22 Valores médios de produtividade, número de frutos por planta, diâmetro médio e peso médio dos frutos de tomate, para cada nível de N e K aplicado via fertirrigação

23 Resumo da análise de variância para produtividade, número de frutos por planta, diâmetro médio e peso médio dos frutos de tomate, em função dos níveis de $\mathrm{N}$ e K aplicados via fertirrigação

24 Valores médios da massa seca de frutos (MSF), folhas (MSFo), haste+cachos (MSHC) e total (MST) do tomateiro, para cada nível de N e K aplicado via fertirrigação

25 Resumo da análise de variância para massa seca de frutos (MSF), folhas (MSFo), haste+cachos (MSHC) e total (MST) do tomateiro, em função dos níveis de $\mathrm{N}$ e K aplicados via fertirrigação 
26 Resumo da análise de variância para massa seca de haste+cachos (MSHC) e massa seca total (MST) das plantas de tomate, em função dos níveis de K dentro dos níveis de $\mathrm{N}$

27 Valores médios da porcentagem de matéria seca de haste+cachos (PMSHC), folhas (PMSFo) e frutos no início $\left(\mathrm{PMSF}_{\mathrm{I}}\right)$ e no final $\left(\mathrm{PMSF}_{\mathrm{F}}\right)$ do período de colheita do tomateiro, para cada nível de $\mathrm{N}$ e K aplicado via fertirrigação

28 Resumo da análise de variância para porcentagem de matéria seca de haste+cachos (PMSHC), folhas (PMSFo) e frutos no início $\left(\mathrm{PMSF}_{\mathrm{I}}\right)$ e no final $\left(\mathrm{PMSF}_{\mathrm{F}}\right)$ do período de colheita do tomateiro, em função dos níveis de $\mathrm{N}$ e K aplicados via fertirrigação

29 Valores médios dos teores de macro e micronutrientes, brix e acidez nos frutos do tomateiro, para cada nível de $\mathrm{N}$ e K aplicado via fertirrigação ........

30 Resumo da análise de variância para teores de macro e micronutrientes, brix e acidez nos frutos do tomateiro, em função dos níveis de N e K aplicados via fertirrigação 


\title{
TOLERÂNCIA DO TOMATEIRO À SALINIDADE SOB FERTIRRIGAÇÃO E CALIBRAÇÃO DE MEDIDORES DE ÍONS ESPECÍFICOS PARA DETERMINAÇÃO DE NUTRIENTES NA SOLUÇÃO DO SOLO E NA PLANTA
}

\author{
Autor: FLÁVIO FAVARO BLANCO \\ Orientador: Prof. Dr. MARCOS VINÍCIUS FOLEGATTI
}

\section{RESUMO}

A concentração de sais na água é um dos principais aspectos a ser observado para se definir uma estratégia de manejo da irrigação, podendo levar a prejuízos pela salinização do solo, com conseqüente redução do rendimento das culturas. Visto que culturas tolerantes à salinidade apresentam maiores teores foliares de certos nutrientes, então a adubação em culturas sensíveis poderia ser conduzida de modo a elevar os teores destes nutrientes nas folhas, promovendo aumento da tolerância da cultura aos sais. Este trabalho teve o objetivo de estudar os efeitos de três doses de $\mathrm{N}$ e K na tolerância da cultura do tomateiro à salinidade, bem como avaliar a performance de medidores de íons específicos (MIE) na determinação de nutrientes na solução do solo e na seiva da planta. Mudas de tomateiro, híbrido Facundo, foram transplantadas em 23/10/2001 em vasos contendo $60 \mathrm{~kg}$ de solo franco-argilo-arenoso, no espaçamento de $1,0 \times 0,5 \mathrm{~m}$, em um ambiente protegido com cobertura de polietileno. Os tratamentos foram compostos pela combinação de três níveis de $\mathrm{N}$ (7,5; 15,0 e 22,5 g planta $^{-1}$ ) e três níveis de $\mathrm{K}$ (8, 16 e $24 \mathrm{gK}_{2} \mathrm{O}$ planta $\left.^{-1}\right)$ aplicados via fertirrigação por gotejamento, no 
esquema fatorial $3 \times 3$ com cinco repetições, sendo que à água de irrigação foram adicionados os sais cloreto de sódio e cloreto de cálcio para obtenção de condutividade elétrica da água de 9,5 dS m ${ }^{-1}$. Foram realizadas coletas da solução do solo e da seiva do pecíolo para determinações dos nutrientes pelos MIE, cujos valores foram comparados com as determinações pelos métodos-padrões. Não foram observados efeitos significativos dos tratamentos sobre o desenvolvimento e a produtividade das plantas, bem como sobre a qualidade dos frutos. As concentrações de nutrientes na solução do solo determinadas com os MIE apresentaram boa correlação com as determinações pelos métodos-padrões, e as concentrações de nutrientes na seiva do pecíolo foram bem correlacionadas aos teores na matéria seca das folhas. A condutividade elétrica e a concentração iônica na solução do solo não puderam ser estimadas a partir dos valores medidos no extrato de saturação ou na solução 1:2 apenas pela correção de umidade, com exceção do K e Na, cujas estimativas foram satisfatórias para baixas concentrações destes elementos na solução do solo. 


\title{
TOLERANCE OF TOMATO TO SALINITY UNDER FERTIGATION AND CALIBRATION OF CARDY-ION METERS FOR DETERMINATION OF NUTRIENTS IN THE SOIL SOLUTION AND PLANT
}

\author{
Author: FLÁVIO FAVARO BLANCO \\ Adviser: Prof. Dr. MARCOS VINÍCIUS FOLEGATTI
}

SUMMARY

The concentration of salts in the water is one of the main aspects to be observed to define a strategy of irrigation management, which could take to damages due to the soil salinization, with consequent reduction of crops yield. Once tolerant crops to salinity present larger tenors of some nutrients in the leaves, then the fertilizing in sensitive crops could be conducted in order to increase the tenors of these nutrients in the leaves to increase the crop tolerance to salts. This work had the objective of studying the effects of three doses of $\mathrm{N}$ and $\mathrm{K}$ in the tomato tolerance to salinity, as well as to evaluate the performance of cardy-ion meters (CIM) in the determination of nutrients in the soil solution and in the sap of the plant. Tomato seedlings, hybrid Facundo, were transplanted in 10/23/2001 in vases containing $60 \mathrm{~kg}$ of a sandy-clay-loam soil, spaced $1.0 \times 0.5 \mathrm{~m}$, in a greenhouse covered with polyethylene film. The treatments were composed by the combination of three levels of $\mathrm{N}$ (7.5; 15.0 and $22.5 \mathrm{~g} \mathrm{plant}^{-1}$ ) and three levels of $\mathrm{K}$ (8, 16 and $24 \mathrm{gK}_{2} \mathrm{O}$ plant $^{-1}$ ) applied by drip fertigation, in the $3 \mathrm{x} 3$ factorial scheme with five replications. Salts (sodium chloride and calcium 
chloride) were added to the irrigation water for obtaining an electric conductivity of $9.5 \mathrm{dS} \mathrm{m}^{-1}$. Soil solution and petiole sap were collected for determinations of the nutrients with the CIM, whose values were compared with the determinations by the standard methods. Significant effects of the treatments were not observed for the development and yield of the plants, as well as for the fruits quality. The concentrations of nutrients in the soil solution determined with CIM showed good correlations with the determinations by the standard methods, and the concentrations of nutrients in the petiole sap were well correlated to the tenors in the dry matter of the leaves. The electric conductivity and the ionic concentration in the soil solution could not be estimated from the measured values in the saturation extract or in the solution 1:2 only by the correction of the water content, except for $\mathrm{K}$ and $\mathrm{Na}$, whose estimates were satisfactory for low concentrations of these elements in the soil solution. 


\section{INTRODUÇÃO}

Dentre as hortaliças cultivadas no Brasil, o tomate é a mais importante, considerando-se os aspectos socioeconômicos (Martins, 1992). No ano de 2002, a produção total de tomate no Brasil ultrapassou 3,6 milhões de toneladas e o Estado de São Paulo contribuiu com 21\% deste total (FNP Consultoria e Comércio, 2003).

Estima-se que a área cultivada com hortaliças em ambiente protegido no Estado de São Paulo corresponda a 1\% da área total cultivada com hortaliças (Trani, 1999). O cultivo em ambiente protegido proporciona diversas vantagens em relação ao cultivo tradicional, em campo aberto, como a proteção das plantas contra as adversidades climáticas, aumento da produtividade, maior eficiência na utilização de água e fertilizantes e a obtenção de produtos de alta qualidade comercial.

O cultivo de verão em ambiente protegido proporciona aumentos expressivos na produtividade do tomateiro do grupo Salada, principalmente devido à redução da incidência de pragas e doenças, mantendo um bom estande de plantas produtivas e permitindo um maior período de colheita em relação ao cultivo em campo aberto (Martins, 1992).

A fertirrigação tem sido bastante utilizada sob este sistema de cultivo, proporcionando redução dos custos de produção, maior produtividade e qualidade dos produtos, além de permitir maior eficiência na utilização dos fertilizantes pelas plantas devido às pequenas quantidades e alta freqüência de aplicação durante o ciclo da cultura. O manejo da fertirrigação normalmente é feito através da aplicação de quantidades preestabelecidas de fertilizantes, sem qualquer monitoramento do estado nutricional da planta durante o período de cultivo. Além disso, as informações sobre os 
níveis adequados de nutrientes na planta são baseadas, geralmente, na porcentagem desses elementos na matéria seca da folha ou pecíolo, sendo que esta determinação é realizada em laboratórios especializados, podendo levar de 10 a 20 dias para que os resultados estejam disponíveis, representando um período extenso visto que as hortaliças são sensíveis à falta ou excesso de nutrientes em determinadas etapas de seu desenvolvimento. Portanto, são necessários estudos de métodos que possibilitem uma determinação rápida e de baixo custo do estado nutricional da planta.

Como a adição de fertilizantes é feita via água de irrigação e a concentração salina da água é diretamente proporcional à quantidade de sais dissolvidos, a salinização dos solos de estufa tem causado preocupação entre os pesquisadores, uma vez que informações sobre práticas de manejo e tolerância das diferentes culturas à salinidade são escassas para as condições de clima e solo do Brasil.

Uma das técnicas de controle da salinidade do solo é a aplicação de uma fração de lixiviação (FL) para remover o excesso de sais da zona radicular, o que é feito irrigando-se com uma certa quantidade de água além daquela requerida para suprir as necessidades hídricas da cultura. Porém, em estudos realizados com a cultura do pimentão (Medeiros, 1998) e pepino (Blanco, 1999) em ambientes protegidos, as diferentes FL aplicadas, bem como diferentes métodos de manejo de FL, não resultaram na redução da salinidade do solo e a produção reduziu linearmente com o aumento da salinidade da água de irrigação.

Estudos têm demonstrado que plantas mais tolerantes à salinidade exibem valores mais elevados de certas relações de nutrientes nas folhas do que aquelas menos tolerantes, sendo as relações $\mathrm{N} / \mathrm{Cl}, \mathrm{K} / \mathrm{Na}$ e $\mathrm{Ca} / \mathrm{Na}$ as que mais se destacam. Então, o aumento da dose de fertilizantes aplicada em uma cultura sensível à salinidade poderia elevar estas relações nas folhas e, conseqüentemente, promover um aumento na tolerância da cultura à salinidade. Neste caso, a fertirrigação é de particular interesse, visto que ajustes nas quantidades aplicadas de acordo com as análises de solo e planta podem ser facilmente realizados. 
Com isso, o presente estudo teve como objetivos: (i) avaliar a resposta do tomateiro fertirrigado com diferentes doses de $\mathrm{N}$ e K sob condições de alta salinidade da água de irrigação; (ii) verificar a relação existente entre a condutividade elétrica e concentração iônica medidas na solução do solo, no extrato de saturação e na solução 1:2 e (iii) avaliar a performance de medidores de íons específicos na determinação dos níveis de $\mathrm{NO}_{3}$, $\mathrm{K}$ e Na na solução do solo e na seiva do tomateiro.

Tais objetivos foram estabelecidos para testar as seguintes hipóteses:

- o aumento das doses de N e K aplicadas via fertirrigação proporcionam aumento da tolerância do tomateiro à salinidade;

- a condutividade elétrica e a concentração iônica da solução do solo não podem ser estimadas a partir dos valores medidos no extrato de saturação ou na solução 1:2 apenas pela correção das diferenças de umidade;

- os medidores de íons específicos, desde que calibrados previamente, apresentam resultados satisfatórios para a determinação da concentração iônica na solução do solo e na seiva da planta. 


\section{REVISÃO DE LITERATURA}

\subsection{A cultura do tomate}

O tomateiro é uma hortaliça da família das Solanáceas, do gênero Lycopersicon, e possui a maior parte do sistema radicular situado até $35 \mathrm{~cm}$ de profundidade, sendo mais superficial para plantas transplantadas. As folhas são alternadas, compostas de número ímpar de folíolos, peciolados e de borda serrilhada. $\mathrm{O}$ fruto é uma baga de tamanho e formato variável, sendo dividido internamente em lojas ou lóculos, podendo ser uniloculares (raro), bi-, tri-, tetra- ou pluriloculares. É originário da região montanhosa dos Andes, no Norte do Chile, Equador, Peru e Colômbia, onde surgiram formas selvagens dessa planta (Trani et al., 1994). Foi levado para a Europa e cultivado como planta ornamental e medicinal, sendo que sua utilização para consumo se deu apenas no final do século XVIII e, nos Estados Unidos, no final do século XIX (Sasaki \& Seno, 1994). No Brasil, segundo Nagai (1989), o tomateiro teria sido introduzido há mais de um século, por meio da imigração italiana e portuguesa. A espécie comumente cultivada no Brasil é L. esculentum Mill., à qual pertencem os tomates dos grupos Santa Clara e Salada, sendo estes os mais cultivados para consumo in natura.

Apesar da sua origem andina, o tomateiro recebeu melhoramento genético intensivo sendo, atualmente, de cultivo cosmopolita. Entretanto, condição de clima ameno e seco com boa luminosidade é ideal para o desenvolvimento da cultura. Quanto ao fotoperíodo, é considerado como planta de dia neutro, ou seja, floresce indiferentemente ao comprimento do dia (Martins, 1992). 
A produção de tomate em condições tropicais, inclusive no Brasil, sempre foi caracterizada pela sazonalidade na oferta e baixa produtividade, sendo que na entressafra há uma acentuação nas diferenças relativas dos índices de sazonalidade das classes de tomate, ampliando-se a comercialização dos tomates de pior qualidade a preços supervalorizados (Ambrosio \& Nagai, 1991). Visando aumentar a produtividade e melhorar a qualidade dos frutos na entressafra, diminuindo a sazonalidade da oferta e a importação de outros estados, a produção de tomate em ambiente protegido vem sendo incentivada tanto no cultivo de inverno como no de verão (Martins, 1991).

No tomateiro de crescimento indeterminado, após a emissão de 7 a 12 folhas, o ponto de crescimento da planta é diferenciado e ocorre o aparecimento da primeira inflorescência que dará origem ao primeiro cacho de frutos da planta; a partir daí ocorre o desenvolvimento do caule e de 2 a 4 folhas seguido de um novo cacho e assim sucessivamente, de modo que, após a emissão do primeiro cacho floral até o final do ciclo da planta, as fases vegetativa e reprodutiva ocorrem sucessivamente (Papadopoulos, 1991).

O cultivo do tomate requer muita mão-de-obra, a qual chega a representar 30\% do custo total de produção (Navarrete \& Jeannequin, 2000). A grande necessidade de mão-de-obra está relacionada aos tratos culturais que incluem: desbrotas e raleio de frutos semanais, condução da planta através do fitilho, retirada das folhas velhas para reduzir a incidência de enfermidades foliares etc. Entretanto, diversos experimentos têm demonstrado que as operações manuais resultam em estresse das plantas devido à vibração do caule e folhas. Os efeitos de tal vibração no crescimento das plantas está relacionado: i) ao estresse físico resultante da movimentação ou dilaceração dos tecidos vegetais; ii) à alteração do microclima foliar e trocas gasosas (Grace \& Thompson, 1973).

Navarrete \& Jeannequin (2000) verificaram que quando a desbrota foi realizada em intervalos de 14 dias não houve efeito significativo na produção em comparação à desbrota semanal, havendo redução de apenas $1,9 \%$ na produção do 
tratamento cuja prática foi realizada com menor freqüência. Marques et al. (2000) avaliaram três cultivares de tomate com e sem desbrota em ambiente protegido e concluíram que a ausência total de desbrota durante o ciclo da cultura não resultou em decréscimo de produção, havendo maior produção de frutos de tamanho grande e médio em relação às plantas que foram submetidas a desbrotas periódicas. Este fenômeno, conhecido como estresse mecânico induzido (Biddington, 1986), também torna desejável a redução das operações manuais diretamente nas plantas, permitindo a redução dos gastos com mão-de-obra.

Do ponto de vista fisiológico, os frutos são fortes drenos de fotoassimilados e, em plantas adultas de tomate industrial, os frutos podem representar 69\% da matéria seca da parte aérea (Cockshull et al., 1992); portanto, o raleio de frutos pode proporcionar o aumento significativo no tamanho dos frutos remanescentes. Saglam \& Yazgan (1999) verificaram que o peso médio de frutos aumentou e a produção total diminuiu linearmente com a redução do número de frutos por cacho. $\mathrm{O}$ aumento de um fruto por cacho dentro do intervalo estudado (4 a 8 frutos por cacho) resultou no aumento de 5,9\% na produção total e na redução de 10,6\% no peso médio dos frutos. Cockshull \& Ho (1995) também obtiveram aumento no peso médio dos frutos e redução na produção total quando se retirou 30\% dos frutos de cada cacho. Estes estudos demonstraram um aumento significativo na produção de frutos grandes e redução de frutos pequenos, sendo portanto vantajosa quando se almeja a alta qualidade comercial.

De acordo com o conhecimento geral dos produtores de tomate, a retirada de folhas das plantas resulta em queda de produção devido à redução da área que intercepta a radiação solar disponível. Além disso, a posição da folha também é fator importante, havendo grandes perdas de produção caso seja retirada a folha localizada imediatamente acima do cacho. Entretanto, o desfolhamento parcial do tomateiro estimula a taxa fotossintética das folhas remanescentes, o que pode compensar parcialmente a perda de área fotossinteticamente ativa promovida pela retirada de folhas (Tanaka \& Fujita, 1974), fazendo com que o tomateiro seja capaz de suportar uma certa 
redução de área foliar sem que haja uma redução significativa na produtividade. Esta suposição foi confirmada por Wolk et al. (1983) que verificaram um aumento significativo na fotossíntese líquida das folhas remanescentes após a retirada de até 80\% das folhas das plantas. Os resultados sugerem que a remoção de até 50\% das folhas não resulta em queda significativa da produção e do teor de sólidos solúveis nos frutos, porém observa-se forte tendência de queda de produção com o aumento da severidade da desfolha.

Andriolo \& Falcão (2000) reportam que a remoção de uma e duas folhas por inflorescência do tomateiro em ambiente protegido reduziu a matéria seca total da planta, porém a produção de matéria seca de frutos foi a mesma em todos os tratamentos; portanto, a quantidade extra de matéria seca acumulada nas plantas que não foram desfolhadas (três folhas por inflorescência) não foi alocada para os frutos, permanecendo nas folhas.

\subsection{Métodos de irrigação e manejo para o tomateiro}

O método mais tradicional de irrigação do tomateiro estaqueado em condições de cultivo a céu aberto é por sulcos, pois a água aplicada por este método não interfere no controle fitossanitário. Também é comum a utilização da aspersão no cultivo do tomate para processamento industrial devido, principalmente, ao fato de que nessa modalidade de cultivo os frutos e ramos ficam em contato com o solo, dificultando a movimentação de água nos sulcos (Manzan, 1980).

Sob condições irrigadas, o manejo da água aplicada deve ser realizado de modo a manter o potencial mátrico do solo entre -10 e $-30 \mathrm{kPa}$ a fim de minimizar os efeitos do estresse hídrico (Stanley \& Maynard, 1990). A aplicação excessiva de água no tomateiro resulta na epinastia de folhas, a qual está associada principalmente ao acúmulo excessivo de etileno sob condições anaeróbicas, além de outros fatores como a redução da condutância estomática, aumento da concentração de ácido abscísico na planta, redução da área foliar e morte de raízes adventícias (Bradford \& Yang, 1981). Irrigações 
leves e frequentes melhoram o tamanho, a forma, a suculência e a cor do fruto, porém reduzem os sólidos totais e o teor de ácido (Doorenbos \& Kassam, 1979).

Soares \& Faria (1983) verificaram que na irrigação por sulcos a ocorrência de podridão apical foi mais severa do que na irrigação por aspersão, embora esta última tenha resultado em maior porcentagem de frutos podres. A produtividades foram semelhantes, em torno de $59 \mathrm{Mg} \mathrm{ha}^{-1}$, porém a eficiência de utilização de água pelo tomate irrigado por sulcos foi de $7,3 \mathrm{~kg} \mathrm{~m}^{-3}$, contra $12,7 \mathrm{~kg} \mathrm{~m}^{-3}$ para o irrigado por aspersão, o que resultou numa aplicação total de 798 e 467 mm de água durante todo o ciclo da cultura, para o tomate irrigado por sulcos e aspersão, respectivamente.

A irrigação por gotejamento surgiu em Israel visando a economia de água, o que é uma preocupação constante nesse país. Essa técnica passou a ser aprimorada a partir da década de 1960, embora já fosse utilizada desde o início do século XIX (Azevedo, 1986). Um dos grandes atrativos dessa técnica é o aumento da produtividade e da qualidade dos produtos, além de proporcionar economia de água, redução das perdas de fertilizantes por lixiviação, economia na mão-de-obra, dentre outras vantagens. Existem estudos comparativos demonstrando o aumento de produção proporcionado pela irrigação por gotejamento em diversas culturas, dentre elas a berinjela (Vieira \& Manfrinato, 1974), melão (Goldberg \& Shmueli, 1970; Abreu et al., 1978), morango (Olitta \& Minami, 1974), pimentão (Bernstein \& Francois, 1975), tomate (Juan, 1993.; Yohannes \& Tadesse, 1998) dentre outras. Vivancos (1993) afirma que a irrigação do tomate por gotejamento proporciona aumentos de produtividade da ordem de 20 a 40\% em relação à irrigação por aspersão.

A relação entre a produção de diferentes culturas e a utilização de água tem sido estudada por diversos autores, sendo que esta relação pode ser representada por uma função linear ou curvilínea. Stegman et al. (1980), a partir de extensa revisão bibliográfica, verificaram que quando a relação é curvilínea, a não-linearidade foi mais pronunciada sob altos níveis de irrigação. Os autores sugerem que a drenagem deficiente, a falta de aeração e a alta incidência de doenças contribuem para a nãolinearidade. A relação entre a produção e o consumo de água pode variar bastante, 
dependendo de vários fatores como o clima, o manejo do cultivo e o crescimento e desenvolvimento que a cultura pode alcançar sob determinadas condições (Musick \& Dusek, 1975; Ferreyra E. et al., 1989).

Ferreyra E. (1987) verificou resposta linear do tomateiro à lâmina de água aplicada variando de zero a, aproximadamente, $1300 \mathrm{~mm}$. A evapotranspiração da cultura variou de 120 a $560 \mathrm{~mm}$ no primeiro cultivo e de 70 a $510 \mathrm{~mm}$ no segundo, havendo um incremento médio na produção comercial e total de $0,47 \%$ e $0,34 \%$, respectivamente, para cada incremento de um milímetro na evapotranspiração. Relação linear entre a lâmina de água aplicada e a qualidade de hastes e botões florais da roseira foi obtida por Folegatti et al. (2001), enquanto que Sousa et al. (1999) verificaram resposta da cana-de-açúcar a níveis crescentes de irrigação descrita por uma função quadrática.

Torrecillas et al. (1995) verificaram que plantas de tomate da espécie $L$. pennellii, espécie selvagem utilizada nos programas de melhoramento, apresentaram maior capacidade de recuperação da turgescência do que $L$. esculentum após um período de sete dias sem irrigação. O mecanismo de tolerância de L. pennellii ao estresse hídrico foi o controle da abertura de estômatos, determinado pelo potencial hídrico das folhas, enquanto que em L. esculentum o principal mecanismo foi o ajuste osmótico pela síntese de açúcares e prolina.

Prashar et al. (1976) revisaram diversos trabalhos que evidenciam o efeito da irrigação na qualidade física e química de frutos de tomate. Comparado-se com plantas não-irrigadas, a irrigação do tomateiro promove melhoria no tamanho e coloração dos frutos, aumentando a porcentagem de frutos que atingem o padrão comercial. Estes autores enfatizam que é necessário um manejo correto da irrigação para que as vantagens proporcionadas por essa técnica sejam alcançadas. O aumento da lâmina de água aplicada reduz a concentração de sólidos solúveis e a acidez dos frutos, porém a produtividade e as qualidades físicas dos frutos, como coloração e tamanho, aumentam. Por outro lado, o déficit hídrico permite a obtenção de frutos com maior concentração de sólidos solúveis, porém com menor produtividade e coloração inferior 
àqueles obtidos sob lâminas de irrigação maiores. Com isso, o manejo da irrigação deve ser função não apenas da demanda hídrica da cultura mas também da finalidade da produção: frutos destinados ao processamento industrial necessitam de maior concentração de sólidos solúveis, enquanto que aqueles destinados ao consumo "in natura” devem apresentar o tamanho e a coloração exigidos pelo mercado consumidor.

\subsection{Aspectos nutricionais e fertirrigação do tomateiro}

A adubação do tomateiro tem sido tema de muitos estudos no Brasil, dada a grande importância econômica desta cultura. Porém, de acordo com Lopes \& Stripari (1998), ainda não foram apresentadas informações suficientes sobre a adubação em ambiente protegido. Segundo estes autores, o aumento no cultivo de tomate em ambiente protegido e o nível elevado de adubação usualmente utilizado nesta cultura têm provocado problemas de desequilíbrios e distúrbios fisiológicos, evidenciando a importância do correto manejo dos adubos e da água de irrigação para evitar a salinização e o desequilíbrio entre os elementos que venham prejudicar não apenas o tomateiro, mas também as outras culturas que forem implantadas na área.

A eficiência de utilização dos fertilizantes geralmente é baixa, estando em torno de 5 a 30\%. Com isso, torna-se importante o desenvolvimento de um esquema de exploração que permita aumentar a eficiência de utilização dos nutrientes aplicados. Na irrigação por gotejamento as raízes se concentram em um volume reduzido de solo e, com isso, a aplicação de fertilizantes através do sistema de irrigação deve ser mais eficiente do que a aplicação pelo método convencional; os nutrientes se depositam no solo na região em que se concentram as raízes, dentro do bulbo úmido, aumentando a recuperação dos fertilizantes aplicados (Juan, 1993). Além disso, a fertirrigação reduz as flutuações da salinidade da solução do solo causada pelos fertilizantes (Papadopoulos, 1985), melhorando as condições da solução do solo especialmente para as culturas sensíveis à salinidade (Papadopoulos, 1987). 
O nitrogênio tem uma ação direta sobre a produção do tomateiro, sendo que o excesso de $\mathrm{N}$ pode produzir efeitos depressivos sobre a qualidade dos frutos. $\mathrm{O}$ fósforo é essencial para a formação do sistema radicular, fecundação e maturação e tem uma ação notável sobre a precocidade de produção. O potássio influi sobre a qualidade do fruto (sabor e coloração) e a necessidade das plantas por K aumenta em dias curtos (Vivancos, 1993). A maior parte dos nutrientes absorvidos pelo tomateiro são acumulados nas folhas, seguido pela raiz, caule e frutos (Liptay \& Arevalo, 2000).

No Estado de São Paulo, o cultivo de pimentão, tomate, pepino e outras hortaliças em ambiente protegido é cerca de 70 a 80\% fertirrigado (Villas Boas et al., 2001); entretanto, devido à carência de estudos sobre as quantidades de fertilizantes a serem aplicadas sob estas condições, é comum a utilização de recomendações de adubação para cultivos a céu aberto que, na maioria dos casos, não é adequada para condições protegidas. Além disso, as recomendações variam bastante entre os diferentes autores. Lopes \& Stripari (1998) recomendam que as adubações de cobertura com K sejam de 120 a $240 \mathrm{~kg} \mathrm{ha}^{-1}$, enquanto que Vivancos (1993) sugere aplicação de $500 \mathrm{~kg} \mathrm{ha}^{-1}$, uma diferença de mais de duas vezes a qual poderia não apresentar tanta importância se o K não fosse, talvez, o nutriente que mais interfere na produção e qualidade de frutos. Voogt (1993) verificou que a absorção de K pelo tomateiro esteve fortemente relacionada à quantidade de frutos presentes na planta, ocorrendo aumento expressivo da quantidade de $\mathrm{K}$ absorvida após o início do período produtivo.

As principais variáveis relacionadas à qualidade dos frutos do tomateiro são a concentração de nutrientes, a concentração de açúcares, expressa por graus Brix, e o teor de acidez. Diversos trabalhos têm demonstrado que o K é o nutriente absorvido em maiores quantidades durante o ciclo do tomateiro (Ward, 1967; Locascio et al., 1997; Gertsson, 1995; Nicola \& Basoccu, 1994; Alcántar et al., 1999). Castellane (1982) cita que a carência de K resulta na redução do peso médio e tamanho dos frutos, coloração desuniforme e redução nos teores de sólidos solúveis. Freire et al. (1980) citam que o K aumenta a produtividade em cerca de $30 \%$, sendo que os principais efeitos são o aprimoramento da qualidade comercial dos frutos, os quais apresentam coloração 
vermelha mais acentuada e o interior bem formado, sem a presença de espaços vazios. Os frutos são mais firmemente presos na planta, não ocorrendo queda prematura.

Bojórquez et al. (2001) não obtiveram efeito de doses de $\mathrm{N}$ e K sobre a concentração desses nutrientes nos frutos e na seiva das brotações em três épocas ao longo do período produtivo do tomateiro. O aumento do teor de $\mathrm{K}$ e a redução do tamanho dos frutos para a sexta colheita em relação às colheitas anteriores levou os autores a concluírem que a elevada concentração de $\mathrm{K}$ nos frutos esteve associada à redução da qualidade comercial.

Hobson \& Davies (1971) observaram que os níveis de macronutrientes no solo tiveram pouca influência sobre o teor de açúcar nos frutos. Macêdo (2002), fertirrigando o tomateiro com doses de $\mathrm{K}_{2} \mathrm{O}$ que variaram de 300 a $900 \mathrm{~kg} \mathrm{ha}^{-1}$, não obteve diferenças significativas para brix e acidez dos frutos. A ausência de resposta para brix com o aumento da dose de K também foi observada por Sampaio (1996), havendo pequeno aumento da acidez, a qual aumentou de 0,22\% para 0,30\% para as doses de zero e $400 \mathrm{~kg} \mathrm{ha}^{-1}$, respectivamente.

Geralmente os sintomas de deficiência nutricional no tomateiro em ambiente protegido são devidos ao antagonismo resultante das altas doses aplicadas como, por exemplo, a deficiência de Mg provocada pelas aplicações pesadas de K, o qual é utilizado para obtenção de frutos de alta qualidade. Outras desordens nutricionais são devidas ao manejo inadequado da irrigação, o qual pode resultar no aumento da salinidade do solo quando a quantidade de água aplicada é abaixo da necessária, ou na lixiviação de nutrientes em condições de excesso de água (Winsor \& Adams, 1987).

\subsection{A solução do solo}

A importância de se conhecer as propriedades químicas da solução do solo para o manejo racional do solo e da água é reconhecida há muitos anos. Hoagland et al. (1920) afirmaram que, uma vez que os nutrientes absorvidos pelas plantas são obtidos da solução do solo, o progresso no estudo do solo como um meio para o 
crescimento das plantas dependerá de um melhor conhecimento da solução do solo. Para Smethurst (2000), as recomendações de adubação não são baseadas nas características químicas da solução do solo devido à dificuldade de obtenção da solução e determinação da concentração dos nutrientes e à alta variabilidade espacial e temporal da solução.

Inicialmente acreditava-se que o equilíbrio químico da solução do solo requeria a precipitação dos sais adicionados com a finalidade de manter a composição da solução constante, a qual era governada principalmente pelos minerais de origem do solo (Cameron, 1911). Posteriormente, Hoagland et al. (1920) demonstraram que a concentração química da solução do solo poderia ser elevada pela adição de sais solúveis e que os elementos adicionados seriam os mesmos a apresentar aumento na concentração.

Diferentes métodos podem ser utilizados para a obtenção da solução do solo. Alguns métodos são apresentados por Wolt (1994), dentre eles o da centrifugação, deslocamento em coluna, extração em membrana sob pressão, extrato de saturação, extratos aquosos e métodos lisimétricos, incluindo o método do lisímetro de tensão, mais conhecido como método dos extratores de cápsula porosa. Segundo este autor, qualquer que seja o método de obtenção da solução do solo, um grande desafio tem sido comprovar que a solução obtida é uma representação fiel da solução antes da sua extração, uma vez que a medição direta da composição da solução do solo ainda é impossível de ser realizada. Moss (1963) afirma que é razoável conceber que a solução deslocada venha das camadas externas do filme de solo, a qual, mesmo em equilíbrio, pode ser sensivelmente menos concentrada que a solução do solo como um todo.

Richards (1941) desenvolveu uma câmara de pressão constituída de uma membrana de celofane permeável por onde a solução seria extraída da amostra de solo. Entretanto, o método apresentava algumas características intrínsecas que limitaram o seu uso, como a necessidade de grande quantidade de amostra de solo (aproximadamente 3,5 kg), grande período de tempo para extração, podendo chegar a vários dias, e pequeno volume relativo de solução extraída (aproximadamente $50 \mathrm{ml}$ ). 
Shimshi (1966) utilizou coletores da solução do solo confeccionados a partir de placas porosas de cerâmica, as mesmas utilizadas para obtenção da curva característica de retenção de água no solo. Estes eram inseridos no solo por um certo período, durante o qual ocorria a absorção da solução do solo pela cerâmica porosa. A análise da solução compreendia um trabalhoso processo de lixiviação das hastes com água destilada para a retirada da solução dos poros, sendo as determinações iônicas corrigidas posteriormente para o volume de água destilada utilizado neste processo.

Nelson \& Faber (1986) apresentaram uma variação do método do deslocamento em coluna visando facilitar a obtenção da solução do solo e concluíram que, apesar de ser mais simples que o método original, a metodologia era demasiadamente trabalhosa e inviável para aplicação nas análises de rotina em cultivos comerciais.

Talvez Wagner (1962) tenha sido o primeiro a utilizar os extratores de cápsula de cerâmica porosa para extrair a solução do solo, embora, freqüentemente, tenha sido atribuída a Reeve e Doering (1965) a invenção deste equipamento. De fato, estes últimos foram os primeiros a apresentar dados de condutividade elétrica medida na solução $\left(\mathrm{CE}_{\mathrm{s}}\right)$ extraída com cápsulas porosas, enquanto que Wagner (1962) realizou apenas uma avaliação do volume de solução coletado para diferentes umidades do solo e uma breve avaliação da adsorção de íons pela cápsula e sugeriu que a metodologia poderia ser utilizada para o estudo do balanço de nutrientes a diferentes profundidades.

A utilização de cápsulas porosas para extrair a solução do solo é bastante difundida, principalmente devido ao manejo fácil, custo relativamente baixo e pelo fato do extrato obtido não requerer tratamentos prévios às determinações físico-químicas e à quantificação de seus componentes (Moraes \& Dynia, 1990). Com o auxílio dos extratores da solução do solo, pode-se conhecer os valores de $\mathrm{pH}$, condutividade elétrica, nitratos e nitritos, assim como de outros elementos presentes que são de importância para a nutrição das plantas (Burgeño, 1994).

A qualidade da solução obtida com os extratores de cápsula porosa tem sido tema de questionamentos, principalmente com relação à intensidade do vácuo 
aplicado, à zona de influência da cápsula, à liberação ou adsorção de íons pela cápsula e à volatilização de compostos promovida pelo vácuo.

A sucção promovida pelo vácuo gera um gradiente de potencial no solo em torno da cápsula e, como resultado, quanto maior o vácuo maior será a zona de influência ou o volume de solo amostrado (Grossmann \& Udluft, 1991). Krone et al. (1952) mediram a variação de potencial mátrico ao redor da cápsula e verificaram que a maior variação ocorreu próximo à cápsula, reduzindo linearmente com a distância, tanto vertical quanto horizontal. Métodos analíticos para estimativa da zona de influência da cápsula porosa foram desenvolvidos para condições de vácuo constante (Warrick \& Amoozegar-Fard, 1977) e transiente (Morrison \& Szecsody, 1985).

Hansen \& Harris (1975) verificaram que houve adsorção de P pela cápsula no início da coleta da solução e que a quantidade adsorvida reduziu rapidamente com o aumento do volume coletado, não ocorrendo adsorção após a saturação da cápsula com P. Para $\mathrm{NO}_{3}$ nenhuma adsorção ocorreu, concordando com trabalho realizado por Wagner (1962) que constatou a adsorção de $\mathrm{NH}_{4}$ na cápsula. Silkworth \& Grigal (1981) utilizaram cápsulas de diferentes tamanhos $\left(22 \mathrm{~cm}^{3}\right.$ e $\left.112 \mathrm{~cm}^{3}\right)$ e verificaram maior concentração de $\mathrm{K}$, Ca, Mg e Na na solução extraída com a cápsula menor, o que foi atribuído à maior adsorção desses íons na cápsula maior. Neste trabalho os extratores foram instalados em área de floresta e, conseqüentemente, as concentrações de nutrientes medidas na solução eram bastante baixas, sendo que as concentrações máximas de K, Ca, Mg e Na obtidas corresponderam a 1,4, 19,8, 18,0 e 10,8 mg L ${ }^{-1}$, respectivamente. Em condições de fertirrigação as concentrações de nutrientes são significativamente mais elevadas, podendo-se afirmar que as quantidades adsorvidas não tenham efeito significativo nas concentrações medidas na solução obtida.

A extração da solução por métodos que utilizam vácuo é um fator de erro na derminação do pH, uma vez que ocorre a eliminação do $\mathrm{CO}_{2}$ e outros compostos voláteis, o que faz aumentar o pH medido na solução (Wood et al., 1981; Suarez, 1987). Miranda (1993) extraiu a solução de um solo de textura argilosa pelo método da centrifugação e verificou que o pH da solução foi próximo do $\mathrm{pH}$ em água determinado 
no solo. De acordo com Suarez (1987), quanto maior é o volume de solução coletado de modo que este se aproxime do volume total do extrator menor é o erro. Para condições de campo, uma vez que a umidade do solo situa-se abaixo da umidade de saturação, o volume coletado corresponde de $10 \%$ a $80 \%$ do volume do extrator e o $\mathrm{pH}$ medido é em torno de 1,06 a 0,11 unidades de $\mathrm{pH}$ acima do $\mathrm{pH}$ real da solução.

De modo geral, a obtenção da solução do solo é realizada em uma amostra de solo seca ao ar, passada em peneira e, posteriormente, a umidade da amostra é elevada até o nível desejado aplicando-se água destilada ou deionizada, formando uma massa de solo úmido da qual a solução é extraída. Entretanto, Qian \& Wolt (1990) extraíram a solução do solo utilizando o método do deslocamento à vácuo e observaram que, em comparação com a solução obtida a partir de amostras que foram mantidas com a umidade em que foram coletadas, o processo de secamento-umedecimento promoveu redução do pH e aumento da $\mathrm{CE}$ e das concentrações de $\mathrm{NO}_{3}$, K, Ca e Cl. Portanto, a obtenção de uma amostra de solução que seja uma representação fiel da solução em seu estado natural não depende apenas do método utilizado para sua obtenção, dependendo também das alterações promovidas no processo como um todo.

Com base no exposto, qualquer que seja o método utilizado para a obtenção da solução do solo haverá um erro envolvido na concentração iônica determinada na solução. Os extratores de solução de cápsula porosa permitem que a solução seja obtida diretamente em campo, com o solo na umidade em que a solução apresenta a concentração iônica à qual as plantas estão diretamente submetidas. A facilidade, rapidez e baixo custo para a obtenção das amostras são fatores adicionais para que este método seja o mais adequado para o manejo da fertirrigação em cultivos comerciais.

\subsection{Análise da solução do solo e da seiva}


As plantas necessitam de um suprimento adequado de nutrientes durante todo o seu período de crescimento e, para isso, a concentração de nutrientes na solução do solo tem que ser mantida em um nível satisfatório (Mengel \& Kirkby, 1987).

Na análise de plantas, o objetivo é estabelecer a relação entre a concentração de nutrientes e o crescimento e produção, utilizando esta relação em situações semelhantes para determinar o status nutricional da planta. Tal relação pode ser estabelecida em experimentos utilizando vasos ou diretamente no solo, variando-se os níveis aplicados de um ou mais nutrientes (Bouma, 1983). Segundo Bar-Yousef (1991), existe a necessidade de pesquisas visando o desenvolvimento de métodos que permitam detectar pequenas variações no estado nutricional das plantas e na concentração de nutrientes na solução do solo para que estas possam ser corrigidas assim que forem observadas.

Recentemente, métodos práticos têm sido avaliados para o monitoramento do nível nutricional das plantas para fins de manejo da fertirrigação. Em meados da década de 1970 surgiram no mercado fitas impregnadas com reagentes específicos para determinação dos níveis de nutrientes que, quando em contato com a solução, reagem com o íon específico resultando em cores de diferentes tonalidades. A coloração obtida é comparada com uma tabela que indica a faixa de concentração que o determinado íon se encontra naquela solução, não fornecendo, portanto, uma determinação precisa do nível de nutriente. Mais tarde, apareceram os medidores portáteis de nutrientes à partir de eletrodos de íons específicos, os quais permitem uma leitura direta, rápida e confiável, além de realizarem as leituras à partir de poucas gotas do material a ser analisado (seiva ou solução do solo).

Para plantas cultivadas em solução contendo $\mathrm{NO}_{3}$, a concentração deste na seiva é um indicador bastante sensível do estado nutricional da planta (Scaife \& Stevens, 1983). Coltman (1987) obteve um nível mínimo de $800 \mathrm{mg} \mathrm{L}^{-1}$ na seiva do pecíolo do tomateiro para a obtenção da máxima produção comercial da cultivar "Tropic". A partir de experimento visando determinar o nível adequado de $\mathrm{N}^{-\mathrm{NO}_{3}}$ na seiva do pecíolo do tomateiro "Caruso" em ambiente protegido, Coltman (1988) estimou 
que a máxima produção de frutos pôde ser alcançada quando a concentração de $\mathrm{N}^{-\mathrm{NO}_{3}}$ na seiva foi mantida em $1105 \mathrm{mg} \mathrm{L}^{-1}$, resultando em uma produção de 3,2 $\mathrm{kg}_{\text {planta }}{ }^{-1}$, sendo a concentração mínima de $900 \mathrm{mg} \mathrm{L}^{-1}$, abaixo da qual resultou em grande porcentagem de frutos defeituosos. A partir dos resultados destes dois trabalhos, os quais foram realizados sob condições bastante semelhantes, verifica-se que diferentes cultivares apresentam comportamentos distintos quanto aos níveis de nutrientes na seiva.

Após a sexta semana do plantio, o tomateiro se encontra no início do período reprodutivo e é após esta fase que a maior parte da matéria seca é produzida, resultando na absorção de $\mathrm{N}$ em grandes quantidades (Halbrook \& Wilcox, 1980). Prasad \& Spiers (1985) concluíram que o nível de $\mathrm{NO}_{3}$ na seiva do tomateiro entre a sexta e oitava semanas deve estar na faixa de 4000-5700 $\mathrm{mg} \mathrm{L}^{-1}$, sendo que as determinações foram realizadas por método semiquantitativo (fitas). Também foi observada redução da concentração de $\mathrm{NO}_{3}$ na seiva a partir da décima semana, quando as plantas apresentavam frutos verdes bastante desenvolvidos, o que é resultado da translocação de nutrientes da planta para os frutos.

Trabalhos como os de Guimarães et al. (1998) e Smith et al. (2000) comprovaram a praticidade e precisão dos medidores de eletrodos específicos da marca Horiba para a determinação das concentrações de $\mathrm{NO}_{3}$ na seiva do tomateiro e algodoeiro, respectivamente. Nestes trabalhos foram determinadas a relação entre as concentrações de $\mathrm{N}-\mathrm{NO}_{3}$ na seiva com os teores na matéria seca do pecíolo e no limbo foliar, obtendo-se coeficientes de determinação $\left(\mathrm{r}^{2}\right)$ acima de 0,90 .

\subsection{Salinidade e tolerância do tomateiro aos sais}

O acúmulo de sais no solo em cultivos protegidos é bastante comum, principalmente devido às altas doses de fertilizantes aplicadas, à falta de lixiviação dos sais acumulados após um cultivo e à utilização de águas de poços de má qualidade.

Segundo Medeiros (1998), recomenda-se que as estufas sejam construídas nas partes mais altas do terreno, onde os solos são mais profundos e têm boa drenagem. 
Então, devido à maior proximidade, águas de poços são comumente utilizadas para irrigação destas áreas. Um estudo desenvolvido por Oliveira \& Salati (1981) visando conhecer a qualidade da água de poços na região de Piracicaba, SP, verificaram que 41, 34 e 7\% dos poços possuíam água com salinidade acima de 0,75, 2,25 e 4,00 dS m m $^{-1}$, respectivamente. Além disso, as águas mais salinas apresentavam mais de $90 \%$ da composição equivalente dos cátions composta de sódio e, com respeito aos ânions, cerca de $60 \%$ era de cloretos e $30 \%$ de sulfatos.

A salinidade máxima no extrato de saturação do solo tolerada pelo tomateiro é de 2,5 dS m ${ }^{-1}$ (Maas \& Hoffman, 1977). Porém, cada espécie, e mesmo cultivares, toleram variavelmente à salinidade (Gorham, 1995). Segundo Cuartero \& Muñoz (1999), sob salinidade moderada a redução no rendimento do tomateiro deve-se, principalmente, à redução no peso médio de frutos, enquanto que em condições de alta salinidade a redução na produtividade é resultado do menor número de frutos por planta; o número de cachos por planta diminui apenas quando a água de irrigação apresenta elevada concentração de sais e sob longos períodos de exposição, sendo esta uma característica pouco sensível à salinidade. Além disso, a salinidade aumenta a incidência de podridão apical (Martinez et al., 1987), tornando os frutos inutilizáveis tanto para o consumo quanto para a indústria.

O ajuste osmótico pelas plantas em resposta ao aumento da salinidade do meio pode ser mediado por uma alteração nas concentrações intracelulares de compostos orgânicos e inorgânicos (Aspinall, 1986; Flowers \& Yeo, 1986; Grumet \& Hanson, 1986; Moftah \& Michel, 1987). Cultivando três variedades de tomateiro em solução com e sem $\mathrm{NaCl}$, Garcia et al. (2002) verificaram aumento nas concentrações de $\mathrm{Na}, \mathrm{Cl}, \mathrm{K}$, Ca e Mg na seiva do xilema, tanto para as plantas enxertadas quanto para as nãoenxertadas.

Uma resposta freqüentemente observada em plantas sob estresse salino é o acúmulo de prolina (Rains, 1989). A prolina é um iminoácido que protege as proteínas contra a desidratação e esta proteção é proporcional à concentração desta substância (Paleg et al., 1984). Uma vez que a prolina é osmoticamente ativa, esta exibe dupla 
função: protege contra a desidratação das proteínas e mantém um gradiente osmótico celular mais favorável (Rains, 1989). Aumento do teor de prolina nas folhas do tomateiro com o aumento da salinidade do meio foram observadas por Cruz et al. (1998), Aziz et al. (1999) e Alian et al. (2000). Rajasekaran et al. (2000) cultivaram dez espécies de tomateiro, incluindo L. esculentum var. cerasiforme e L. esculentum 'Duke', em solução nutritiva com adição de $\mathrm{NaCl}$; para todas as espécies houve aumento no teor de prolina nas folhas, o qual foi de 11 a 116 vezes maior do que o observado para o tratamento controle, sem adição de $\mathrm{NaCl}$.

Irrigando duas espécies de tomateiro com água do mar em diferentes diluições, Rush \& Epstein (1976) verificaram que L. cheesmanii sobreviveram mesmo quando cultivadas em solução com $70 \%$ da água do mar, enquanto que L. esculentum não sobreviveu quando a concentração superou 50\%. Pequenas modificações genéticas poderiam conferir maior tolerância à salinidade para plantas sensíveis, o que permitiria que águas de qualidade marginal ou mesmo a água do mar pudessem ser utilizadas na irrigação, reduzindo a necessidade de desmatamento para incorporar terras produtivas ao sistema agrícola (Frommer et al., 1999). Trabalhos nos quais genes de outras espécies de plantas são adicionados ao código genético do tomateiro visando aumento da tolerância à salinidade têm sido desenvolvidos, resultando em plantas que chegam a tolerar salinidade 50 vezes maior do que plantas não-transgênicas (Travis, 2001; Cummings, 2001).

\subsection{Interação entre a nutrição mineral e a tolerância das culturas à salinidade}

A alta concentração salina do meio dificulta a absorção de água e nutrientes pelas plantas devido ao baixo potencial total da solução do solo e da competição química entre nutrientes e sais (Yeo \& Flowers, 1989). O método mais direto para se restabelecer os níveis normais de N, P, Ca e K na planta em condições salinas seria elevando a concentração destes nutrientes na zona radicular, pelo aumento da dosagem de fertilizantes (Cuatero \& Muñoz, 1999). 
Em extensa revisão bibliográfica sobre os efeitos de doses de nutrientes na tolerância de culturas à salinidade, Grattan \& Grieve (1999) verificaram que muitos estudos têm sido conduzidos com o solo ou o substrato deficiente em N, P e/ou K. Com isso, os efeitos benéficos de altas doses de nutrientes não implicam em aumento da tolerância das culturas à salinidade, uma vez que as culturas respondem positivamente aos níveis crescentes de fertilizantes mesmo nos tratamentos não-salinos. Plantas que se desenvolvem em solos férteis podem parecer mais tolerantes aos sais em relação àquelas que crescem em solos deficientes, pois a fertilidade é o principal fator limitante do crescimento; então, a adição de fertilizante extra não alivia a inibição do desenvolvimento causada pela salinidade (Rhoades et al., 2000).

Kafkafi et al. (1982) observaram redução dos teores de Cl e Na nas folhas do tomateiro com o aumento das doses aplicadas de $\mathrm{N}$ e $\mathrm{K}$, respectivamente. Schachtman \& Schroeder (1994) assumiram a existência de um mecanismo comum de absorção de $\mathrm{K}$ e $\mathrm{Na}$ em plantas superiores, o qual seria regulado pelas concentrações destes nutrientes no substrato; então, níveis elevados de K poderiam modular a absorção e o transporte de Na e poderiam limitar os danos atribuídos a este. Botrini et al. (2000) verificaram que para uma solução nutritiva altamente salina, com $8770 \mathrm{mg} \mathrm{L}^{-1}$ de $\mathrm{NaCl}$

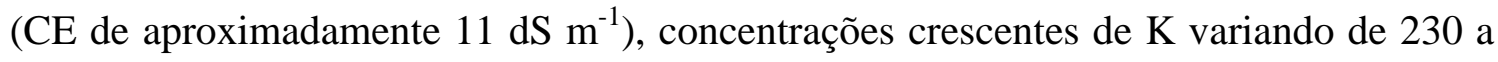
$2900 \mathrm{mg} \mathrm{L}^{-1}$ reduziram o rendimento e a matéria seca da parte aérea e do sistema radicular, embora estes resultados tinham sido atribuídos ao aumento da condutividade elétrica da solução devido à alta concentração de fertilizantes.

Chow et al. (1990), utilizando a cultura do espinafre, demonstrou que o requerimento de $\mathrm{K}$ para o crescimento da planta foi maior em condições de alta salinidade do que sob baixa salinidade e o aumento na quantidade de K aplicada resultou em um maior crescimento das plantas. Cuartero \& Muñoz (1999) afirmam que as plantas de tomate absorvendo maior quantidade de Ca e $\mathrm{K}$ de um meio salino apresentarão menores valores das relações $\mathrm{Na} / \mathrm{Ca}$ e $\mathrm{Na} / \mathrm{K}$ e, conseqüentemente, um equilíbrio nutricional mais próximo daquelas cultivadas em meio não-salino. 
A concentração de $\mathrm{NaCl}$ na solução nutritiva variando de zero a 17,5 g L' ${ }^{1}$ promoveu redução nos teores foliares de $\mathrm{Ca}, \mathrm{Mg}$, e $\mathrm{NO}_{3}$ de L. esculentum, cv. Pelican, e não teve efeito sobre os teores de $\mathrm{K}$ e $\mathrm{N}$ total, apesar do aumento dos teores de $\mathrm{Na}$ e $\mathrm{Cl}$ (Phills et al., 1979). Pessarakli \& Tucker (1988) verificaram que sob baixas concentrações de $\mathrm{NaCl}$ na solução nutritiva a absorção de $\mathrm{N}$ não foi afetada, porém esta foi reduzida em 70\% sob altos níveis de salinidade. A inibição da absorção de nitrato pode ocorrer devido à interação $\mathrm{NO}_{3} / \mathrm{Cl}$ nos sítios de absorção (Cram, 1983) ou à despolarização da membrana pelo Na (Suhayda et al., 1990), o que tem sido associado à inibição não-competitiva de absorção de $\mathrm{NO}_{3}$ (Hawkins \& Lewis, 1993).

Além do $\mathrm{N}$ e do $\mathrm{K}$, outros íons também podem conferir certo grau de tolerância das culturas à salinidade. A aplicação de Si em plantas de moringa cultivadas em solução nutritiva elevou os teores foliares de $\mathrm{K}$ e $\mathrm{Ca}$ e reduziu os de $\mathrm{Na}$ e $\mathrm{Cl}$; entretanto, não se observou redução nos efeitos depressivos do $\mathrm{NaCl}$ sobre a produção de matéria seca das folhas, caule e raízes (Miranda et al., 2002). Por outro lado, Matoh et al. (1986) e Liang et al. (1996) demonstraram que o Si promove aumento do teor de K e da relação K/Na nas folhas e da produção de matéria seca nas culturas do arroz e cevada, respectivamente.

O aumento no teor de determinado íon na matéria seca das folhas geralmente é associado à maior tolerância à salinidade. Rush \& Epstein (1976) atribuíram a maior tolerância de L. cheesmanii à salinidade, em relação a L. esculentum, à maior absorção de $\mathrm{Na}$, determinada pelo teor desse elemento na matéria seca da planta. Visto que a suculência do tecido vegetal é maior para $L$. cheesmanii, então a maior quantidade de Na absorvida estaria mais diluída, podendo ser este o mecanismo pelo qual L. cheesmanii tolerou uma concentração iônica interna aparentemente mais elevada (Rajasekaran et al., 2000). 


\section{MATERIAL E MÉTODOS}

\subsection{Localização e características da área experimental}

O experimento foi conduzido na área experimental do Departamento de Engenharia Rural da Escola Superior de Agricultura "Luiz de Queiroz" - USP, no município de Piracicaba, SP, situado nas coordenadas geográficas de $22^{\circ} 42^{\prime}$ de latitude sul e 47038' de longitude oeste e altitude de $540 \mathrm{~m}$. O clima da região, na classificação climática de Köppen, é do tipo Cfa, com transição para Cwa, sendo classificado como clima tropical chuvoso, com três meses mais secos (junho, julho e agosto), chuvas de verão, seca de inverno, temperatura média do mês mais quente superior a $22^{\circ} \mathrm{C}$ e a do mês mais frio inferior a $18^{\circ} \mathrm{C}$ (Mariano, 1998).

\subsection{Cultura utilizada}

A cultura utilizada foi o tomateiro (Lycopersicon esculentum Mill.), híbrido Facundo, o qual pertence ao grupo Salada apresentando frutos tipo caqui, de formato redondo, levemente achatado, multilocular. Este híbrido foi desenvolvido para cultivo de verão e apresenta frutos com características longa vida e resistência ou tolerância às principais enfermidades, como o vírus do vira-cabeça (TSWV) e do mosaico (TMV), Fusarium 1 e 2, nematóides, Verticilium e Stemphylium, sendo a planta de crescimento indeterminado e vigorosa. 


\subsection{Descrição da estrutura experimental}

O experimento foi instalado em um ambiente protegido com cobertura de polietileno de 0,15 mm de espessura com aditivo contra radiação ultravioleta, sendo suas dimensões de 6,40 $\mathrm{m}$ de largura, 22,5 $\mathrm{m}$ de comprimento e 3,0 $\mathrm{m}$ de pé direito, apresentando tela anti-afídios nas laterais e nos fundos (Figura1).

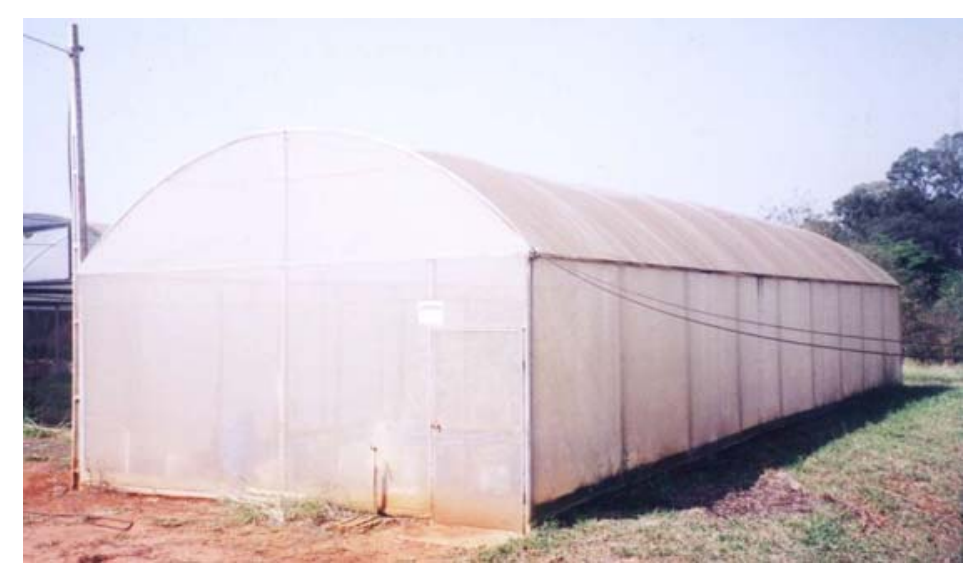

Figura 1 - Ambiente protegido utilizado no cultivo do tomateiro

Não foi necessária a instalação de cortinas laterais, uma vez que a água proveniente das chuvas não atingia as parcelas experimentais e a cultura foi conduzida no período de verão, dispensando a necessidade de controle de temperatura noturna.

\subsection{Características físico-hídricas do solo}

As seguintes características físico-hídricas do solo foram determinadas: (i) curva característica de retenção de água, (ii) densidade, e (iii) composição granulométrica.

A curva característica de retenção de água no solo foi determinada por Silva (2002) em vasos contendo em torno de $10 \mathrm{~L}$ do mesmo tipo de solo utilizado no presente estudo. Entretanto, como a curva obtida por este autor era válida apenas para a faixa de potencial mátrico variando de -5 a $-62 \mathrm{kPa}$, cinco amostras indeformadas de 
solo foram coletadas em vasos tomados ao acaso para obtenção dos pontos da curva inferiores a $-5 \mathrm{kPa}$ e uma curva foi ajustada para melhor representar a relação entre o potencial matricial e a umidade do solo.

A densidade do solo foi determinada pelo método do anel volumétrico (Kiehl, 1979) nas mesmas amostras utilizadas para determinação da curva de retenção de água no solo, dividindo-se a massa de solo seco em estufa a $105{ }^{\circ} \mathrm{C}$ pelo volume do anel.

A análise granulométrica foi realizada pelo método descrito por Bouyoucos $(1927,1951)$. As amostras foram coletadas ao final do período de cultivo na profundidade $0-20 \mathrm{~cm}$, sendo utilizadas 14 amostras.

\subsection{Características químicas do solo e adubação de fundação}

O material de solo utilizado no ensaio foi retirado da camada superficial, na profundidade de 0-30 cm, de um Latossolo Vermelho Amarelo, série Sertãozinho, o qual apresentava acidez moderada e baixos teores para a maioria dos macro e micronutrientes (Tabela 1).

Tabela 1. Características químicas do solo antes da adubação de fundação

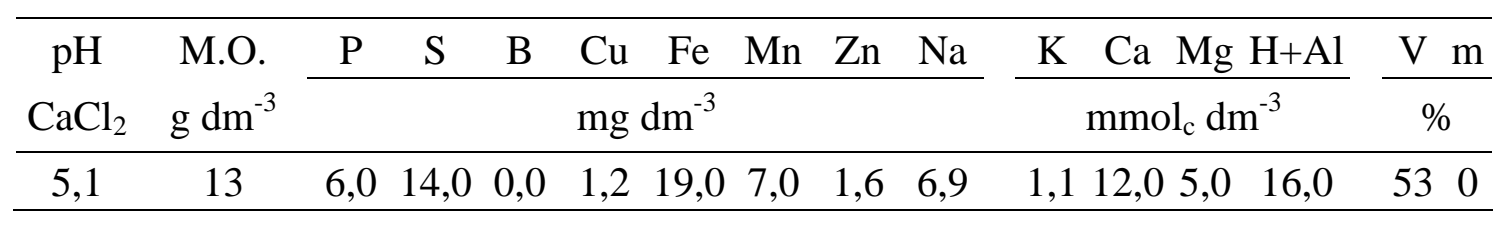

O tratamento para esterilização do solo foi realizado com brometo de metila, utilizando-se uma lata do produto comercial para cada $7 \mathrm{~m}^{2}$ de solo, o qual foi amontoado de modo que formasse uma faixa contínua com $30 \mathrm{~cm}$ de altura e $2 \mathrm{~m}$ de largura. Antes das latas serem perfuradas, o solo foi coberto com lona de polietileno preto utilizando-se terra para vedação das laterais. O solo foi mantido coberto por dez dias após a aplicação a fim de se obter a máxima eficiência do produto.

Após o tratamento, o solo foi peneirado em peneira de malha $5 \mathrm{~mm}$ e acondicionados no interior de vasos plásticos de $60 \mathrm{~L}$ de capacidade, os quais 
apresentavam as seguintes dimensões: $31 \mathrm{~cm}$ de diâmetro inferior, 40 cm de diâmetro superior e $53 \mathrm{~cm}$ de altura. No fundo dos vasos foram feitas perfurações e foi adicionada uma camada de $3 \mathrm{~cm}$ de brita coberta com manta geotêxtil para permitir a drenagem do excesso de água, caso ocorresse. Cada vaso recebeu, aproximadamente, $60 \mathrm{~kg}$ de solo e, após agitação manual e irrigação, apresentou altura livre de $15 \mathrm{~cm}$ na superfície do vaso.

Para a correção da acidez e elevação dos teores dos nutrientes, aplicou-se $100 \mathrm{~g}$ de termofosfato por vaso em 25/09/2001, o qual foi misturado manualmente ao solo a fim de distribuir homogeneamente o fertilizante na camada de 0-30 cm. O termofosfato apresentava a seguinte composição: $17,5 \% \mathrm{P}_{2} \mathrm{O}_{5}, 28 \% \mathrm{CaO}, 14,5 \% \mathrm{MgO}$, 0,55\% Zn, 0,12\% Mn, 0,1\% B, 0,05\% Cu e 0,006\% Mo. Devido às características de correção da acidez do solo desse fertilizante, a calagem não foi realizada. Após a adubação de fundação, aplicou-se água em quantidade suficiente para elevar o solo à capacidade de campo a fim de acelerar a reação do fertilizante com o solo.

\subsection{Condução das plantas e tratos culturais}

O transplantio foi realizado com uma muda de tomate por vaso em 23/10/2001, os quais foram dispostos de modo que o espaçamento entre plantas fosse de 1,0 x 0,5 m. No início e no final de cada linha de plantas foram adicionadas três plantas

a mais, as quais não pertenciam aos blocos experimentais, e foi adicionada uma linha de plantas em cada lado do ambiente protegido para que estas exercessem a função de bordadura e para fins de proteção das parcelas experimentais, uma vez que as plantas localizadas nas laterais dos ambientes protegidos geralmente são mais afetadas por pragas e doenças.

As plantas foram conduzidas em haste única, através de uma espaldeira. Para a condução das plantas, foi instalado um fio de arame sobre as linhas de plantio, a $2 \mathrm{~m}$ de altura em relação à superfície do solo no vaso, e as plantas foram conduzidas através de um fitilho.

Realizaram-se desbrotas e raleio de frutos semanalmente, permitindo o desenvolvimento de apenas 4 frutos por cacho. Foi estabelecido que quando as plantas 
alcançassem o arame estas teriam os ponteiros cortados (decepa apical), o que não foi realizado visto que as plantas não atingiram esta altura.

O controle de pragas e enfermidades foi realizado por pulverizações semanais utilizando oxicloreto de cobre, mancozeb, deltametrina, benomil, acetamiprid, abamectina e propargite, com os quais foi feito um “rodízio” a fim desfavorecer o desenvolvimento de patógenos e pragas tolerantes aos produtos.

\subsection{Equipamentos para monitoramento meteorológico}

No interior do ambiente protegido, para fins de caracterização das condições meteorológicas em que o ensaio foi conduzido, foram instalados sensores para determinação da temperatura e umidade relativa do ar e um tanque de evaporação reduzido.

Para medida da temperatura e umidade relativa do ar foi utilizado um conjunto psicrométrico aspirado (Marin et al., 2001) o qual utiliza termopares de cobreconstantan conectados a um sistema de aquisição de dados Campbell, modelo CR10. As leituras foram efetuadas a cada $1 \mathrm{~s}$ e as médias foram armazenadas em intervalos de 20 min. O psicrômetro foi instalado na região central do ambiente protegido a $2 \mathrm{~m}$ de altura em relação à superfície do solo no interior dos vasos.

Um tanque de evaporação reduzido, de $60 \mathrm{~cm}$ de diâmetro e $25 \mathrm{~cm}$ de altura, foi instalado entre a primeira linha de plantas e a linha de bordadura, sobre um estrado de madeira em nível, sendo as leituras realizadas diariamente por meio de um micrômetro de gancho com graduação de 0,01 mm.

\subsection{Tratamentos e delineamento estatístico}

Inicialmente, os tratamentos foram compostos de três fatores: salinidade da água de irrigação ( $\mathrm{S} 1 \cong 2 \mathrm{dS} \mathrm{\textrm {m } ^ { - 1 }}$; S2 $=6 \mathrm{dS} \mathrm{m}^{-1}$; $\mathrm{S} 3=10 \mathrm{dS} \mathrm{m}^{-1}$ ), níveis de nitrogênio $\left(\mathrm{N} 1=7,5\right.$ g planta $^{-1}$; N2 $=15,0$ g planta $^{-1}$; N3 = 22,5 g planta $\left.^{-1}\right)$ e níveis de potássio $\left(\mathrm{K} 1=8 \mathrm{gK}_{2} \mathrm{O}\right.$ planta $^{-1} ; \mathrm{K} 2=16 \mathrm{gK}_{2} \mathrm{O}$ planta $^{-1} ; \mathrm{K} 3=24 \mathrm{gK}_{2} \mathrm{O}$ planta $\left.{ }^{-1}\right)$, num fatorial 
completo com 27 tratamentos e cinco repetições. Entretanto, ao longo do período experimental constatou-se a salinização excessiva das parcelas irrigadas com a água S1, chegando a apresentar valores de condutividade elétrica da solução do solo iguais àqueles verificados nas parcelas irrigadas com as águas mais salinas. Além disso, a concentração de Na na solução do solo obtida nas parcelas S1 aumentou rapidamente após o início da aplicação dos tratamentos e, uma vez que as irrigações com as diferentes águas eram realizadas por um mesmo sistema de irrigação, sendo a irrigação com cada água realizada separadamente, a contaminação da água S1 pelas águas S2 e S3 tornou-se evidente, pois um aumento na concentração de Na nas parcelas S1 não poderia ter ocorrido, pois a água de irrigação deste tratamento não recebia Na. Esta contaminação provavelmente foi devida à mistura da água S1 com o volume de água remanescente na tubulação após uma irrigação com as águas S2 e S3 do dia anterior e, com isso, a salinidade da água S1 que chegava às plantas era, na verdade, maior do que aquela medida nos reservatórios por ocasião do seu preparo. Este fato não era esperado, sendo que outros autores (Medeiros, 1998; Blanco, 1999; Blanco et al., 1999) utilizaram metodologia semelhante e nenhum problema de contaminação foi verificado.

Com isso, foram considerados apenas os tratamentos irrigados com a água S3 com o intuito de se avaliar os efeitos das diferentes doses de nutrientes na tolerância da cultura do tomateiro submetida à irrigação com água de alta salinidade.

O delineamento estatístico adotado foi o de blocos casualizados completos com cinco repetições e os tratamentos foram arranjados no esquema fatorial 3x3 (3 níveis de $\mathrm{N}$ e 3 níveis de $\mathrm{K}$ ), resultando em 9 tratamentos e 45 parcelas úteis, sendo cada parcela representada por uma planta.

\subsection{Sistema de irrigação e manejo}

Adotou-se um sistema de irrigação por gotejamento com dois, três ou quatro emissores por planta, de acordo com o tratamento correspondente. Nas irrigações, prepararam-se três diferentes soluções, sendo uma para o $\mathrm{N}+\mathrm{Ca}$, outra para $\mathrm{K}+\mathrm{Ca}$ e uma terceira para a complementação das quantidades de água e Ca necessárias em cada 
irrigação, de modo que cada planta recebesse as quantidades preestabelecidas de cada nutriente e um mesmo volume de água. Assim, foram utilizadas três motobombas e ao lado de cada linha de plantio haviam nove linhas de irrigação, sendo três de cada motobomba (uma linha para cada nível de nutriente), de modo que a quantidade de um determinado nutriente pudesse ser controlada pelo tempo que cada linha de irrigação permanecia aberta (Figura 2A e 2B).

Utilizaram-se gotejadores de vazão $2 \mathrm{~L} \mathrm{~h}^{-1}$, os quais operaram à pressão de $100 \mathrm{kPa}$. Os gotejadores foram instalados a $1 \mathrm{~cm}$ de altura em relação à superfície do solo nos vasos e foram conectados às linhas de irrigação por microtubos (Figura 2C).

(A)

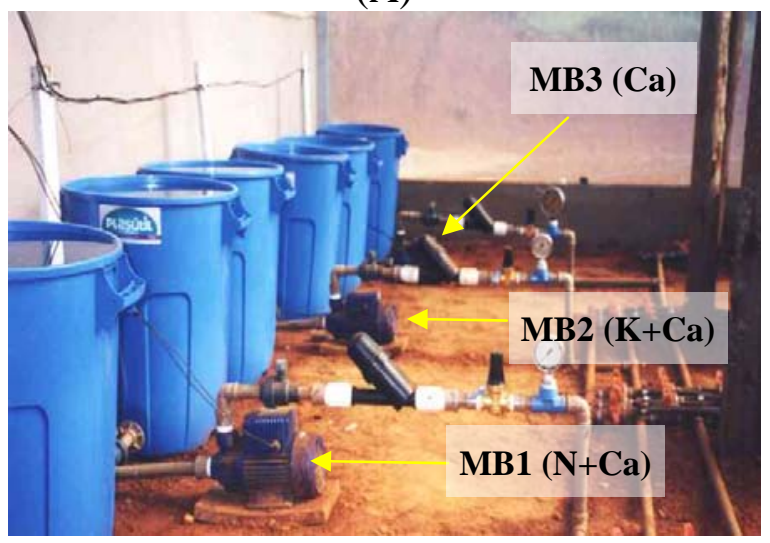

(C)
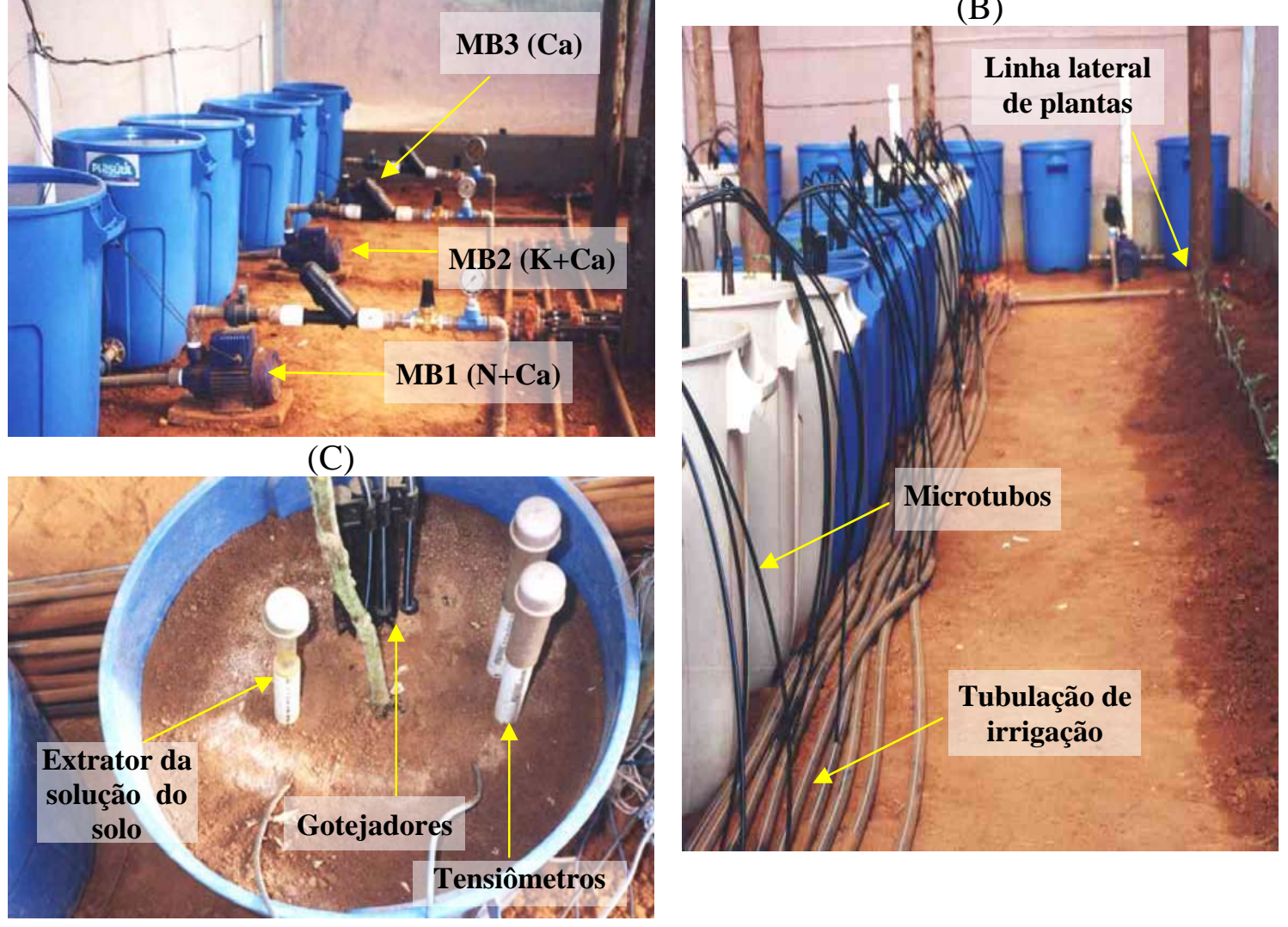

Figura 2 - Sistema de irrigação e equipamentos de manejo: (A) Motobombas (MB) e reservatórios; (B) tubulação de irrigação com microtubos e linha lateral de plantas; (C) gotejadores, tensiômetros e extrator da solução do solo 
Após a instalação, o sistema de irrigação foi avaliado quanto às suas características de uniformidade de emissão de água (UE) pelo método Pattern-Efficiency (Pinto et al., 1991). Foi medida a vazão de cinqüenta gotejadores, escolhidos ao acaso, correspondentes às três motobombas, as quais foram ligadas simultaneamente. Após a estabilização da pressão, medida em manômetros no início da linha lateral, iniciou-se a coleta da água emitida por cada um dos gotejadores avaliados. O volume de água aplicado por cada gotejador durante um período de 6 min foi coletado em recipientes plásticos e o volume coletado foi medido em uma proveta graduada, sendo a UE calculada por:

$$
\mathrm{UE}=\frac{\overline{\mathrm{x}}_{25}}{\overline{\mathrm{X}}} \cdot 100
$$

em que:

$\overline{\mathrm{x}}_{25}=$ média dos $25 \%$ do total de valores coletados, com os menores valores (ml); $\overline{\mathrm{X}}=$ média de todos os valores coletados (ml).

Tensiômetros de câmara de ar (Marthaler et al., 1983) foram construídos e avaliados. As cápsulas de cerâmica porosa utilizadas foram aquelas recomendadas por Cápsulas (1985). Todos os tensiômetros foram colocados em um recipiente com água para saturação das cápsulas durante $12 \mathrm{~h}$ e foi realizado o teste de borbulhamento aplicando-se ar comprimido no interior dos tensiômetros a uma pressão de $100 \mathrm{kPa}$. Uma amostra de quarenta tensiômetros foi tomada e avaliou-se a condutância hidráulica das cápsulas pelo método da carga decrescente, aplicando-se uma pressão adicional de $100 \mathrm{kPa}$ sobre o menisco do tubo transparente, com a finalidade de acelerar o processo, observando-se o tempo necessário para a coluna de água abaixar $50 \mathrm{~cm}$.

Os tensiômetros foram instalados nas profundidades de 15 e $30 \mathrm{~cm}$ para o monitoramento da irrigação, a qual foi realizada sempre que o potencial mátrico médio das cinco repetições de cada tratamento aproximava-se de $-30 \mathrm{kPa}$. As leituras 
tensiométricas foram realizadas diariamente sempre no período compreendido entre as sete e oito horas da manhã e, semanalmente, foi realizada a inspeção dos tensiômetros para verificar o nível da água em seu interior, a qual era reposta sempre que necessário para evitar problemas de variação de pressão na câmara de ar devido a variações na temperatura (Butters \& Cardon, 1998).

O manejo da irrigação foi realizado a fim de elevar a umidade do solo à capacidade de campo, a qual corresponde ao potencial mátrico de, aproximadamente, -6 kPa. Para o cálculo do volume de água a ser aplicado foi considerada a diferença entre o volume de água armazenado no solo no momento da irrigação e o volume de água armazenado à capacidade de campo, utilizando-se a equação de ajuste da curva característica de retenção de água no solo.

\subsection{Preparo das águas de irrigação}

Todos os tratamentos receberam nitrogênio na forma de nitrato de amônio $\left(\mathrm{NH}_{4} \mathrm{NO}_{3}\right)$, potássio pelo cloreto de potássio $(\mathrm{KCl})$ e cálcio pelo cloreto de cálcio $\left(\mathrm{CaCl}_{2}\right)$. O total de nitrogênio e potássio aplicados durante o ciclo para o tratamento N2K2 correspondeu à recomendação de Vivancos (1993) e a quantidade de cálcio foi aquela determinada por Fayad (1998), sendo que o parcelamento de cada nutriente (Figura 3) seguiu a marcha de absorção de nutrientes pelo tomateiro em ambiente protegido (Fayad, 1998).

A salinidade da água de irrigação $\left(\mathrm{CE}_{\mathrm{a}}\right)$ foi obtida através da adição de partes iguais dos sais cloreto de sódio $(\mathrm{NaCl})$ e cloreto de cálcio, nas quantidades necessárias para elevar a salinidade da água até o nível desejado. Como a concentração de nutrientes na água de irrigação variou ao longo do período de cultivo, de acordo com a marcha de absorção de nutrientes, então a quantidade de sais adicionada à água também variou, uma vez que quanto maior a concentração de fertilizantes menor era a quantidade de sais adicionada para se atingir a $\mathrm{CE}_{\mathrm{a}}$ desejada. 


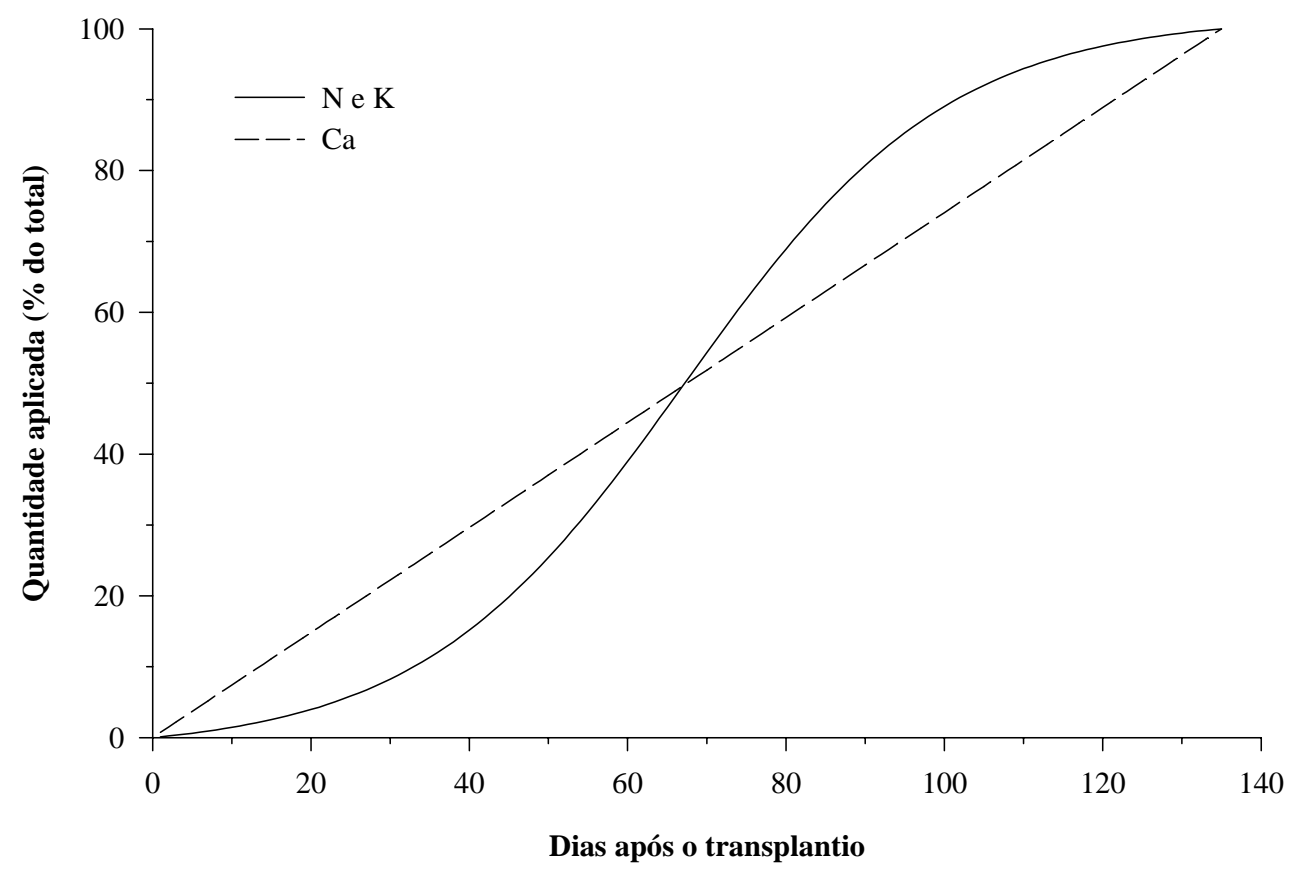

Figura 3 - Quantidades acumuladas de N, K e Ca aplicadas ao longo do ciclo do tomateiro em ambiente protegido

\subsection{Variáveis avaliadas}

\subsubsection{Variáveis relacionadas ao solo}

\subsubsection{Condutividade elétrica e pH da solução do solo}

Durante o período de cultivo, foi realizada a coleta da solução do solo em intervalos de, aproximadamente, 15 dias. A solução foi coletada com o auxílio de um extrator da solução do solo, que consiste em um tubo de PVC com uma cápsula de cerâmica porosa em sua extremidade, a qual foi enterrada na profundidade de $15 \mathrm{~cm}$ em todos os vasos. Vácuo de, aproximadamente, $-70 \mathrm{kPa}$ foi aplicado nos extratores entre 24 e $48 \mathrm{~h}$ após a irrigação, quando os tensiômetros instalados a $15 \mathrm{~cm}$ de profundidade indicavam potencial mátrico em torno de $-6 \mathrm{kPa}$, que corresponde ao potencial mátrico 
na capacidade de campo. A solução foi coletada com uma seringa conectada a uma mangueira de silicone 24 h após a aplicação do vácuo nos extratores.

Após a coleta, as amostras da solução do solo eram armazenadas em frascos plásticos e levadas ao laboratório, onde eram feitas as leituras da condutividade elétrica $\left(\mathrm{CE}_{\mathrm{s}}\right)$ e do $\mathrm{pH}\left(\mathrm{pH}_{\mathrm{s}}\right)$ por um condutivímetro de bancada microprocessado e potenciômetro, respectivamente, ambos com compensação automática de temperatura.

\subsubsection{Concentração iônica na solução do solo}

As concentrações de $\mathrm{NO}_{3}$, K e Na na solução do solo foram determinadas através de testes rápidos, utilizando medidores de íons específicos (MIE) da marca Horiba. Os MIE foram calibrados antes do início das análises de acordo com as recomendações do fabricante e, a cada dez amostras analisadas, estes foram recalibrados para garantir a máxima precisão dos resultados.

\subsubsection{Relação entre variáveis medidas no extrato de saturação, no extrato 1:2 e na solução do solo}

Com a finalidade de verificar a existência de correlação entre as variáveis medidas no extrato de saturação e no extrato 1:2 (proporção solo:água destilada) com as medidas realizadas na solução do solo, ao final do ciclo de cultivo, por ocasião da sexta e última coleta da solução do solo, os extratores de solução foram retirados e uma amostra de solo foi obtida na profundidade $0-20 \mathrm{~cm}$, sendo esta coletada na mesma posição em que os extratores estavam inseridos.

As amostras de solo foram secas ao ar, destorroadas e peneiradas em peneira de malha de $2 \mathrm{~mm}$ para preparação da pasta de saturação e do extrato 1:2. A pasta de saturação foi obtida colocando-se uma porção do solo seco em um recipiente de massa conhecida e, em seguida, adicionando-se água destilada para obtenção do ponto de saturação, como recomenda Richards (1954). O recipiente com o solo foi pesado 
antes do início da adição de água e após o solo atingir a saturação, sendo a umidade de saturação calculada por:

$$
U_{\text {sat }}=\frac{M_{u}-M_{s}}{M_{s}-M_{r}} \cdot 100
$$

onde:

$\mathrm{U}_{\mathrm{sat}}=$ umidade do solo saturado em base peso (\%);

$\mathrm{M}_{\mathrm{u}}=$ massa do recipiente + solo saturado (g);

$\mathrm{M}_{\mathrm{s}}$ = massa do recipiente + solo seco (g);

$\mathrm{M}_{\mathrm{r}}=$ massa do recipiente ( $\mathrm{g}$ ).

O extrato 1:2 foi preparado adicionando-se $50 \mathrm{~g}$ de solo seco e $100 \mathrm{~g}$ de água destilada em um recipiente e, após agitação durante 1 min, o recipiente foi coberto com papel alumínio e deixado em repouso por $12 \mathrm{~h}$. Após este período, o solo foi novamente agitado e, após $1 \mathrm{~h}$, a leitura da condutividade elétrica $\left(\mathrm{CE}_{1: 2}\right)$ foi realizada no sobrenadante.

O extrato de saturação foi obtido pela filtragem a vácuo da pasta de saturação. Determinaram-se sua condutividade elétrica $\left(\mathrm{CE}_{\mathrm{es}}\right)$ e concentrações de nitrato $\left(\mathrm{NO}_{3 e s}\right)$, potássio $\left(\mathrm{K}_{\mathrm{es}}\right)$, cálcio $\left(\mathrm{Ca}_{\mathrm{es}}\right)$ e sódio $\left(\mathrm{Na}_{\mathrm{es}}\right)$. As determinações de $\mathrm{NO}_{3 e s}$, $\mathrm{K}_{\mathrm{es}} \mathrm{e}$ $\mathrm{Na}_{\text {es }}$ foram feitas com os MIE e corrigidas para os métodos-padrões pelas equações de calibração obtidas (ver item 3.12), enquanto que a determinação de $\mathrm{Ca}_{\text {es }}$ foi realizada em laboratório por espectrofotometria de absorção atômica (Prince, 1965). As amostras da solução do solo retiradas no final do período de cultivo também foram submetidas às mesmas análises químicas para fins de comparação.

Como a solução do solo e o extrato de saturação foram obtidos em umidades diferentes do solo, os valores de $\mathrm{CE}_{\mathrm{es}}, \mathrm{NO}_{3 \mathrm{es}}, \mathrm{K}_{\mathrm{es}}, \mathrm{Ca}_{\mathrm{es}}$ e $\mathrm{Na}_{\mathrm{es}}$ foram corrigidos para a umidade da solução do solo pela expressão: 


$$
\mathrm{X}_{\text {s-estES }}=\frac{\mathrm{X}_{\mathrm{es}} \cdot \mathrm{U}_{\mathrm{sat}}}{\mathrm{U}_{\mathrm{a}}}
$$

em que:

$\mathrm{X}_{\text {s-estES }}=$ valor estimado da variável (CE, $\mathrm{NO}_{3}, \mathrm{~K}, \mathrm{Ca}$ ou $\mathrm{Na}$ ) na solução do solo a partir do valor medido no extrato de saturação ( $\mathrm{dS} \mathrm{m}^{-1}$ ou $\left.\mathrm{mg} \mathrm{L}^{-1}\right)$;

$\mathrm{X}_{\mathrm{es}} \quad$ = valor medido da variável no extrato de saturação $\left(\mathrm{dS} \mathrm{m}^{-1}\right.$ ou $\left.\mathrm{mg} \mathrm{L}^{-1}\right)$;

$\mathrm{U}_{\mathrm{a}} \quad$ = umidade atual do solo no momento da aplicação do vácuo nos extratores (\%).

$\mathrm{O}$ valor de $\mathrm{U}_{\mathrm{a}}$ foi determinado a partir da curva característica de retenção de água no solo e da leitura do tensiômetro instalado a $15 \mathrm{~cm}$ de profundidade no momento da aplicação do vácuo nos extratores.

Analogamente, a análise da relação entre $\mathrm{CE}_{\mathrm{s}}$ e $\mathrm{CE}_{1: 2}$ foi realizada por:

$$
\mathrm{CE}_{\text {s-est1:2 }}=\frac{\mathrm{CE}_{1: 2} \cdot \mathrm{U}_{1: 2}}{\mathrm{U}_{\mathrm{a}}}
$$

onde:

$\mathrm{CE}_{\text {s-est1:2 }}$ = condutividade elétrica da solução do solo estimada pela $\mathrm{CE}_{1: 2}\left(\mathrm{dS} \mathrm{m}^{-1}\right)$;

$\mathrm{U}_{1: 2} \quad=$ umidade do solo no extrato 1:2 $\left(\mathrm{U}_{1: 2}=200 \%\right)$.

\subsubsection{Variáveis relacionadas à cultura}

\subsubsection{Altura das plantas e diâmetro da haste}

A altura das plantas foi medida semanalmente até o final do período de cultivo com o auxílio de uma trena graduada em escala de $1 \mathrm{~mm}$, medindo-se a distância entre o nível do solo e a gema apical da planta. 
As medidas do diâmetro da haste das plantas foram realizadas quinzenalmente, tomando-se como referência a região da haste localizada a $1 \mathrm{~cm}$ de altura em relação à superfície do solo. $\mathrm{O}$ diâmetro da haste foi medido com um paquímetro graduado com escala de $0,1 \mathrm{~mm}$.

\subsubsection{2 Área foliar}

A área foliar da cultura foi medida aos 43 dias após o transplantio (DAT) pela metodologia desenvolvida por Blanco (1999). Foram coletadas vinte folhas, sendo uma de cada parcela escolhida ao acaso de modo que as folhas apresentassem dimensões distintas e variadas. O comprimento (C) e a largura (L) das folhas foram medidos com uma régua graduada e a área foliar de cada uma das folhas foi determinada em um medidor digital de área foliar LI-COR 3000, de modo que a relação entre o produto CxL e a área foliar medida pudesse ser estabelecida.

Para determinação do Padrão de Distribuição de Área Foliar (PDAF) foram utilizadas cinco plantas, sendo estas correspondentes ao tratamento N2K2 dos

cinco blocos experimentais. O PDAF foi obtido pela medida da altura de inserção de cada folha na haste e da medida do maior comprimento e largura da folha. Então, pôdese estimar a área foliar para cada altura relativa e, com isso, estabelecer a altura relativa da folha que representasse a área foliar média de cada planta.

A determinação da área foliar foi realizada para todas as parcelas medindo-se apenas C e L da folha representativa de cada planta e assumindo-se que esta representava a área foliar média (AFM) da planta. A partir da contagem do número de folhas (NF) de cada planta, a área foliar total (AFT) foi obtida pelo produto AFM x NF.

\subsubsection{Florescimento}

Diariamente foi realizada a contagem do número de cachos com pelo menos uma flor aberta em todas as plantas e o número de dias transcorridos desde o transplantio das mudas até o florescimento de cada cacho da planta foi contabilizado. 


\subsubsection{Componentes de produção}

As colheitas foram iniciadas aos 67 DAT e realizadas em intervalos de 1 a 4 dias. Após o início do período produtivo, determinaram-se o número de frutos por planta, a produtividade e o peso médio dos frutos. Os frutos foram colhidos quando já apresentavam coloração avermelhada devido às características longa-vida do híbrido utilizado.

Para a avaliação do tamanho dos frutos, mediu-se o diâmetro de todos os frutos colhidos e o diâmetro de cada fruto correspondeu à média de duas leituras perpendiculares entre si efetuadas na região central do fruto onde ocorre o maior diâmetro.

\subsubsection{Produção e porcentagem de matéria seca}

Para a determinação da produção de matéria seca da planta, os componentes avaliados foram secos em estufa de ventilação forçada a $60^{\circ} \mathrm{C}$ até atingirem peso constante.

Ao final do período de cultivo as plantas foram colhidas e separadas em folhas e haste+cachos, tomando-se o peso verde e seco de cada componente. As produções de matéria seca de folhas (MSFo) e hastes+cachos (MSHC) foram avaliadas, bem como as suas respectivas porcentagens (PMSFo e PMSHC). A MSHC compreendeu a análise da matéria seca da haste da planta mais a matéria seca dos cachos onde os frutos eram produzidos, uma vez que apenas os frutos eram retirados nas colheitas, permanecendo os cachos na planta.

Por ocasião da primeira e da última semana de colheita, tomaram-se dois a quatro frutos de cada planta, dependendo do tamanho dos frutos, e as porcentagens de matéria seca dos frutos no início $\left(\mathrm{PMSF}_{\mathrm{I}}\right)$ e no final $\left(\mathrm{PMSF}_{\mathrm{F}}\right)$ do período de produção foram determinadas. Assumiu-se uma variação linear da porcentagem de matéria seca dos frutos ao longo do período produtivo e, com isso, a produção de matéria seca de frutos (MSF) pôde ser estimada pelo somatório da multiplicação do peso dos frutos 
obtidos em cada colheita realizada pela respectiva porcentagem de matéria seca para o dia em questão.

A matéria seca das brotações e dos frutos (MSBF) retirados semanalmente por ocasião das desbrotas e raleios, respectivamente, também foi contabilizada. A matéria seca total (MST) produzida por cada planta durante o período de cultivo foi obtida pela soma de MSFo, MSHC, MSF e MSBF.

\subsubsection{Concentração iônica na seiva}

Por ocasião do florescimento do terceiro e quinto cachos, determinaramse as concentrações de $\mathrm{NO}_{3}, \mathrm{~K}$ e $\mathrm{Na}$ na seiva do pecíolo através de testes rápidos, utilizando os MIE. Para a extração da seiva, coletou-se a terceira folha a partir do ápice da planta sendo utilizada a base do seu pecíolo (Figura 4), do qual a seiva foi retirada com o auxílio de uma prensa manual.

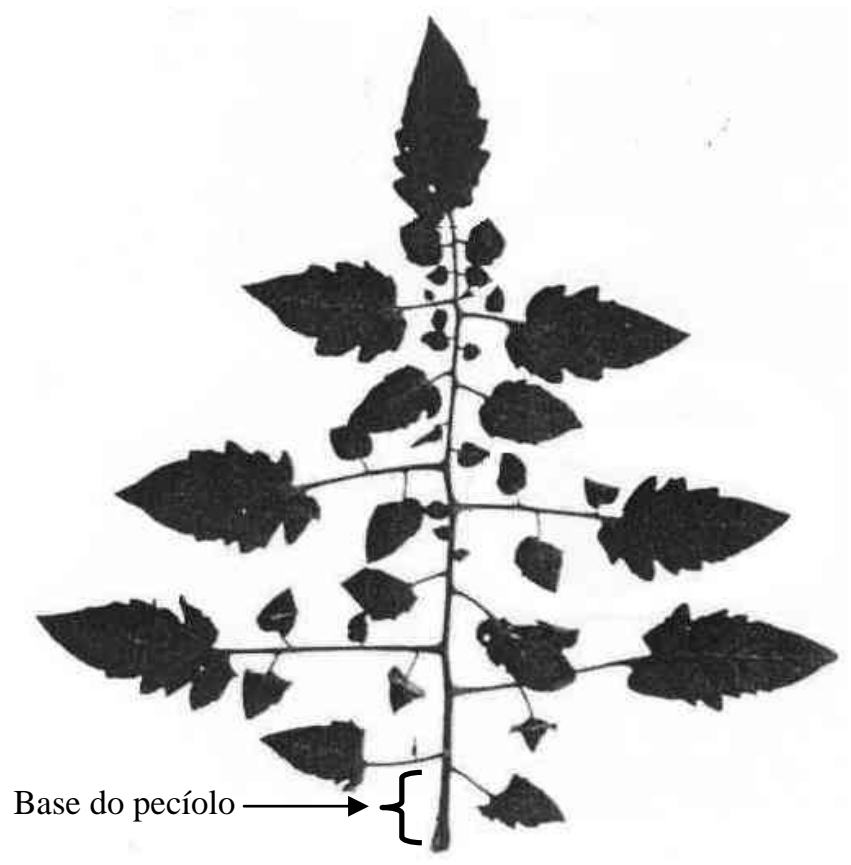

Figura 4 - Esquema da folha do tomateiro demonstrando a parte utilizada nas determinações de concentração de nutrientes na seiva 


\subsubsection{Teor de prolina nas folhas}

Logo após a coleta da folha e remoção do pecíolo, as folhas coletadas para determinação da concentração iônica na seiva por ocasião do florescimento do quinto cacho foram congeladas em nitrogênio líquido e armazenadas em congelador.

A metodologia utilizada foi aquela descrita por Torello \& Rice (1986) com as modificações utilizadas por Rossi et al. (1997). Aproximadamente 0,5 g de amostra foi homogeneizada em almofariz de porcelana com $10 \mathrm{ml}$ de ácido sulfossalicílico a 3\% e, em seguida, submetidas a centrifugação a 5000 rpm e 3100 G por 20 minutos. Em um tubo de ensaio, adicionaram-se 0,5 ml do sobrenadante, 0,5 ml de ácido acético glacial e 0,5 ml de ninhidrina ácida (Bates et al., 1973), o qual foi mantido em banho-maria fervente por 60 minutos. Após o resfriamento, a intensidade da cor foi medida a $520 \mathrm{~nm}$ em um espectrofotômetro Hitachi, modelo U-3210.

As absorbâncias obtidas foram comparadas com a curva-padrão de prolina e os resultados foram expressos em microgramas de prolina por grama de material fresco.

\subsubsection{Teor de macro e micronutrientes nas folhas}

Após a secagem das folhas no final do período de cultivo, estas foram encaminhadas ao laboratório para análise do teor de macro e micronutrientes. Todas as folhas presentes na planta foram secas, trituradas e homogeneizadas, sendo as análises realizadas de acordo com a metodologia apresentada por Malavolta et al. (1997).

\subsubsection{Qualidade dos frutos}

A análise dos frutos quanto às características de qualidade foi realizada por ocasião das colheitas efetuadas na última semana do período de cultivo. Determinaram-se o teor de macronutrientes, sólidos solúveis e acidez total titulável. A 
análise de macronutrientes foi realizada em laboratório especializado segundo a metodologia descrita por Malavolta et al. (1997).

Quatro frutos de cada planta foram triturados e homogeneizados, sendo a determinação dos sólidos solúveis realizada em um refratômetro. Uma alíquota de $10 \mathrm{~g}$ foi tomada e colocada em um erlenmeyer com $100 \mathrm{ml}$ de água destilada sobre um agitador. A acidez foi determinada através da titulação com solução 0,1 N de $\mathrm{NaOH}$ até que a solução atingisse $\mathrm{pH}$ de 8,1, conforme metodologia recomendada pelo Instituto Adolfo Lutz (Pregnolatto \& Pregnolatto, 1985).

A concentração de sólidos solúveis foi expressa de graus brix ( ${ }^{\circ}$ Brix) e a acidez em termos de porcentagem de ácido cítrico.

\subsection{Calibração dos medidores de íons específicos}

Ao final do período experimental foi realizada a calibração dos MIE. As amostras da solução do solo coletadas durante o período foram armazenadas em geladeira e, ao final do experimento, foram escolhidas 350 amostras para análise de $\mathrm{K} \mathrm{e}$ Na por fotometria de chamas (Rich, 1965) e 82 amostras para determinação de $\mathrm{NO}_{3}$ pelo método da destilação (Bremner, 1965).

Coletaram-se 50 amostras de folhas provenientes de plantas submetidas aos diferentes tratamentos, sendo cada amostra composta por cinco folhas. As concentrações de $\mathrm{NO}_{3}$, $\mathrm{K}$ e Na foram determinadas na seiva do pecíolo utilizando os MIE e a matéria seca foi analisada para determinação dos teores de N, K e Na. Os resultados das análises na seiva e na matéria seca foram confrontados para verificar a existência de correlação.

Para a obtenção das equações de calibração dos MIE foi utilizado o procedimento apresentado por Menk \& Igue (1992). De acordo com estes autores, quando duas variáveis são independentes e sujeitas a erro, o modelo de regressão não se aplica e, então, a escolha é a análise estrutural para se chegar à relação funcional. Portanto, a relação funcional foi obtida pelo método do eixo principal reduzido, que minimiza a soma das áreas dos triângulos formados pelas linhas traçadas de cada ponto à 
reta desejada e paralelas aos eixos $\mathrm{X}$ e $\mathrm{Y}$, assumindo-se que a variabilidade dos erros das duas medidas envolvidas não são iguais.

\subsection{Análise estatística}

Para cada variável analisada foi realizado o teste de normalidade, utilizando-se os testes de Kolmogorov-Smirnov e Shapiro-Wilks, e os dados foram transformados sempre que os testes indicavam ausência de distribuição normal. As transformações foram realizadas conforme recomendam Steel \& Torrie (1980) e, quando estas não eram suficientes, utilizou-se o procedimento apresentado por Nogueira (1997) para a obtenção das funções estabilizadoras da variância.

As análises estatísticas foram realizadas utilizando-se o procedimento dos modelos lineares generalizados do SAS. Os efeitos dos diferentes níveis de $\mathrm{N}$ e K sobre as variáveis medidas na planta e no solo foram avaliados pelos métodos convencionais da análise de variância (teste F), aplicando-se o teste de regressão polinomial de segunda ordem para os casos em que ocorreu efeito significativo, conforme recomenda Nogueira (1997).

Para dados em que ocorreram medidas repetidas ao longo do tempo foi realizada a análise multivariada para dados repetidos no tempo e, na presença de efeito significativo, procedeu-se a análise estatística univariada com o objetivo de verificar o efeito de cada fator estudado para cada época de coleta dos dados (Morrison, 1990; Lima, 1996).

As comparações entre os valores de $\mathrm{NO}_{3}, \mathrm{~K}$ e Na medidos na solução do solo e na seiva das plantas com os MIE com aqueles determinados pelos métodospadrões na solução do solo e na matéria seca das folhas, respectivamente, foram realizadas pelo teste t para dados pareados (Steel \& Torrie, 1980). Os valores de $X_{\text {s-estES }}$

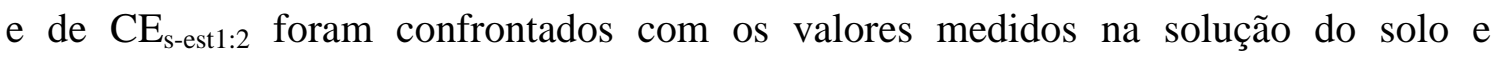
submetidos ao teste de regressão linear, analisando-se também os valores de $\mathrm{r}^{2}$ e do índice de concordância de Willmott, d (Willmott, 1981). O valor do $\mathrm{r}^{2}$ representa a precisão da estimativa, sendo um indicativo do grau de dispersão dos dados obtidos em 
relação à média, ou seja, o erro aleatório, enquanto que d expressa a exatidão das estimativas, a qual está relacionada ao afastamento dos valores estimados em relação aos observados. Tanto o $\mathrm{r}^{2}$ quanto o d variam de zero a 1 e, quanto maiores os seus valores, melhor é a estimativa. 


\section{RESULTADOS E DISCUSSÃO}

\subsection{Características físico-hídricas do material de solo}

Pela curva característica de retenção de água pelo solo (Figura 5), nota-se que a capacidade do solo em reter água é bastante reduzida para $\Psi \mathrm{m}$ abaixo de $-30 \mathrm{kPa}$. Na capacidade de campo o solo apresenta 20,1\% de água em base peso, correspondendo a $61 \%$ da umidade do solo saturado, que é de 32,9\%.

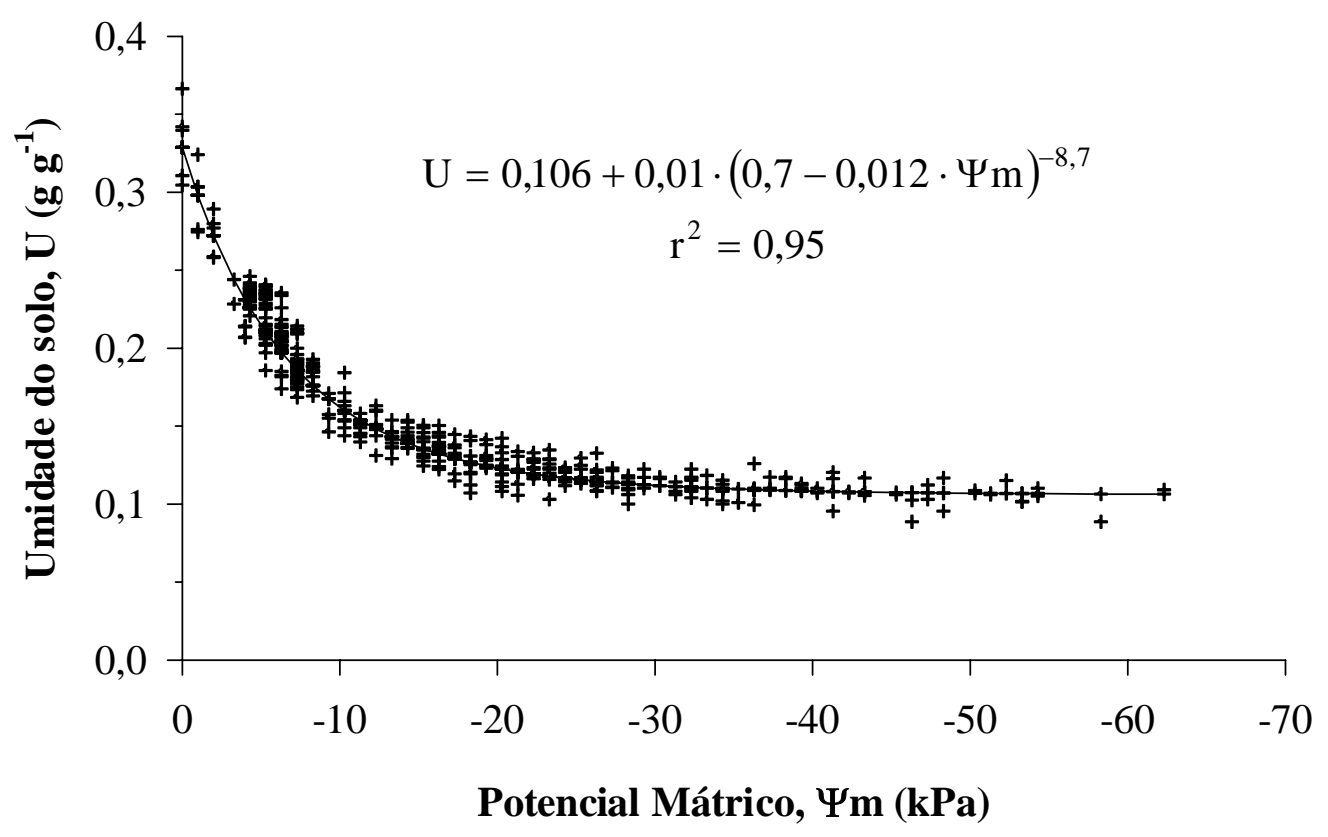

Figura 5 - Curva característica de retenção de água pelo material de solo utilizado 
Os teores de argila, silte e areia e seus respectivos erros-padrões (entre parênteses) foram $25 \%( \pm 1,2), 4 \%( \pm 0,6)$ e $71 \%( \pm 0,7)$, respectivamente, sendo o solo classificado como franco argilo-arenoso pela classificação da Sociedade Brasileira de Ciência do Solo (Kiehl, 1979). A densidade do solo apresentou valores variando de 1250 a $1370 \mathrm{~kg} \mathrm{~m}^{-3}$ dentre as cinco amostras coletadas, com média de $1300 \mathrm{~kg} \mathrm{~m}^{-3}$.

\subsection{Características meteorológicas durante o período de cultivo do tomateiro}

Altas temperaturas foram observadas durante o período experimental (Figura 6A), sendo a máxima e a mínima observadas de $45,9^{\circ} \mathrm{C}$ e $13,0^{\circ} \mathrm{C}$, respectivamente. A temperatura média diária variou de $18,3^{\circ} \mathrm{C}$ a $31,6^{\circ} \mathrm{C}$, com média de $25,2^{\circ} \mathrm{C}$ para o período de cultivo. A faixa de temperatura à qual a cultura estava submetida é aceitável, uma vez que os híbridos de tomateiro desenvolvidos para cultivo no verão chegam a suportar temperaturas acima de $40^{\circ} \mathrm{C}$ (Stevens \& Rick, 1986), não tendo sido observado problema de queda de flores.

\section{(A)}

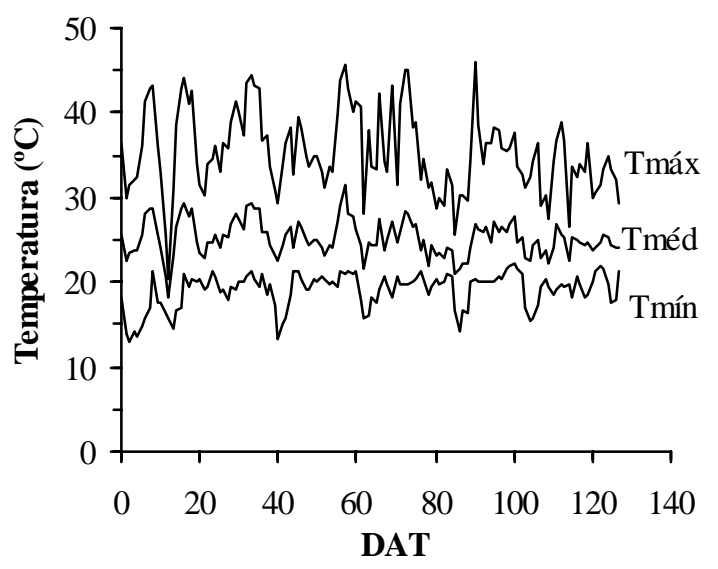

(B)

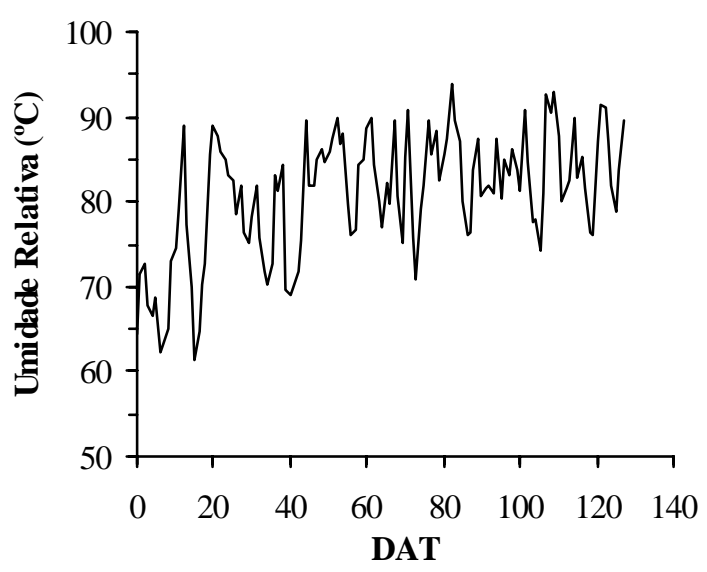

Figura 6 - Variação das temperaturas máxima, média e mínima do ar (A) e umidade relativa média (B) no interior do ambiente protegido durante o período experimental. DAT = dias após o transplantio 
A umidade relativa média do ar variou de $61 \%$ a $94 \%$, com média de $81 \%$ (Figura 6B), enquanto que a evaporação do minitanque variou de 0,71 a 7,18 $\mathrm{mm} \mathrm{d}^{-1}$, com média de 3,64 $\mathrm{mm} \mathrm{d}^{-1}$ (Figura 7). Observa-se uma tendência de aumento da UR e redução da evaporação ao longo do período experimental, o que se deve à maior freqüência de ocorrência de precipitação pluviométrica nos dois últimos meses de cultivo do tomateiro.

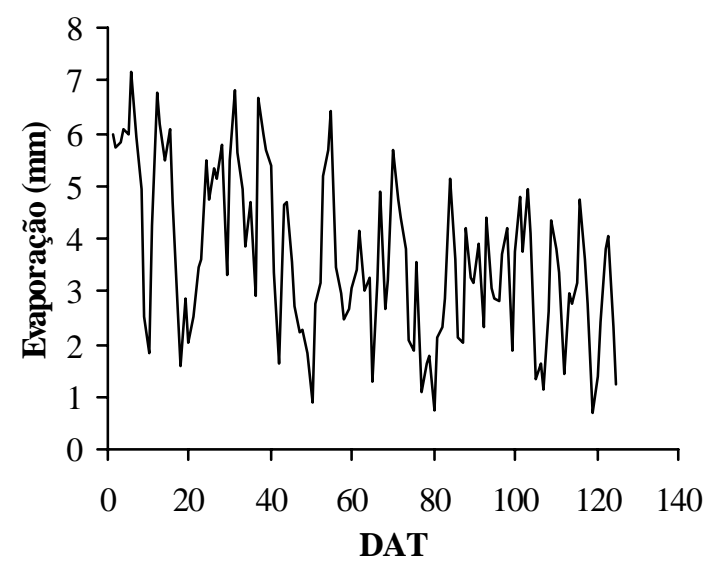

Figura 7 - Variação da evaporação do minitanque no interior do ambiente protegido durante o período experimental. DAT = dias após o transplantio

\subsection{Avaliação do sistema de irrigação e equipamentos de manejo}

O ensaio de avaliação do sistema de irrigação revelou que o sistema apresentava alta uniformidade de aplicação de água. O coeficiente de variação de fabricação dos gotejadores foi de 2,3\% e a uniformidade de emissão de 98\%; portanto, o sistema de irrigação apresentou performance satisfatória, podendo-se afirmar que as variações encontradas não exerceram efeito significativo na aplicação dos tratamentos.

Todos os tensiômetros utilizados passaram pelo teste de borbulhamento, não sendo observada formação de bolhas de ar à pressão de 100 kPa. A condutância hidráulica mínima, máxima e média observadas para as quarenta cápsulas avaliadas foi 
$1,3.10^{-4}, 3,2.10^{-4}$ e $2,1 \cdot 10^{-4} \mathrm{~cm}^{2} \mathrm{~s}^{-1}$, respectivamente, as quais superaram o valor mínimo recomendado para medidas em campo que é de $1,0.10^{-5} \mathrm{~cm}^{2} \mathrm{~s}^{-1}$ (Cassel \& Klute, 1986).

\subsection{Condutividade elétrica e pH da água de irrigação}

A condutividade elétrica da água de irrigação $\left(\mathrm{CE}_{\mathrm{a}}\right)$ variou ao longo das irrigações, sendo esta sempre em torno de 9-10 dS $\mathrm{m}^{-1}$ (Figura 8A), com média de 9,5 dS m ${ }^{-1}$. A variação da $\mathrm{CE}_{\mathrm{a}}$ foi devida às aproximações realizadas no cálculo da concentração de cada sal adicionado, ou seja, estimava-se as quantidades de $\mathrm{NaCl}$ e $\mathrm{CaCl}_{2}$ a serem adicionadas baseando-se na concentração de fertilizantes para cada dia e para cada água de irrigação, sendo a medida da $\mathrm{CE}_{\mathrm{a}}$ realizada após a irrigação utilizando uma amostra da água coletada em cada reservatório. $\mathrm{O} \mathrm{pH}$ da água de irrigação $\left(\mathrm{pH}_{\mathrm{a}}\right)$ oscilou entre 4,7 e 7,5, com média de 6,3 (Figura 8B), a qual encontra-se próxima da faixa recomendada (Burt et al., 1998; López, 2001).

(A)

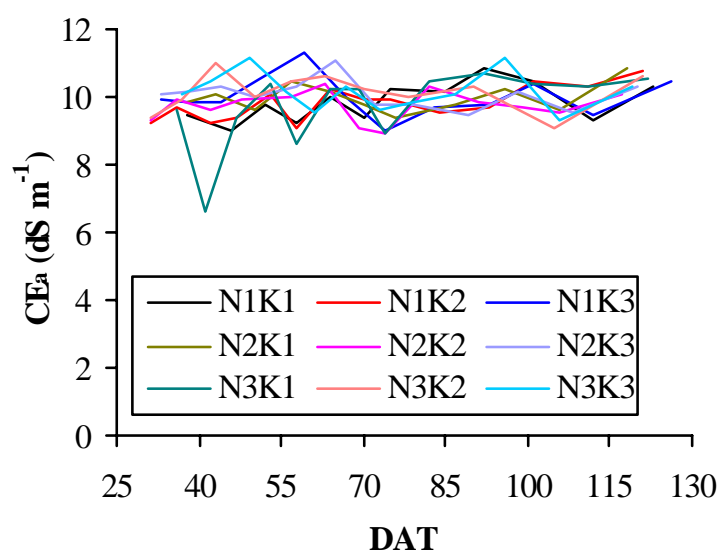

(B)

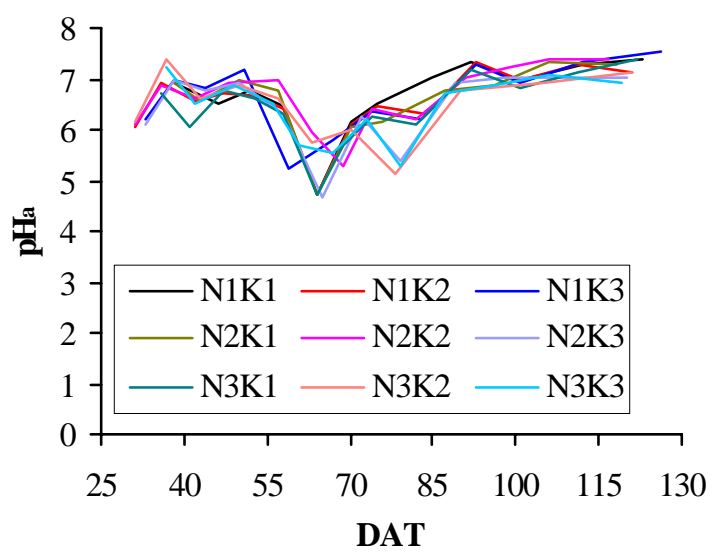

Figura 8 - Variação da condutividade elétrica $\left(\mathrm{CE}_{\mathrm{a}}\right)$ e $\mathrm{pH}\left(\mathrm{pH}_{\mathrm{a}}\right)$ da água de irrigação para cada tratamento ao longo do período de cultivo do tomateiro. DAT = dias após o transplantio 


\subsection{Variação do potencial mátrico e freqüência de irrigação}

O potencial mátrico manteve-se na faixa de -6 a $-30 \mathrm{kPa}$ para a maior parte dos tratamentos durante o período de cultivo (Figura 9), podendo-se afirmar que o manejo da irrigação foi adequado e que o potencial mátrico não exerceu efeito sobre os resultados obtidos.

A freqüência de irrigação variou bastante ao longo do período de cultivo (Figura 10). No início do período experimental o intervalo entre irrigações era em torno de 3 a 4 dias e manteve-se em torno de 6 dias entre a terceira e a oitava irrigação realizada. Após este período, devido aos efeitos da alta salinidade e do menor ritmo de crescimento das plantas, ocorreu aumento nos intervalos entre irrigações, sendo estes em torno de 10 dias, embora para alguns tratamentos o intervalo tenha ultrapassado este valor.

Não foi observada ocorrência de drenagem no fundo dos vasos para nenhuma das irrigações realizadas, o que permitiu que toda água, fertilizantes e sais adicionados ficassem retidos na região radicular da cultura. 

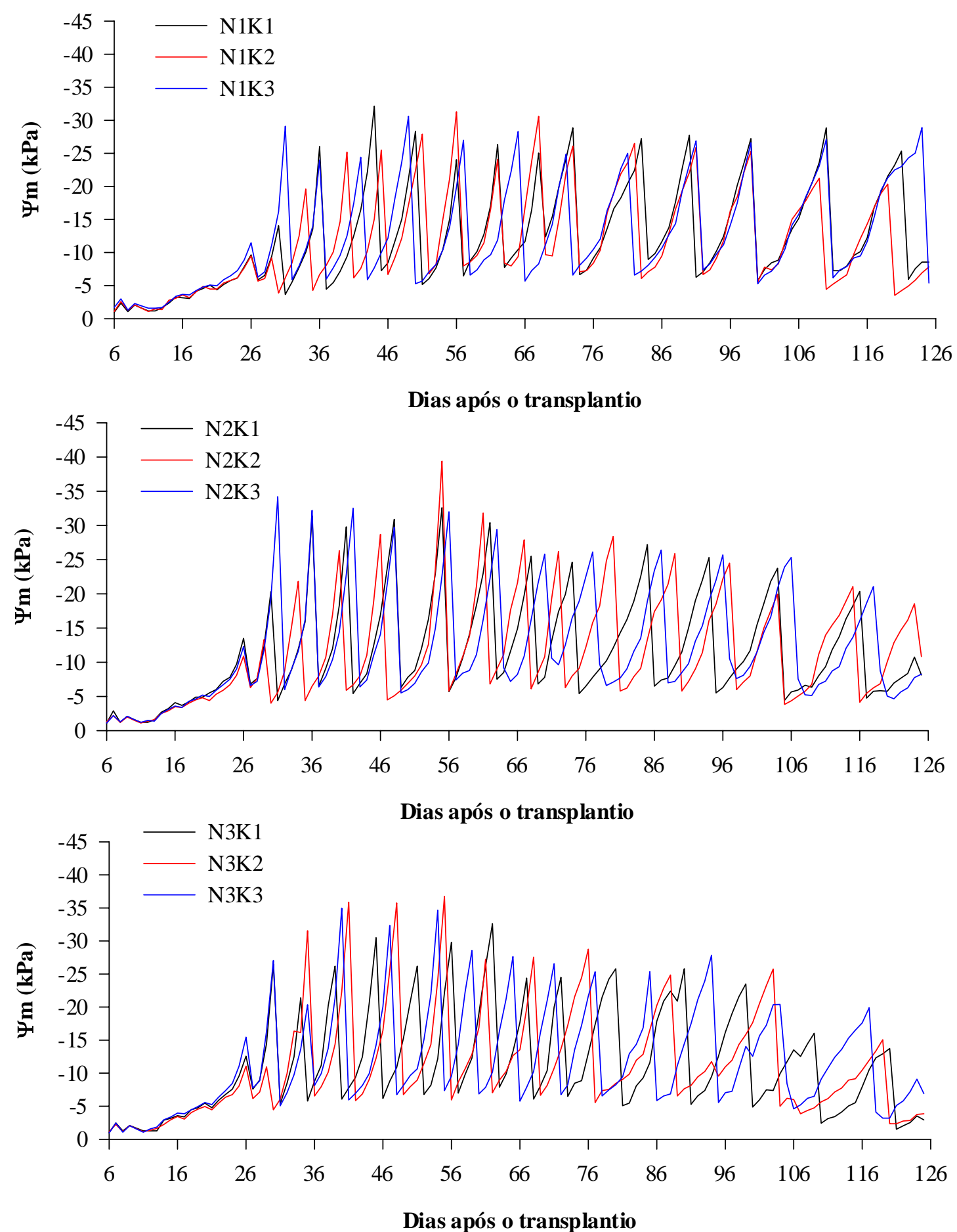

Figura 9 - Variação do potencial mátrico ( $\Psi \mathrm{m})$ para os diferentes tratamentos ao longo do período de cultivo do tomateiro 


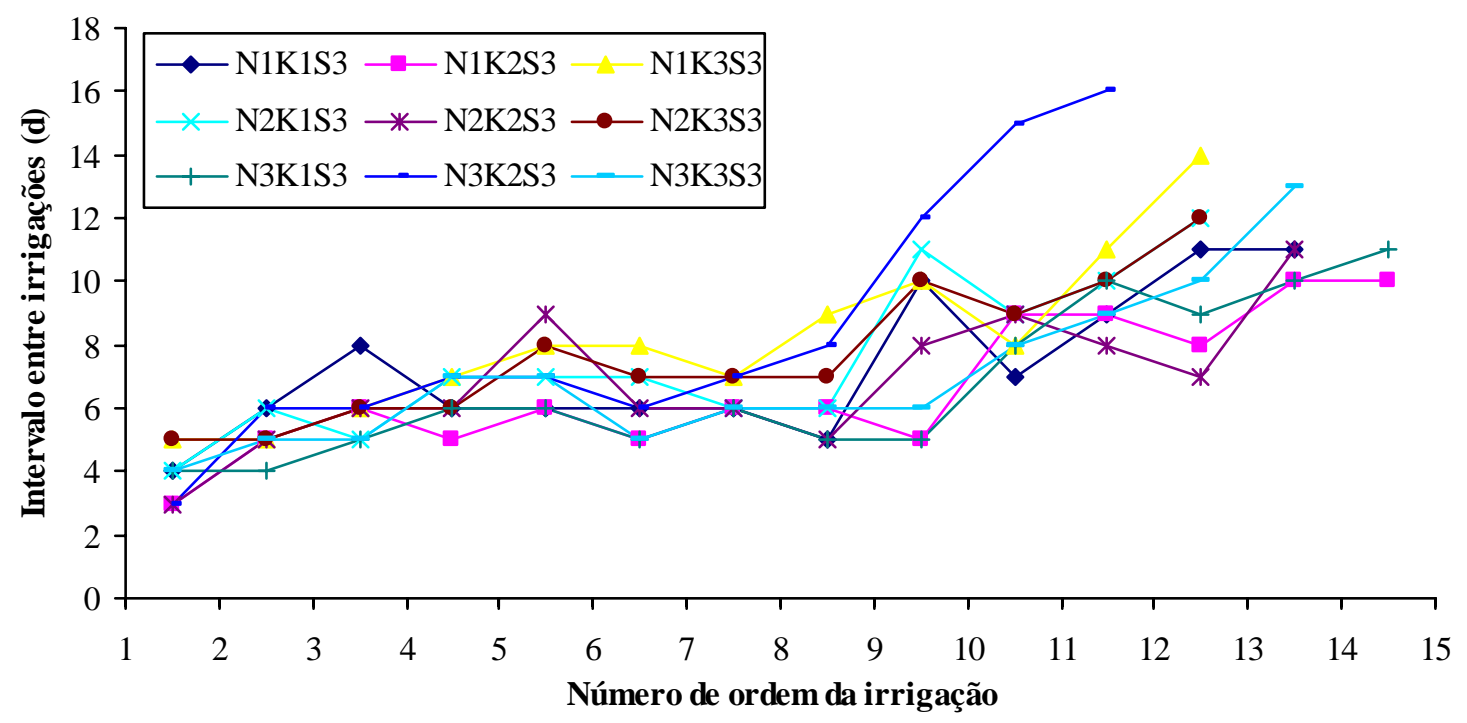

Figura 10 - Intervalo entre as irrigações ao longo do período de cultivo do tomateiro

\subsection{Calibração dos medidores de íons específicos}

\subsubsection{Solução do solo}

Observou-se alta correlação entre as concentrações de $\mathrm{NO}_{3}$, $\mathrm{K}$ e $\mathrm{Na}$ na solução do solo medidas com os MIE e pelos métodos-padrões (Figura 11). A concentração de $\mathrm{NO}_{3}$ medida com o MIE foi, em média, 39\% inferior àquela medida pelo método da destilação. Para as determinações de K e Na, os MIE superestimaram as concentrações em 21\% e 67\% em média, respectivamente.

Para todos os íons analisados obtiveram-se altos valores do coeficiente de

determinação $\left(\mathrm{r}^{2}\right)$, sendo as relações significativas a $1 \%$ de probabilidade, indicando que as estimativas apresentaram precisão satisfatória. Portanto, a utilização dos MIE para fins de manejo da fertirrigação é vantajosa, devido à rapidez na obtenção dos resultados, podendo-se realizar ajustes no esquema de fertirrigação tão logo sejam detectadas variações na concentração da solução do solo. 
(A)

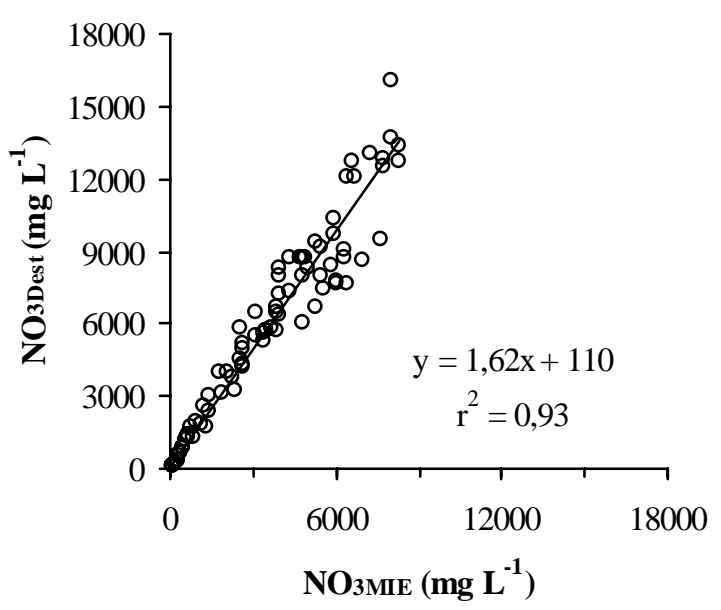

(B)

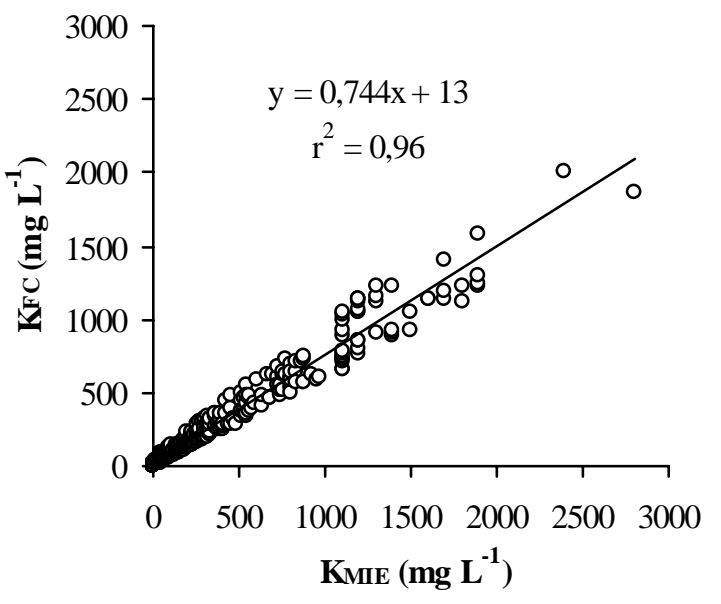

(C)

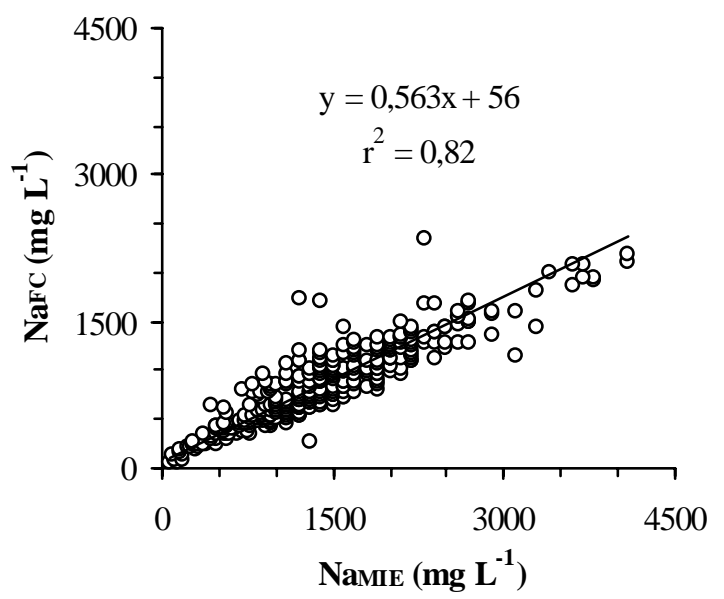

Figura 11 - Relação entre as concentrações de $\mathrm{NO}_{3}$ (A), $\mathrm{K}$ (B) e $\mathrm{Na}$ (C) determinadas pelos medidores de íons específicos (MIE) e pelos métodos-padrões (Dest=destilação, FC=fotometria de chama) na solução do solo

Atualmente o MIE para determinação de $\mathrm{NO}_{3}$ é comercializado ao valor de US\$ 339,00 e os MIE para K e Na a US\$ 329,00, enquanto que os sensores adicionais apresentam custo de US\$79,00 e cada sensor, segundo o fabricante, tem capacidade para realizar de 200 a 400 análises. Considerando-se os impostos e encargos para a importação do equipamento e supondo-se que sejam realizadas 2.000 análises com cada equipamento, o custo total das análises seria de US\$1.220,00 para $\mathrm{NO}_{3}$ e US\$1.205,00 para K e Na. Se as mesmas análises fossem realizadas em laboratórios especializados, 
considerando valor médio por amostra analisada de US\$ 4,00 para $\mathrm{NO}_{3}$ e US\$ 1,00 para $\mathrm{K}$ e Na, o custo total seria de US\$ 8.000,00 para $\mathrm{NO}_{3}$ e US\$2.000,00 para K e Na. Portanto, a utilização dos MIE para análise da solução do solo é viável tanto técnica quanto economicamente.

\subsubsection{Folhas das plantas de tomate}

As concentrações de $\mathrm{NO}_{3}$, $\mathrm{K}$ e $\mathrm{Na}$ na seiva do pecíolo $\left(\mathrm{NO}_{3 \text { seiva, }} \mathrm{K}_{\text {seiva }} \mathrm{e}\right.$ $\mathrm{Na}_{\text {seiva }}$, respectivamente) apresentaram boa correlação com os teores de $\mathrm{N}$, K e $\mathrm{Na}$, respectivamente, medidos na matéria seca das folhas $\left(\mathrm{N}_{\mathrm{MS}}, \mathrm{K}_{\mathrm{MS}}\right.$ e $\mathrm{Na}_{\mathrm{MS}}$, respectivamente), sendo a relação significativa para todos os nutrientes analisados (Figura 12).

As correlações obtidas entre os nutrientes na seiva do pecíolo e na matéria seca das folhas são próximas àquelas observadas por outros autores. Ronchi et al. (2001) obtiveram $\mathrm{r}^{2}$ igual a 0,65 quando compararam a concentração de $\mathrm{N}-\mathrm{NO}_{3 \text { seiva }}$ com $\mathrm{N}_{\mathrm{MS}}$. Locascio et al. (1997) obtiveram $r^{2}$ variando de zero a 0,80 dependendo da época de coleta da folha e do local de cultivo, enquanto que Guimarães et al. (1998) verificaram variação de 0,37 a 0,97 dependendo da folha amostrada e do tipo de solo. Não foram encontradas na literatura comparações entre $K_{\text {seiva }}$ e $\mathrm{Na}_{\text {seiva }}$ com $K_{M S}$ e $\mathrm{Na}_{M S}$, respectivamente.

Com relação à viabilidade econômica, utilizando-se o mesmo raciocínio do item anterior, a um custo total de US\$ 6,00 por amostra, as análises laboratoriais para $\mathrm{NO}_{3}$, K e Na teriam custo de US\$12.000,00, contra US\$2.425,00 se as mesmas análises fossem realizadas com os MIE. Neste caso, os MIE poderiam proporcionar redução de 80\% nos custos, o que os torna altamente viáveis para manejo da fertirrigação na produção comercial. 
(A)

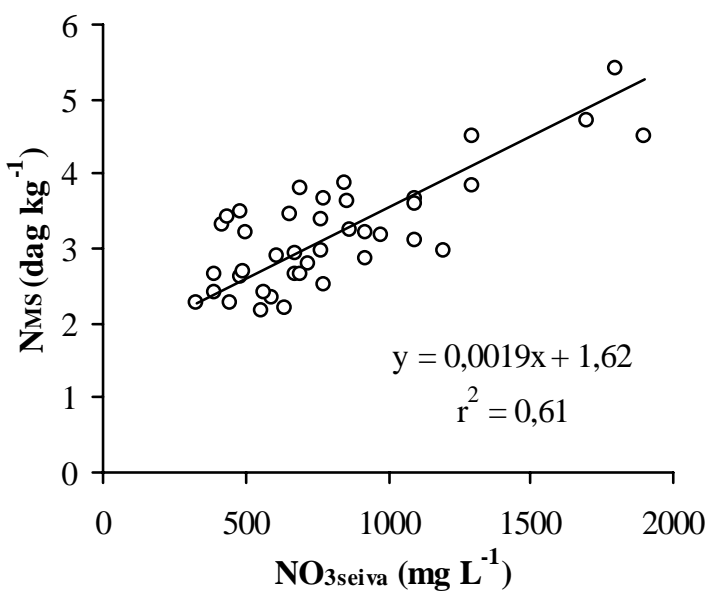

(B)

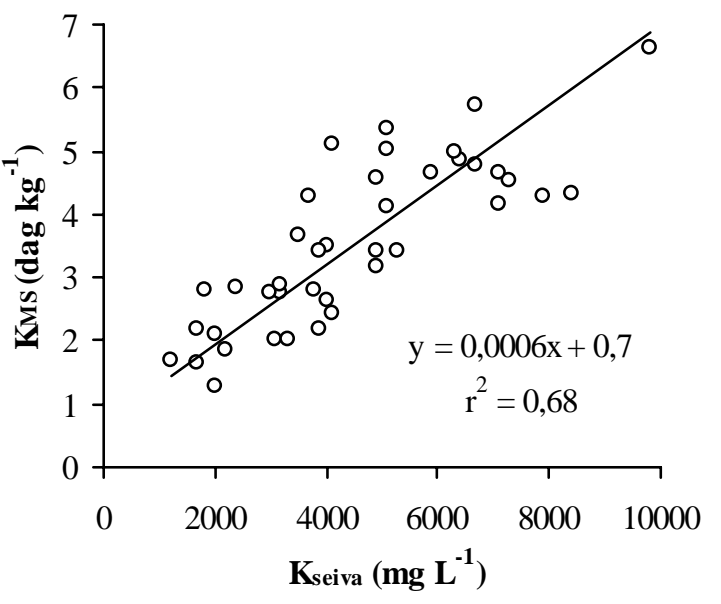

(C)

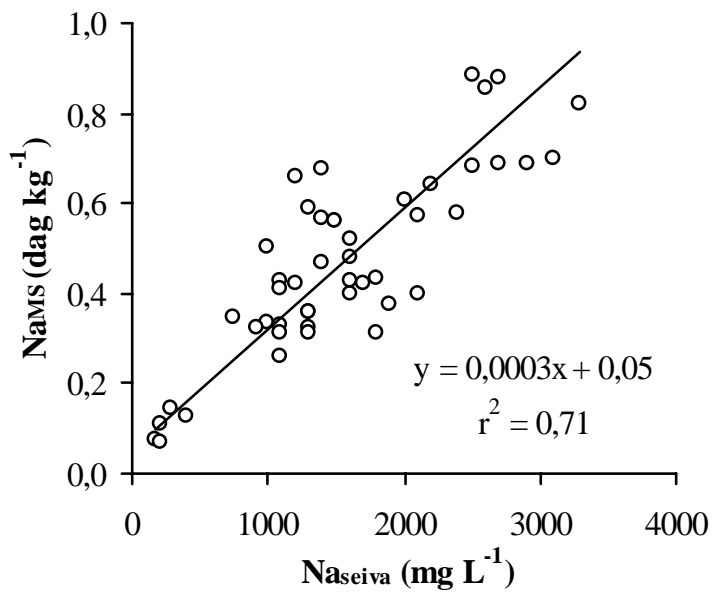

Figura 12 - Relação entre as concentrações de nitrato, $\mathrm{NO}_{3 \text { seiva }}(\mathrm{A})$, potássio, $\mathrm{K}_{\text {seiva }}$ (B) e sódio, $\mathrm{Na}_{\text {seiva }}(\mathrm{C})$, determinadas pelos medidores de íons específicos na seiva do pecíolo e os teores de N, K e Na na matéria seca, MS, das folhas de tomateiro, híbrido Facundo 


\subsection{Variáveis relacionadas ao solo}

\subsubsection{Características químicas da solução do solo}

\subsubsection{Condutividade elétrica e pH}

A condutividade elétrica da solução do solo $\left(\mathrm{CE}_{\mathrm{s}}\right)$ apresentou aumento ao longo do período de cultivo para todos os níveis de $\mathrm{N}$ e K (Figuras 13A e 13B). Em média, a $\mathrm{CE}_{\mathrm{s}}$ aumentou de 9,8 dS m $\mathrm{m}^{-1}$ aos $36 \mathrm{DAT}$ para 14,7 dS m $\mathrm{m}^{-1}$ aos $122 \mathrm{DAT}$, correspondendo a um aumento de $50 \%$, sendo a $\mathrm{CE}_{\mathrm{s}}$ final $55 \%$ superior à $\mathrm{CE}_{\mathrm{a}}$ média.

$\mathrm{O}$ pH da solução $\left(\mathrm{pH}_{\mathrm{s}}\right)$ apresentou um ligeiro aumento entre a primeira e a segunda amostragem, reduzindo após este período (Figura 13C e 13D), o que pode ser devido à nitrificação do amônio. No processo de nitrificação, para cada molécula de $\mathrm{NH}_{4}$ que é convertida em $\mathrm{NO}_{3}$ ocorre a liberação de dois átomos de hidrogênio na solução do solo. Sob condições de alta temperatura e umidade do solo há uma aceleração do processo de nitrificação e, conseqüentemente, uma redução gradativa do $\mathrm{pH}$ do solo, a qual é acelerada com a aplicação contínua de fertilizantes amoniacais (Tisdale et al., 1993).

Moraes (1991), extraindo a solução do solo com extratores de cápsula porosa, verificou que houve rápido decréscimo do $\mathrm{pH}_{\mathrm{s}}$ entre a primeira e a quinta semana de cultivo de arroz e guandu-anão, o que foi atribuído à produção de ácidos orgânicos provenientes da decomposição da matéria orgânica e à lixiviação de bases trocáveis pela água da chuva. 
(A)

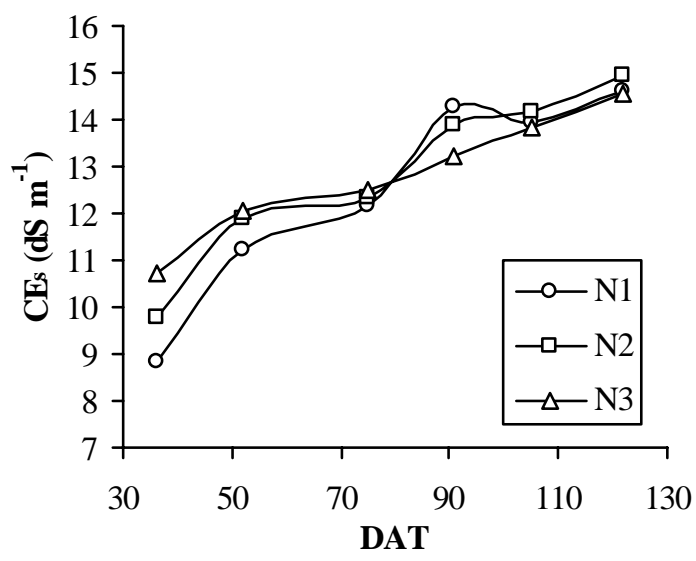

(C)

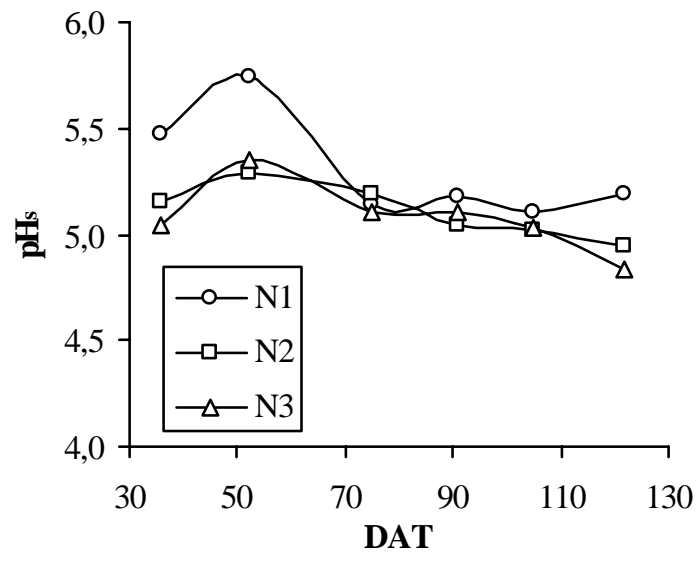

(B)

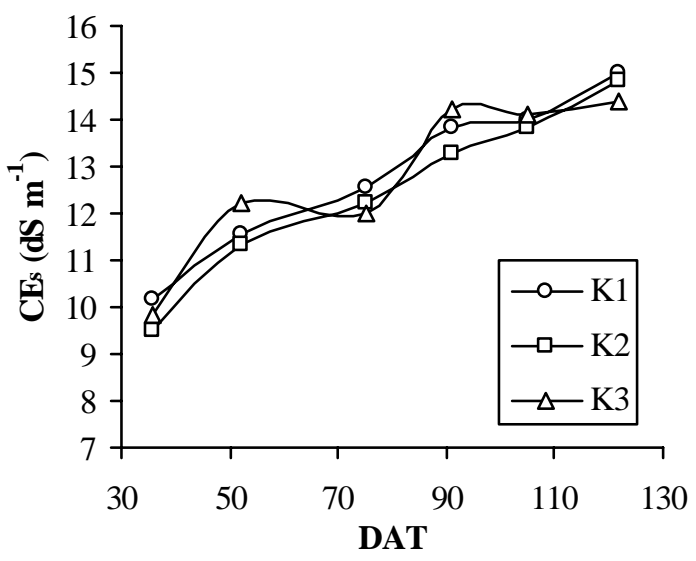

(D)

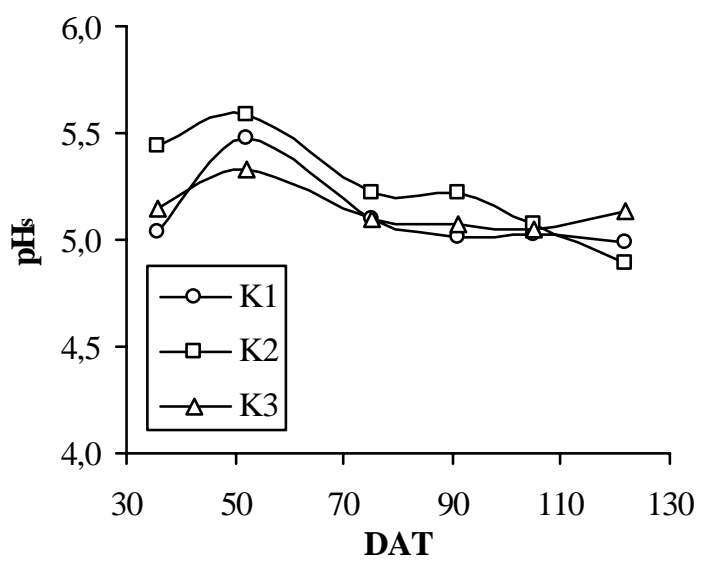

Figura 13 - Variação da condutividade elétrica, $\mathrm{CE}_{\mathrm{s}}$ (A e B), e do pH, $\mathrm{pH}_{\mathrm{s}}$ (C e D), da solução do solo ao longo do período de cultivo do tomateiro, para cada nível de N e K aplicado via fertirrigação. DAT = dias após o transplantio

A análise multivariada indicou efeito significativo das doses de $\mathrm{N}$ e da interação NxK sobre a $\mathrm{CE}_{\mathrm{s}}$ ao longo do tempo, não havendo efeito dos fatores experimentais sobre o $\mathrm{pH}_{\mathrm{s}}$ (Tabela 2). 
Tabela 2. Resumo da análise multivariada para condutividade elétrica $\left(\mathrm{CE}_{\mathrm{s}}\right)$ e $\mathrm{pH}\left(\mathrm{pH}_{\mathrm{s}}\right)$ da solução do solo, em função do tempo (T) e dos níveis de $\mathrm{N}$ e K aplicados via fertirrigação

\begin{tabular}{|c|c|c|c|c|c|c|}
\hline \multirow{4}{*}{$\begin{array}{l}\text { Causa da } \\
\text { variação }\end{array}$} & \multicolumn{3}{|c|}{$\mathrm{CE}_{\mathrm{s}}$} & \multicolumn{3}{|c|}{$\mathrm{pH}_{\mathrm{s}}$} \\
\hline & \multicolumn{6}{|c|}{ Estatística } \\
\hline & Wilks & Pillai & $\begin{array}{l}\text { Hotelling- } \\
\text { Lawley }\end{array}$ & Wilks & Pillai & $\begin{array}{l}\text { Hotelling- } \\
\text { Lawley }\end{array}$ \\
\hline & \multicolumn{6}{|c|}{$\mathrm{F}$} \\
\hline $\mathrm{T}$ & $129,76 * *$ & $129,76 * *$ & $129,76 * *$ & $4,93^{*}$ & $4,93 *$ & $4,93^{*}$ \\
\hline $\mathrm{T} \times \mathrm{N}$ & $2,78^{*}$ & 2,18 & $3,30 *$ & 0,85 & 0,91 & 0,77 \\
\hline $\mathrm{T} \times \mathrm{K}$ & 1,06 & 1,03 & 1,04 & 1,21 & 1,37 & 1,04 \\
\hline $\mathrm{T} \times \mathrm{N} \times \mathrm{K}$ & $2,41^{*}$ & $2,45^{*}$ & 2,01 & 0,78 & 0,90 & 0,63 \\
\hline
\end{tabular}

A $\mathrm{CE}_{\mathrm{s}}$ apresentou relação linear com as diferentes doses de $\mathrm{N}$ apenas para a primeira amostragem realizada, aos 36 DAT, não havendo efeito para as amostragens seguintes pela análise univariada (Tabela 3). Já a interação NxK exerceu efeito sobre a $\mathrm{CE}_{\mathrm{s}}$ apenas nas duas últimas amostragens realizadas, aos 105 e 122 DAT.

Tabela 3. Resumo da análise de variância para condutividade elétrica da solução do solo para cada amostragem realizada ao longo do período de cultivo, em função dos níveis de $\mathrm{N}$ e da interação $\mathrm{NxK}$

\begin{tabular}{lcccccc}
\hline \multicolumn{1}{c}{ Causa da variação } & 1 & 2 & 3 & 4 & 5 & 6 \\
& & \multicolumn{7}{c}{ Amostragem } \\
\hline Nitrogênio (N) & $10,07 * *$ & 1,47 & 0,23 & 1,49 & 0,30 & 0,47 \\
Linear & $20,29 * *$ & - & - & - & - & - \\
Quad. & 0,05 & - & - & - & - & - \\
Interação N x K & 0,54 & 0,50 & 0,49 & 1,71 & $3,47 *$ & $4,57 * *$ \\
$* * * *$ Significativo a 0,05 e 0,01 de probabilidade pelo teste F, respectivamente.
\end{tabular}

O desdobramento da interação NxK para as duas últimas coletas indicou que os níveis de $\mathrm{N}$ promoveram aumento linear da $\mathrm{CE}_{\mathrm{s}}$ dentro do nível K3 de potássio e 
redução dentro de $\mathrm{K} 2$, enquanto que os níveis de $\mathrm{K}$ resultaram na redução da $\mathrm{CE}_{\mathrm{s}}$ dentro de N1 (Tabela 4).

Tabela 4. Resumo da análise de variância para condutividade elétrica da solução do solo para a quinta e sexta amostragens realizadas ao longo do período de cultivo, em função dos níveis de $\mathrm{N}$ dentro dos níveis de $\mathrm{K}$ e dos níveis de $\mathrm{K}$ dentro dos níveis de $\mathrm{N}$

\begin{tabular}{|c|c|c|c|c|c|c|}
\hline \multirow[t]{3}{*}{$\begin{array}{l}\text { Causa da } \\
\text { variação }\end{array}$} & \multicolumn{3}{|c|}{ Amostragem 5} & \multicolumn{3}{|c|}{ Amostragem 6} \\
\hline & \multicolumn{6}{|c|}{ Nível de Potássio } \\
\hline & K1 & K2 & K3 & K1 & K2 & K3 \\
\hline & \multicolumn{6}{|c|}{$\mathrm{F}$} \\
\hline Nitrogênio (N) & 0,64 & 4,28 & $5,87 *$ & 0,07 & $35,71^{* *}$ & $14,72^{* *}$ \\
\hline Linear & - & - & $10,05^{*}$ & - & $71,33^{* *}$ & $23,16^{* *}$ \\
\hline \multirow[t]{2}{*}{ Quadr. } & - & - & 1,69 & - & 0,08 & $6,27 *$ \\
\hline & \multicolumn{6}{|c|}{ Médias (dS m ${ }^{-1}$ ) } \\
\hline N1 & - & - & 12,4 & - & 15,5 & 13,0 \\
\hline $\mathrm{N} 2$ & - & - & 14,6 & - & 15,0 & 15,2 \\
\hline \multirow[t]{4}{*}{ N3 } & - & - & 15,0 & - & 13,2 & 15,3 \\
\hline & \multicolumn{6}{|c|}{ Nível de N } \\
\hline & N1 & $\mathrm{N} 2$ & N3 & N1 & $\mathrm{N} 2$ & N3 \\
\hline & \multicolumn{6}{|c|}{$\mathrm{F}$} \\
\hline Potássio (K) & $5,27^{*}$ & 1,91 & 1,35 & $6,60^{*}$ & 0,9 & 1,67 \\
\hline Linear & $6,58^{*}$ & - & - & $8,43^{*}$ & - & - \\
\hline \multirow[t]{2}{*}{ Quadr. } & 4,97 & - & - & 4,77 & - & - \\
\hline & \multicolumn{6}{|c|}{ Médias (dS m $\left.{ }^{-1}\right)$} \\
\hline K1 & 14,3 & - & - & 15,5 & - & - \\
\hline K2 & 14,5 & - & - & 15,5 & - & - \\
\hline K3 & 12,4 & - & - & 13,0 & - & - \\
\hline
\end{tabular}

\subsubsection{Concentração iônica}

A concentração de nitrato $\left(\mathrm{NO}_{3 \mathrm{~s}}\right)$ e potássio $\left(\mathrm{K}_{\mathrm{s}}\right)$ na solução do solo tiveram rápido aumento após o início da aplicação dos tratamentos e apresentaram certa 
estabilização para as três últimas coletas realizadas (Figura 14). Como era esperado, as concentrações de $\mathrm{NO}_{3 \mathrm{~s}}$ e $\mathrm{K}_{\mathrm{s}}$ foram proporcionais às doses de $\mathrm{N}$ e $\mathrm{K}$ aplicadas na fertirrigação, embora para $\mathrm{K}_{\mathrm{s}}$ as diferenças só foram evidenciadas a partir da quarta coleta da solução.

(A)

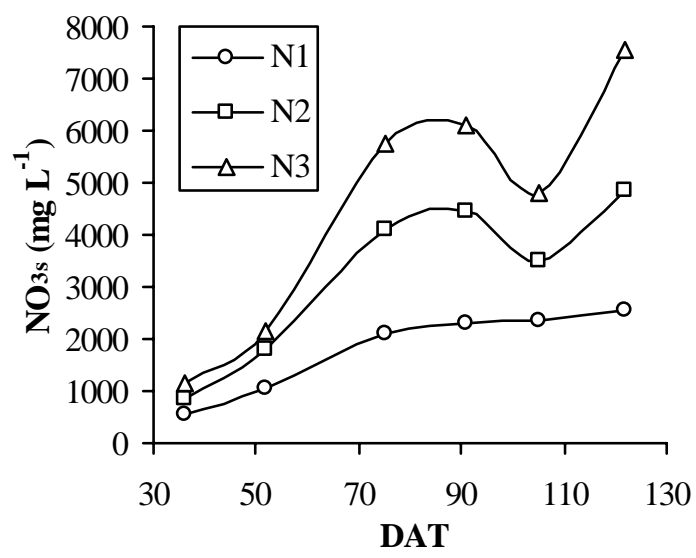

(C)

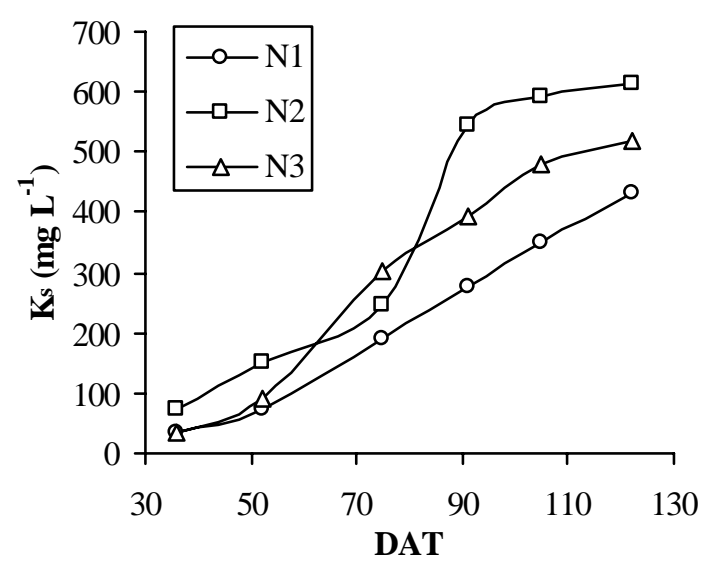

(B)

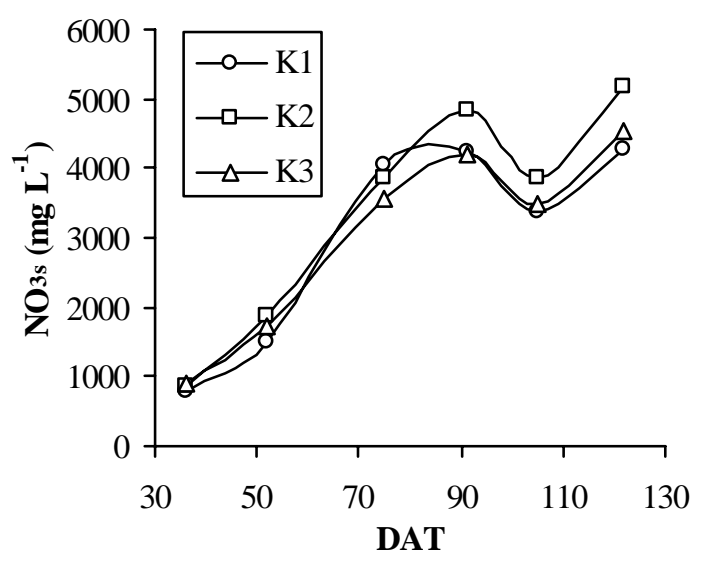

(D)

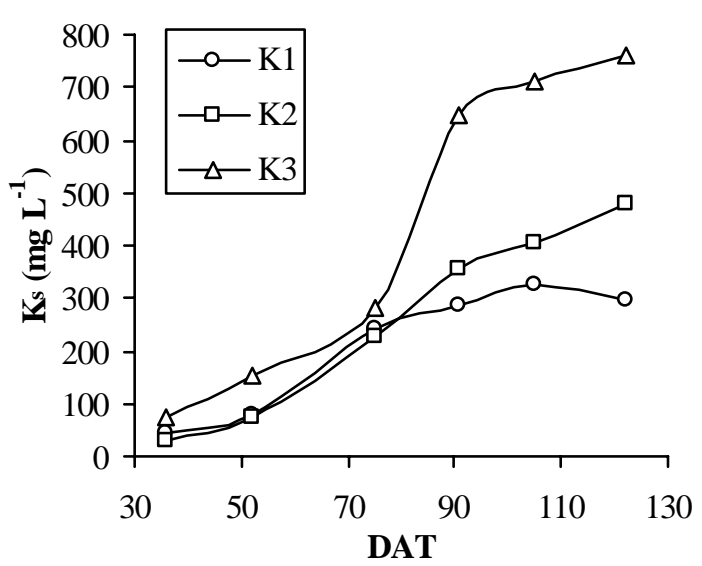

Figura 14 - Variação da concentração de nitrato, $\mathrm{NO}_{3 \mathrm{~s}}$ (A e B), e potássio, $\mathrm{K}_{\mathrm{s}}$ (C e D), na solução do solo ao longo do período de cultivo do tomateiro, para cada nível de N e K aplicado via fertirrigação. DAT = dias após o transplantio 
A concentração ótima de $\mathrm{K}$ na solução do solo é entre 10 e $60 \mathrm{mg} \mathrm{L}^{-1}$, dependendo da cultura, estrutura e fertilidade do solo e suprimento hídrico (Tisdale et al., 1993). As concentrações observadas estiveram sempre dentro ou acima deste limite, podendo-se afirmar que a concentração de $\mathrm{K}_{\mathrm{s}}$ foi suficiente durante todo o período de cultivo, mesmo para as plantas que receberam o nível K1.

A concentração de sódio na solução $\left(\mathrm{Na}_{\mathrm{s}}\right)$ também aumentou ao longo do período experimental (Figura 15). Observa-se relação inversa entre $\mathrm{Na}_{\mathrm{s}}$ e os níveis de N; uma vez que a $\mathrm{CE}_{\mathrm{a}}$ era mantida em torno de $9,5 \mathrm{dS} \mathrm{m}^{-1}$ para todas as irrigações, então um aumento na quantidade de $\mathrm{N}$ era compensado pela redução na quantidade de $\mathrm{NaCl}$ aplicada, resultando em menor $\mathrm{Na}_{\mathrm{s}}$. O mesmo efeito não foi observado para os diferentes níveis de $\mathrm{K}$.

(A)

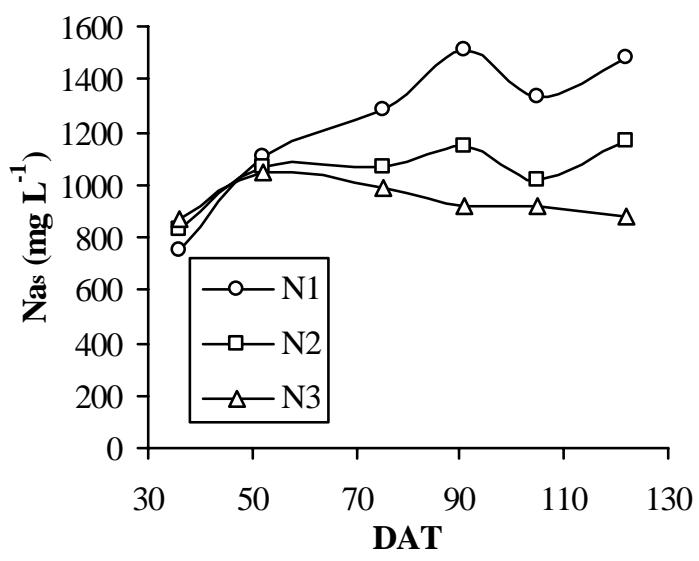

(B)

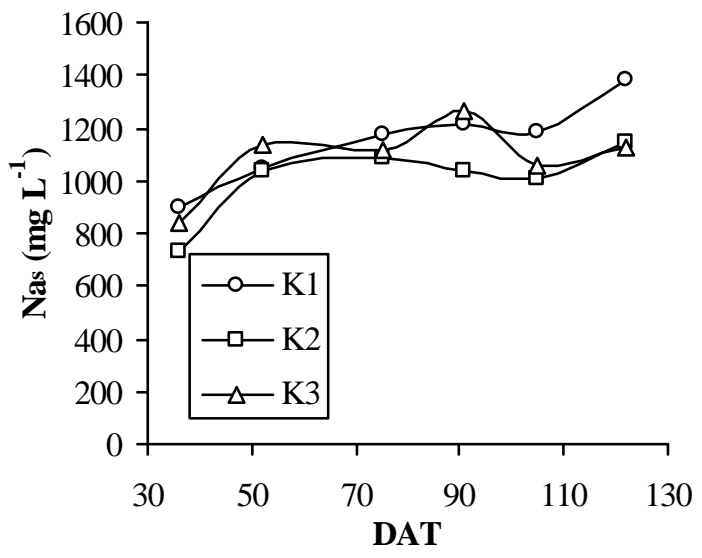

Figura 15 - Variação da concentração de sódio na solução do solo, $\mathrm{Na}_{\mathrm{s}}$, ao longo do período de cultivo do tomateiro, para cada nível de $\mathrm{N}$ (A) e K (B) aplicado via fertirrigação. DAT = dias após o transplantio

A análise multivariada revelou que as concentrações de $\mathrm{NO}_{3 \mathrm{~s}}$ e $\mathrm{K}_{\mathrm{s}}$ foram afetadas apenas pelos níveis de $\mathrm{N}$ e $\mathrm{K}$, respectivamente, enquanto que tanto os níveis de $\mathrm{N}$ quanto a interação $\mathrm{NxK}$ tiveram efeito sobre $\mathrm{Na}_{\mathrm{s}}$ ao longo do período experimental (Tabela 5). 
Tabela 5. Resumo da análise multivariada para concentração de nitrato $\left(\mathrm{NO}_{3 \mathrm{~s}}\right)$, potássio $\left(\mathrm{K}_{\mathrm{s}}\right)$ e sódio $\left(\mathrm{Na}_{\mathrm{s}}\right)$ na solução do solo, em função do tempo $(\mathrm{T})$ e dos níveis de N e K aplicados via fertirrigação

\begin{tabular}{|c|c|c|c|c|c|c|c|c|c|}
\hline \multirow{3}{*}{$\begin{array}{l}\text { Causa da } \\
\text { variação }\end{array}$} & \multicolumn{3}{|c|}{$\mathrm{NO}_{3 \mathrm{~s}}$} & \multicolumn{3}{|c|}{$\begin{array}{l}\mathrm{K}_{\mathrm{s}} \\
\text { Estatística }\end{array}$} & \multicolumn{3}{|c|}{$\mathrm{Na}_{\mathrm{s}}$} \\
\hline & Wilks & Pillai & $\begin{array}{l}\text { Hotelling- } \\
\text { Lawley }\end{array}$ & Wilks & Pillai & $\begin{array}{l}\text { Hotelling- } \\
\text { Lawley }\end{array}$ & Wilks & Pillai & $\begin{array}{l}\text { Hotelling- } \\
\text { Lawley }\end{array}$ \\
\hline & \multicolumn{9}{|c|}{$\mathrm{F}$} \\
\hline $\mathrm{T}$ & $36,64 * *$ & $36,64^{* *}$ & $36,64^{* *}$ & $70,18^{* *}$ & $70,18^{* *}$ & $70,18^{* *}$ & $12,57^{* *}$ & $12,57 * *$ & $12,57 * *$ \\
\hline $\mathrm{T} \times \mathrm{N}$ & $3,47^{*}$ & 2,19 & $4,85^{*}$ & 1,49 & 1,54 & 1,44 & $6,31^{* *}$ & $5,20 * *$ & $7,49 * *$ \\
\hline $\mathrm{T} \times \mathrm{K}$ & 1,27 & 1,32 & 1,17 & $2,19 *$ & $2,11^{*}$ & $2,26^{*}$ & 2,16 & 2,38 & 1,87 \\
\hline $\mathrm{T} \times \mathrm{N} \times \mathrm{K}$ & 1,72 & 1,51 & 1,69 & 1,60 & 1,55 & 1,59 & $3,53^{* *}$ & $2,64 * *$ & $4,43^{* *}$ \\
\hline
\end{tabular}

*** Significativo a 0,05 e 0,01 de probabilidade pelo teste $\mathrm{F}$, respectivamente.

A concentração de $\mathrm{NO}_{3 \text { s }}$ foi afetada linearmente pelo nível de $\mathrm{N}$ para todas as coletas da solução do solo realizadas ao longo do período de cultivo (Tabela 6), enquanto que $\mathrm{K}_{\mathrm{s}}$ foi afetado pelos níveis de $\mathrm{K}$ apenas nas três últimas amostragens (Tabela 7).

Tabela 6. Resumo da análise de variância para concentração de nitrato na solução do solo, para cada amostragem realizada ao longo do período de cultivo, em função dos níveis de $\mathrm{N}$ aplicados via fertirrigação

\begin{tabular}{lcccccc}
\hline \multirow{2}{*}{$\begin{array}{c}\text { Causa da } \\
\text { variação }\end{array}$} & 1 & 2 & 3 & 4 & 5 & 6 \\
& & \multicolumn{5}{c}{$\mathrm{F}$} \\
\hline Nitrogênio & $17,45^{* *}$ & $10,40^{* *}$ & $21,97^{* *}$ & $17,35^{* *}$ & $16,25^{* *}$ & $17,42^{* *}$ \\
Linear & $34,70^{* *}$ & $18,56^{* *}$ & $43,95^{* *}$ & $33,92^{* *}$ & $32,00^{* *}$ & $39,67^{* *}$ \\
Quad. & 0,00 & 0,90 & 0,08 & 0,21 & 0,03 & 0,06 \\
\hline
\end{tabular}

** Significativo a 0,01 de probabilidade pelo teste $\mathrm{F}$.

Tanto $\mathrm{NO}_{3 \mathrm{~s}}$ quanto $\mathrm{K}_{\mathrm{s}}$ aumentaram em função dos níveis de $\mathrm{N}$ e $\mathrm{K}$, respectivamente (Figura 16). As equações de ajuste para cada variável e o respectivo coeficiente de determinação são apresentados na Tabela 8. 
Tabela 7. Resumo da análise de variância para concentração de potássio na solução do solo, para cada amostragem realizada ao longo do período de cultivo, em função dos níveis de K aplicados via fertirrigação

\begin{tabular}{lcccccc}
\hline $\begin{array}{l}\text { Causa da } \\
\text { variação }\end{array}$ & 1 & 2 & 3 & 4 & 5 & 6 \\
& & & \multicolumn{5}{c}{ Amostragem } \\
\hline Potássio & 2,73 & 1,42 & 2,87 & $7,23^{* *}$ & $5,57^{*}$ & $5,20^{*}$ \\
Linear & - & - & - & $12,50^{* *}$ & $9,55^{* *}$ & $8,91^{* *}$ \\
Quad. & - & - & - & 1,87 & 2,76 & 0,96 \\
\hline
\end{tabular}

*, ** Significativo a 0,05 e 0,01 de probabilidade pelo teste $\mathrm{F}$, respectivamente.

(A)

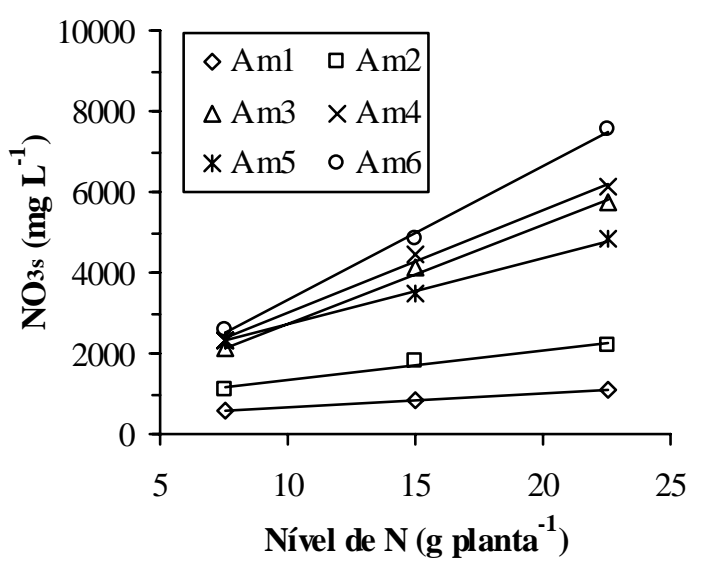

(B)

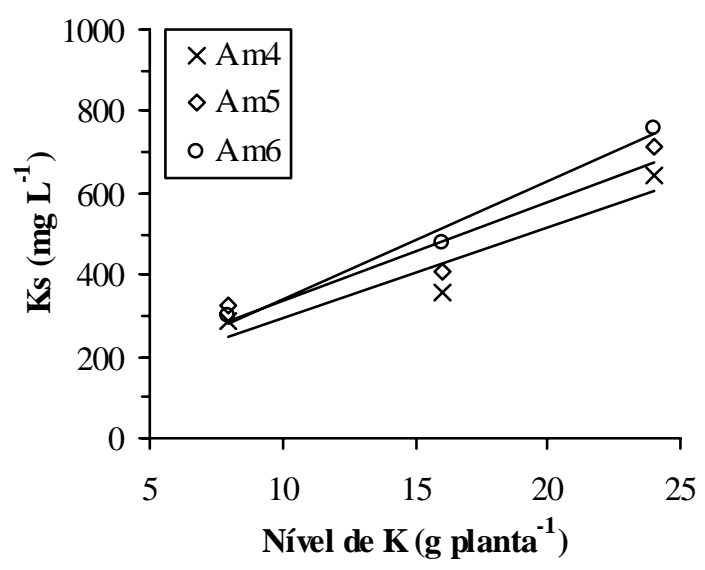

Figura 16 - Relação entre as concentrações de nitrato, $\mathrm{NO}_{3 s}$, e potássio, $\mathrm{K}_{\mathrm{s}}$, na solução do solo e os níveis de $\mathrm{N}$ (A) e K (B) aplicados via fertirrigação, respectivamente, para cada amostragem realizada durante o período de cultivo 
Tabela 8. Equações de regressão linear e coeficientes de determinação $\left(r^{2}\right)$ para concentração de nitrato e potássio na solução do solo, em função dos níveis de $\mathrm{N}$ e K, respectivamente, aplicados via fertirrigação

\begin{tabular}{lcccc}
\hline \multirow{2}{*}{ Amostragem } & \multicolumn{2}{c}{ Nitrato } \\
Equação
\end{tabular}

$\mathrm{N}, \mathrm{K}$ - Doses de $\mathrm{N}$ e $\mathrm{K}_{2} \mathrm{O}$, respectivamente, aplicadas via fertirrigação (g planta ${ }^{-1}$ )

Um dos processos que ocorrem com o K no solo é a sua fixação entre as lâminas de argila (Kardos, 1964; Sparks \& Huang, 1985; Tisdale et al., 1993). Resultados apresentados por Instituto Internacional de la Potasa (1977) revelaram que para um solo contendo $30 \mathrm{~kg} \mathrm{~m}^{-3}$ de argila, as concentrações de $\mathrm{K}_{\mathrm{s}}$ foram 14, 39, 90 e $123 \mathrm{mg} \mathrm{L}^{-1}$ quando os teores correspondentes de K na CTC do solo foram de 2,5, 4,2, 7,2 e 10,9 $\mathrm{mmol}_{\mathrm{c}} \mathrm{dm}^{-3}$, respectivamente. Para um solo contendo $250 \mathrm{~kg} \mathrm{~m}^{-3}$ de argila, os valores de $\mathrm{K}_{\mathrm{s}}$ foram de 8, 17, 30, 50 e $122 \mathrm{mg} \mathrm{L}^{-1}$ quando os seus teores no solo foram de 2,5, 7,4, 15,4, 24,9 e 29,5 $\mathrm{mmol}_{\mathrm{c}} \mathrm{dm}^{-3}$, respectivamente. Portanto, o maior conteúdo de argila no solo exigiu grande quantidade de K na CTC para a obtenção de uma mesma concentração na solução e, além disso, para o solo mais argiloso um grande aumento de $\mathrm{K}_{\mathrm{s}}$ foi observado quando o teor de $\mathrm{K}$ no solo foi superior a $24,9 \mathrm{mmol}_{\mathrm{c}} \mathrm{dm}^{-3}$, nível a partir do qual o solo já se encontrava “saturado" com K, de modo que não ocorria fixação e que um número suficiente de posições do complexo de troca já estava ocupado pelo K.

Portanto, a fixação de K pelas argilas e sua retenção na CTC do solo podem ter contribuído para a ausência de diferenças significativas para concentração de $\mathrm{K}_{\mathrm{s}}$ nas três primeiras amostragens. 
Visto que o $\mathrm{NH}_{4}$ pode ser fixado entre as plaquetas de argila de maneira similar ao $\mathrm{K}$, na presença de $\mathrm{NH}_{4}$ pode ocorrer o bloqueio do $\mathrm{K}$ fixado o qual não é liberado para a solução do solo. Em geral, a quantidade de K necessária para aumentar o teor de $\mathrm{K}$ trocável no solo em $1 \mathrm{mmol}_{\mathrm{c}} \mathrm{dm}^{-3}$ pode variar de 44 a $1967 \mathrm{~kg} \mathrm{ha}^{-1}$, dependendo do tipo de solo, sendo esta diferença devido, em parte, à variação do potencial de fixação de K entre os solos (Tisdale et al., 1993).

Adams et al. (1978), cultivando tomateiro em turfa, verificaram que os efeitos do $\mathrm{K}_{\mathrm{s}}$ e do $\mathrm{NO}_{3 \mathrm{~s}}$ na $\mathrm{CE}_{\mathrm{s}}$ foram semelhantes; por outro lado, no cultivo em solo, o efeito do $\mathrm{NO}_{3 \mathrm{~s}}$ sobre a $\mathrm{CE}_{\mathrm{s}}$ foi mais de duas vezes superior ao do $\mathrm{K}_{\mathrm{s}}$. Tal fato foi atribuído à retenção de $\mathrm{K}$ no complexo de troca do solo, sendo que uma apreciável proporção do K trocável não foi imediatamente solubilizada na solução do solo.

A concentração de $\mathrm{Na}_{\mathrm{s}}$ foi afetada pelos níveis de $\mathrm{N}$ e pela interação $\mathrm{NxK}$ apenas nas três últimas amostragens (Tabela 9). O desdobramento da interação revelou que o $\mathrm{N}$ exerceu efeito significativo apenas dentro dos níveis K1 e K2 (Tabela 10), havendo redução de $\mathrm{Na}_{\mathrm{s}}$ com o aumento da dose de $\mathrm{N}$ aplicada (Figura 17).

Tabela 9. Resumo da análise de variância para concentração de sódio na solução do solo, para cada amostragem realizada ao longo do período de cultivo, em função dos níveis de $\mathrm{N}$ aplicados via fertirrigação e da interação NxK

\begin{tabular}{|c|c|c|c|c|c|c|}
\hline \multirow{3}{*}{$\begin{array}{l}\text { Causa da } \\
\text { variação }\end{array}$} & \multicolumn{6}{|c|}{ Amostragem } \\
\hline & 1 & 2 & 3 & 4 & 5 & 6 \\
\hline & \multicolumn{6}{|c|}{$\mathrm{F}$} \\
\hline \multicolumn{7}{|l|}{ Fator: } \\
\hline Nitrogênio (N) & 2,66 & 0,54 & 2,80 & $8,54 * *$ & $11,49 * *$ & $13,92 * *$ \\
\hline Linear & - & - & - & $18,30 * *$ & $22,09 * *$ & $26,31^{* *}$ \\
\hline Quad. & - & - & - & 0,32 & 2,56 & 0,29 \\
\hline \multicolumn{7}{|l|}{ Interação: } \\
\hline $\mathrm{N} \times \mathrm{K}$ & 1,22 & 1,00 & 0,45 & $3,51^{*}$ & $3,45^{*}$ & $4,05^{* *}$ \\
\hline
\end{tabular}

*, ** Significativo a 0,05 e 0,01 de probabilidade pelo teste $\mathrm{F}$, respectivamente. 
Tabela 10. Resumo da análise de variância para concentração de sódio na solução do solo, em função dos níveis de $\mathrm{N}$ dentro dos níveis de $\mathrm{K}$, para a quarta, quinta e sexta amostragens

\begin{tabular}{|c|c|c|c|c|c|c|c|c|c|}
\hline \multirow{4}{*}{$\begin{array}{l}\text { Causa da } \\
\text { variação }\end{array}$} & \multirow{2}{*}{\multicolumn{3}{|c|}{ Amostragem 4}} & \multirow{2}{*}{\multicolumn{3}{|c|}{$\begin{array}{l}\text { Amostragem } 5 \\
\text { Nível de Potássio }\end{array}$}} & \multicolumn{3}{|c|}{ Amostragem 6} \\
\hline & & & & & & & & & \\
\hline & K1 & $\mathrm{K} 2$ & K3 & K1 & K2 & K3 & K1 & $\mathrm{K} 2$ & K3 \\
\hline & \multicolumn{9}{|c|}{$\mathrm{F}$} \\
\hline Nitrogênio & $10,37 * *$ & $6,67^{*}$ & 0,58 & $10,88 * *$ & $13,30 * *$ & 0,49 & $7,81^{*}$ & $35,37 * *$ & 0,06 \\
\hline Linear & $16,24^{* *}$ & $8,76^{*}$ & - & $21,46 * *$ & $18,78 * *$ & - & $15,39 * *$ & $69,18 * *$ & - \\
\hline Quadr. & 4,50 & 4,59 & - & 0,31 & $7,81^{*}$ & - & 0,23 & 1,56 & - \\
\hline
\end{tabular}

*, ** Significativo a 0,05 e 0,01 de probabilidade pelo teste $\mathrm{F}$, respectivamente.

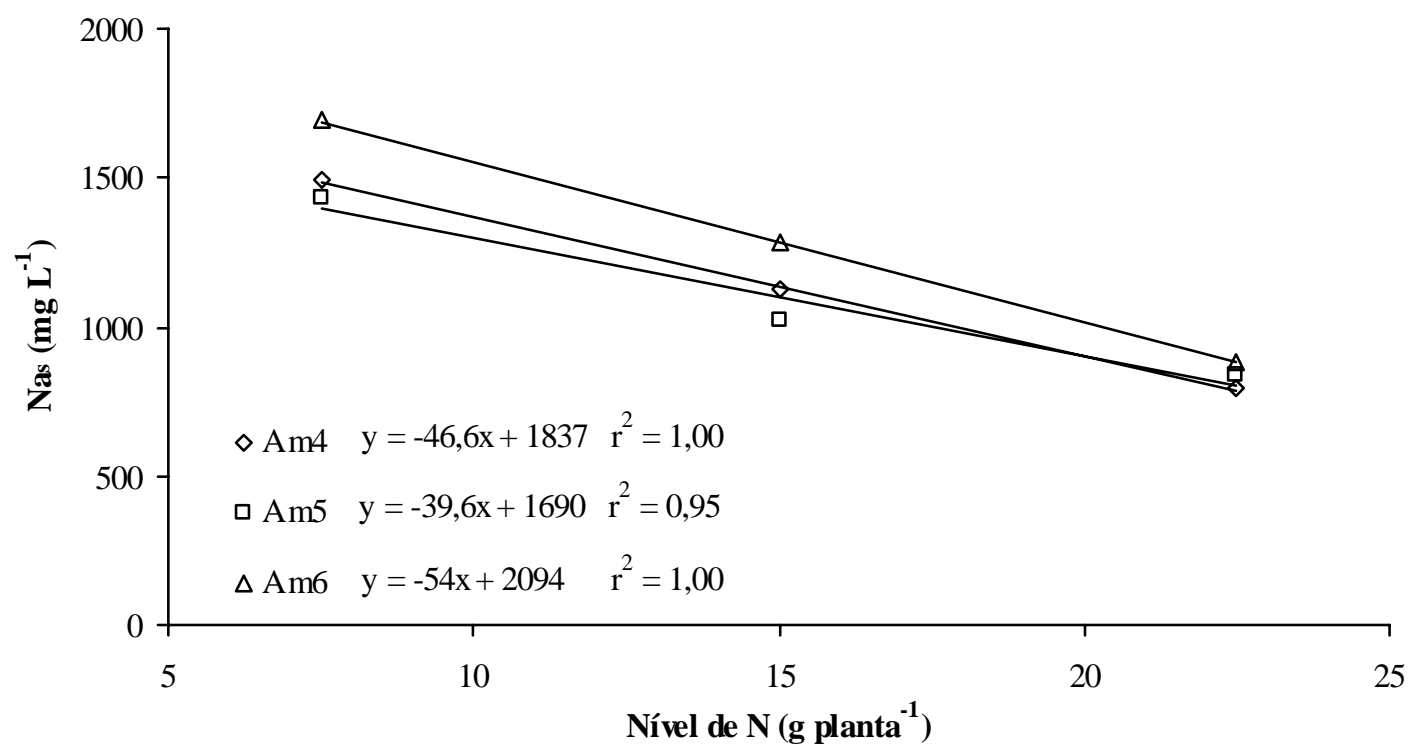

Figura 17 - Concentração média de sódio na solução do solo $\left(\mathrm{Na}_{\mathrm{s}}\right)$ dentro dos níveis $\mathrm{K} 1$ e K2 de potássio, na quarta, quinta e sexta amostragens (Am4, Am5 e Am6, respectivamente), em função do nível de $\mathrm{N}$ aplicado via fertirrigação 


\subsubsection{Relação entre a condutividade elétrica e a concentração iônica medidas na solução do solo, no extrato de saturação e na solução 1:2}

A correlação entre a $\mathrm{CE}_{\mathrm{s}}$ e a condutividade elétrica no extrato de saturação ( $\left(\mathrm{E}_{\mathrm{es}}\right)$ não apresentou resultado satisfatório (Figura 18A), havendo grande dispersão entre os valores medidos. Pode-se notar que, a partir de determinado valor, a $\mathrm{CE}_{\mathrm{s}}$ permanece praticamente constante com o aumento da $\mathrm{CE}_{\mathrm{es}}$, o que pode estar relacionado à maior proporção de sais precipitados na solução do solo em relação ao extrato de saturação (van den Ende et al., 1975), uma vez que a quantidade de água presente no solo no momento da extração da solução $(U \cong 0,17)$ era sempre inferior àquela na pasta de solo saturado ( $\mathrm{U} \cong 0,27)$. Além disso, a precipitação de sais é dependente das condições de lixiviação empregadas, sendo que sob frações de lixiviação inferiores a 0,1 a precipitação é freqüentemente significativa (Rhoades, 1974; van Schilfgaarde et al., 1974).

(A)

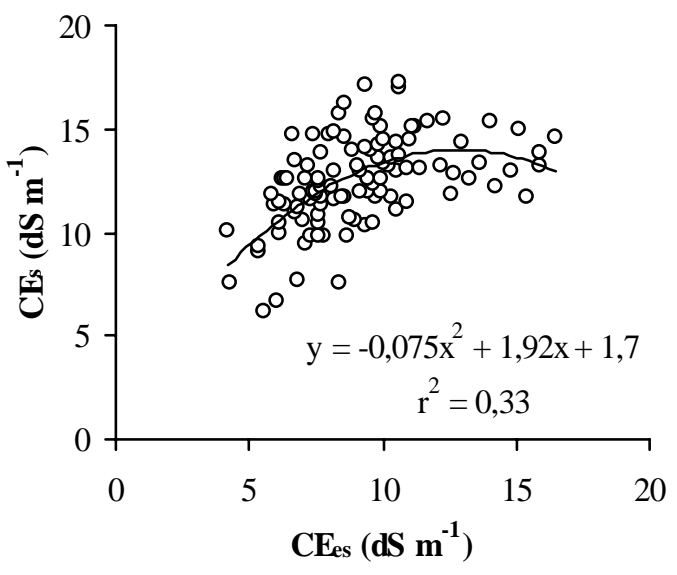

(B)

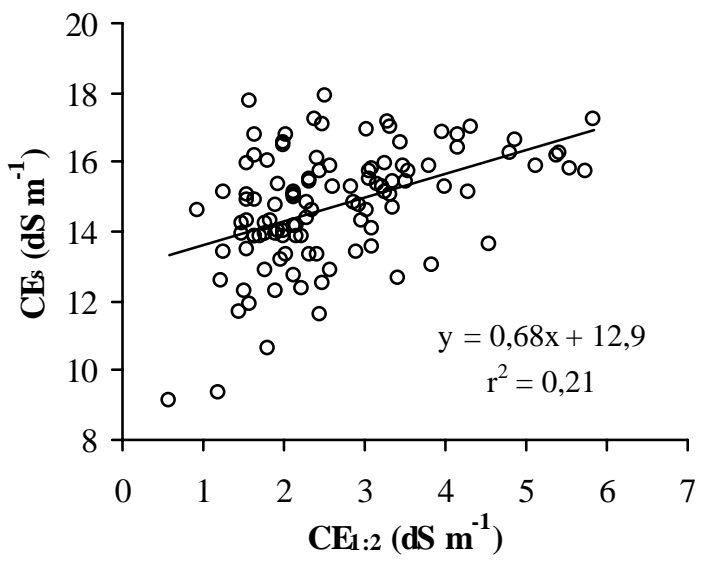

Figura 18 - Relação entre a condutividade elétrica medida no extrato de saturação, $\mathrm{CE}_{\mathrm{es}}$ (A), e na solução 1:2, $\mathrm{CE}_{1: 2}(\mathrm{~B})$, com a condutividade elétrica medida da solução do solo, $\mathrm{CE}_{\mathrm{s}}$ 
A relação entre a condutividade elétrica medida na solução 1:2 $\left(\mathrm{CE}_{1: 2}\right)$ e a $\mathrm{CE}_{\mathrm{s}}$ também não foi satisfatória, a qual apresentou grande dispersão quando ajustada por uma função linear (Figura 18B).

As relações entre as concentrações de nitrato, potássio, sódio e cálcio medidas na solução do solo e no extrato de saturação foram mais bem ajustadas por equações do tipo potencial e, de modo geral, apresentaram alta dispersão (Figura 19).

(A)

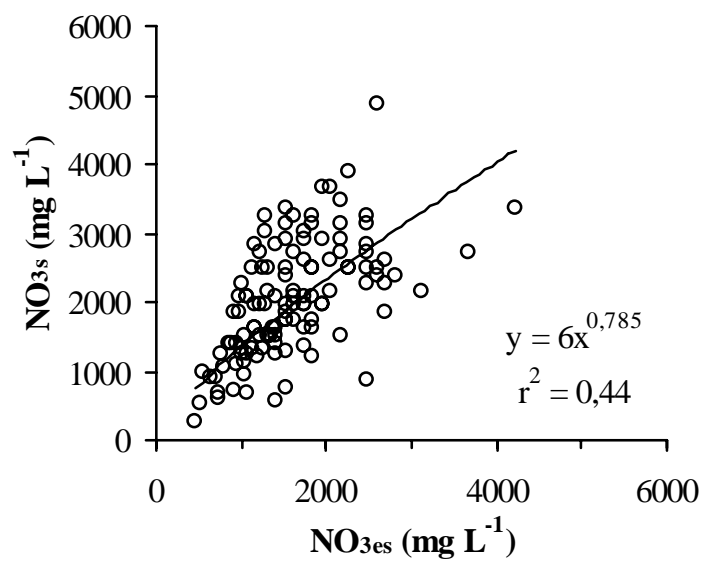

(C)

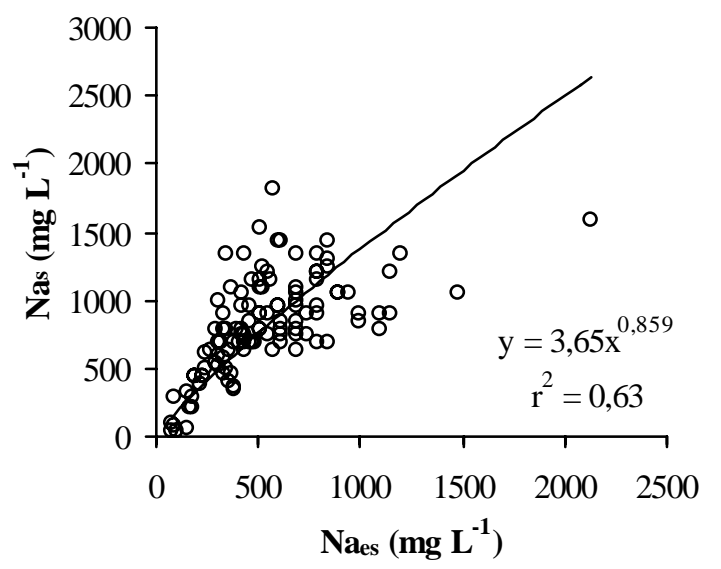

(B)

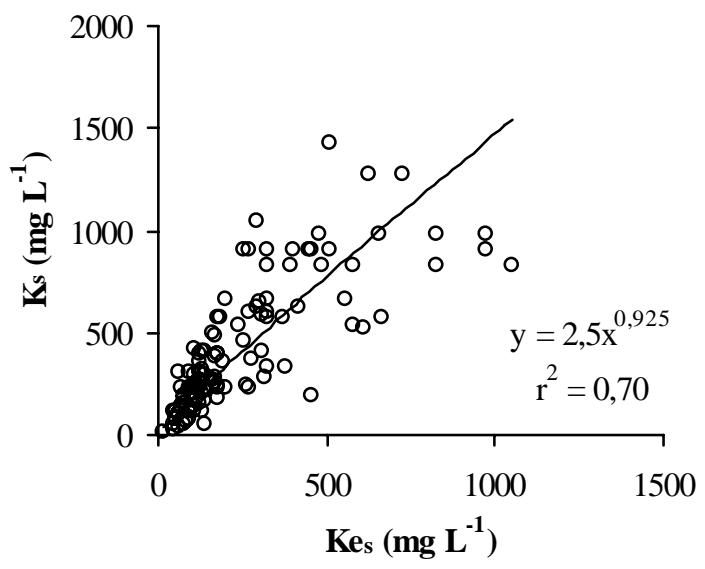

(D)

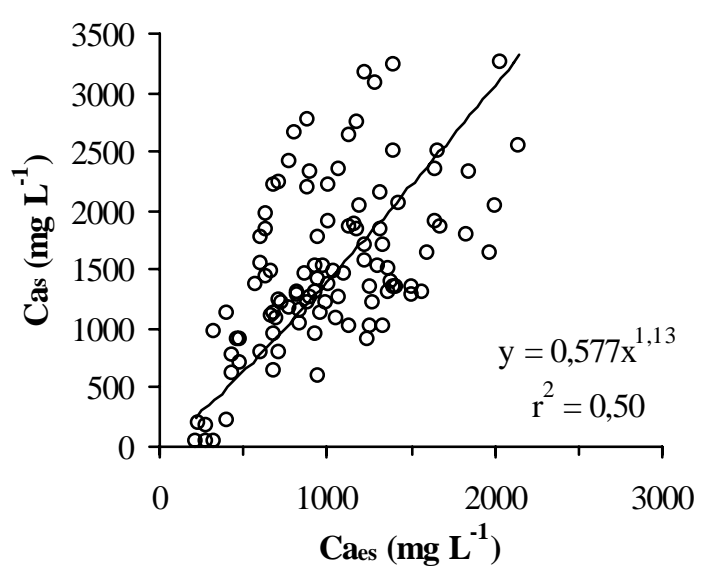

Figura 19 - Relação entre as concentrações de nitrato, $\mathrm{NO}_{3 \mathrm{~s}}(\mathrm{~A})$, potássio, $\mathrm{K}_{\mathrm{s}}(\mathrm{B})$, sódio, $\mathrm{Na}_{\mathrm{s}}(\mathrm{C})$ e cálcio, $\mathrm{Ca}_{\mathrm{s}}(\mathrm{D})$, medidas na solução do solo, com as concentrações medidas no extrato de saturação $\left(\mathrm{NO}_{3 \mathrm{es}}, \mathrm{K}_{\mathrm{es}}, \mathrm{Na}_{\mathrm{es}}\right.$ e $\mathrm{Ca}_{\mathrm{es}}$, respectivamente) 
Considerando que a umidade do solo no momento da extração da solução do solo foi, em media, $17 \%$, a umidade da pasta de saturação de $27 \%$ e a umidade do solo na solução 1:2 de 200\%, então era de se esperar que a concentração iônica da solução do solo fosse $59 \%$ superior àquela observada no extrato de saturação e a $\mathrm{CE}_{1: 2}$ em torno de $8 \%$ da $\mathrm{CE}_{\mathrm{s}}$. Os valores de $\mathrm{CE}, \mathrm{NO}_{3}, \mathrm{~K}$, $\mathrm{Na}$ e Ca medidos na solução do solo superaram os valores medidos no extrato de saturação, em média, em 36\%, 27\%, 71\%, $53 \%$ e $49 \%$, respectivamente, e a $\mathrm{CE}_{1: 2}$ correspondeu a $22 \%$ da $\mathrm{CE}_{\mathrm{es}}$, o que sugere de antemão que as diferenças obtidas não são apenas devido às diferentes umidades em que as amostras foram obtidas.

De fato, os valores de CE na solução do solo estimados a partir dos valores no extrato de saturação e na solução 1:2 não resultaram em bom ajuste com os valores observados (Figura 20). Tanto a $\mathrm{CE}_{\mathrm{s} \text {-estEs }}$ quanto a $\mathrm{CE}_{\mathrm{s} \text {-est1:2 }}$ apresentaram baixa correlação com os valores medidos e baixos valores do índice de concordância de Willmott, d, indicando que tanto a precisão quanto a exatidão das estimativas foram insatisfatórias. A pior estimativa foi quando se utilizaram os valores medidos na solução $1: 2$, uma vez que os valores estimados na solução do solo variaram de 6 a $54 \mathrm{dS} \mathrm{m} \mathrm{m}^{-1}$, enquanto os valores medidos foram na faixa de 9 a $18 \mathrm{dS} \mathrm{m} \mathrm{m}^{-1}$. Pela análise de regressão não foram observadas tendências definidas entre as variáveis confrontadas, sendo as regressões não-significativas a 5\% de probabilidade. 
(A)

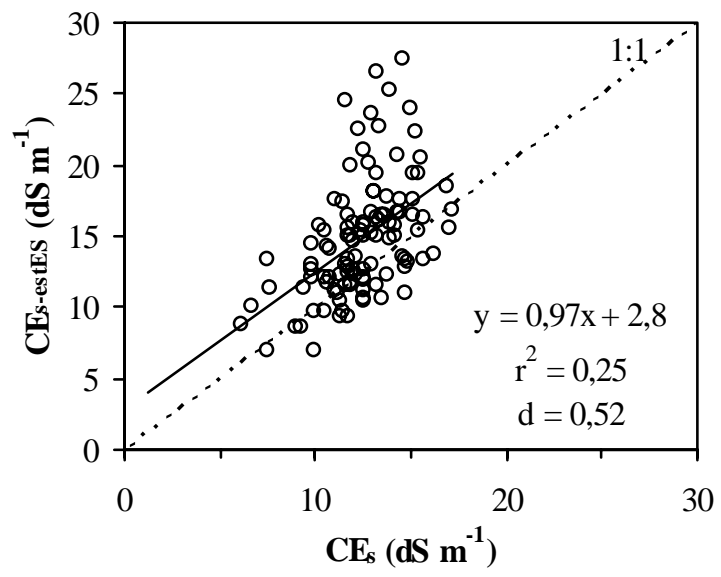

(B)

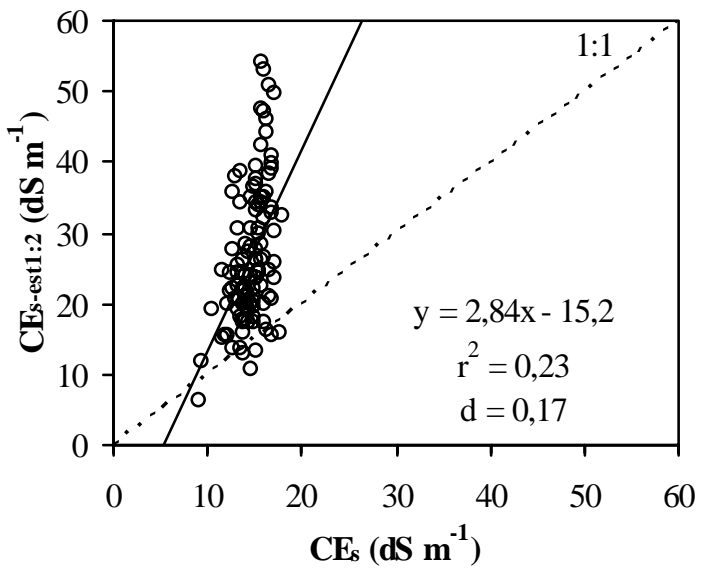

Figura 20 - Relação entre os valores de condutividade elétrica medida, $\mathrm{CE}_{\mathrm{s}}$, e estimada na solução do solo a partir dos valores medidos: (A) no extrato de saturação $\left(\mathrm{CE}_{\mathrm{s} \text {-estES }}\right)$ e (B) na solução 1:2 (CEs-est1:2)

As estimativas das concentrações dos íons na solução do solo a partir dos valores medidos no extrato de saturação apresentaram resultados distintos de acordo com o íon considerado (Figura 21). A regressão linear foi significativa para todas as variáveis avaliadas, indicando tendência de aumento do valor estimado com o aumento do valor medido na solução do solo. A estimativa para potássio foi a que apresentou melhor resultado, com $\mathrm{r}^{2}=0,61$ e $\mathrm{d}=0,88$, embora tenha apresentado grande variação para valores medidos acima de $500 \mathrm{mg} \mathrm{L}^{-1}$ (Figura 21B). A estimativa para Na também apresentou grande variação para valores acima de $700 \mathrm{mg} \mathrm{L}^{-1}$, sendo que para valores abaixo desta concentração os valores estimados foram próximos à reta 1:1 (Figura 21C). As estimativas para nitrato e cálcio (Figuras 21A e 21D, respectivamente) apresentaram baixos valores de $r^{2}$ e d, indicando a ocorrência de grande dispersão em torno da reta de regressão e da reta 1:1, podendo-se afirmar que estas variáveis não foram adequadamente estimadas pelo procedimento utilizado. 
(A)

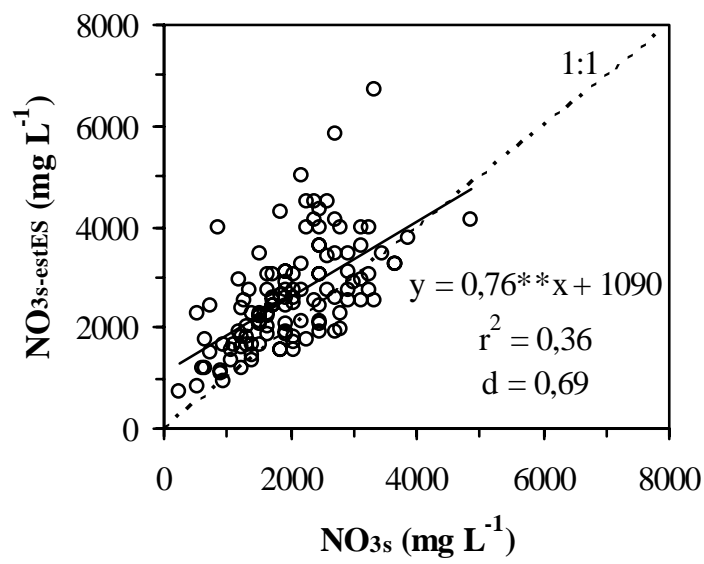

(C)

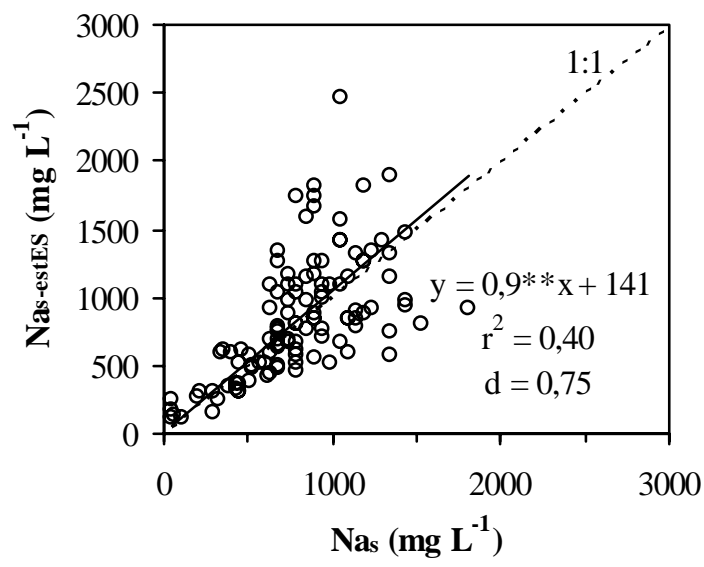

(B)

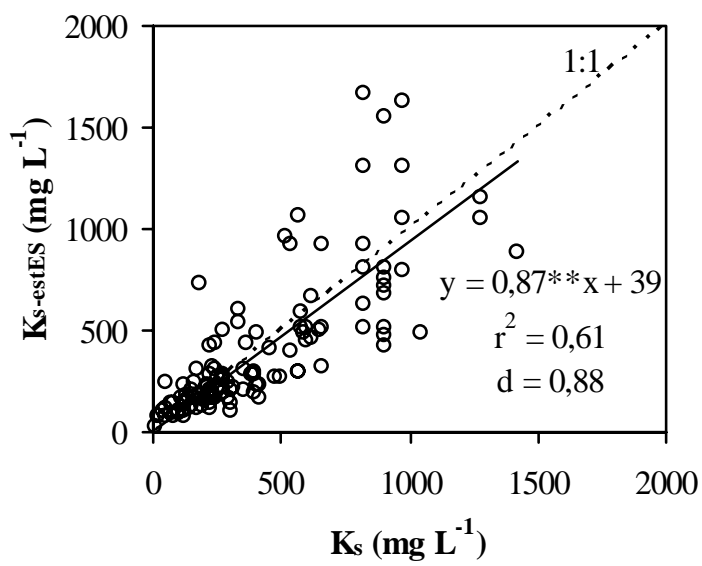

(D)

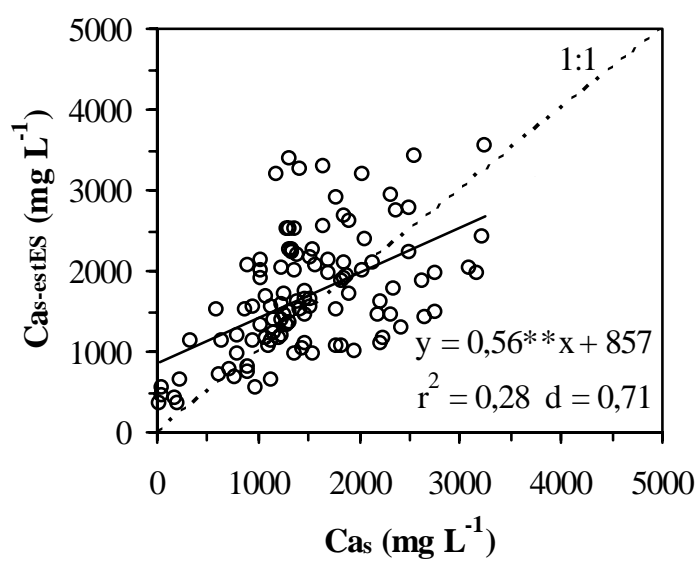

Figura 21 - Relação entre as concentrações de nitrato (A), potássio (B), sódio (C) e cálcio (D) medidas $\left(\mathrm{NO}_{3 s}, \mathrm{~K}_{\mathrm{s}}, \mathrm{Na}_{\mathrm{s}}\right.$ e $\mathrm{Ca}_{\mathrm{s}}$, respectivamente) e estimadas ( $\mathrm{NO}_{3 \text { s-estES}}, \mathrm{K}_{\text {s-estES}}, \mathrm{Na}_{\text {s-estES }}$ e $\mathrm{Ca}_{\text {s-estES }}$ respectivamente) na solução do solo, a partir das concentrações medidas no extrato de saturação

Rhoades et al. (1989) demonstraram que $\mathrm{CE}_{s} \theta_{\mathrm{s}}$ não é equivalente a $\mathrm{CE}_{\mathrm{es}} \theta_{\mathrm{es}}\left(\theta=\right.$ umidade do solo com base em volume, $\left.\mathrm{cm}^{3} \mathrm{~cm}^{-3}\right)$ pois estas medidas envolvem volumes diferentes de solo e afirmam que "este é um erro que ainda é freqüentemente cometido". Por outro lado, Silva (2002) obteve altas correlações lineares quando comparou os valores de $\mathrm{CE}$ e das concentrações de $\mathrm{NO}_{3}$, $\mathrm{K}$ e Ca estimados pela eq. (3) com os valores no extrato de saturação, porém utilizando os valores medidos na 
solução do solo para estimar aqueles medidos no extrato de saturação; entretanto, nesse trabalho, a irrigação foi realizada por gotejamento e, visto que a distribuição espacial de sais no solo sob irrigação por gotejamento é muito variável (Yaron et al., 1973; Bresler, 1975; Blanco \& Folegatti, 2002), as posições de instalação do extrator de solução e de coleta da amostra de solo em relação ao gotejador provavelmente contribuíram para as altas correlações obtidas, ao contrário do observado no presente estudo no qual a variação espacial da salinidade e da concentração iônica da solução do solo influiu negativamente nas relações obtidas.

Gillman \& Bell (1978) encontraram boas correlações entre a CE da solução do solo com a CE medida no extrato solo:água 1:1, 1:2,5, $1: 5$ e 1:10, sempre

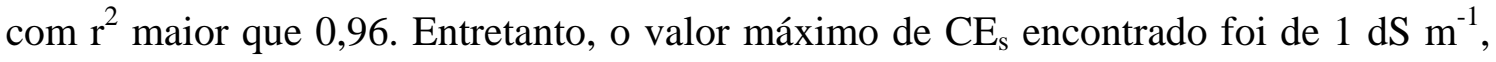
sendo que sob condições de baixa concentração eletrolítica os resultados são menos sujeitos a erros promovidos pela precipitação dos sais menos solúveis. Os dados apresentados no presente trabalho corroboram com a afirmação de Wolt (1994) de que “a condutividade elétrica medida em extratos solo:água não pode ser diretamente convertida para $\mathrm{CE}_{\mathrm{s}}$ na umidade do solo em condições de campo devido aos fenômenos de solubilização e diluição de sais”.

Segundo Willmott (1981) a análise individual dos gráficos de dispersão não é suficiente para se verificar o grau e tipo de influência que o erro exerce na habilidade do método em predizer uma dada variável. Esse autor sugere que os erros baseados no quadrado médio, assim como o índice de concordância d, deveriam ser calculados e apresentados, pois são adequados e necessários para a interpretação e validação das predições de um modelo. Quando um modelo apresenta o erro quadrado médio (EQM) composto na maior parte pelo erro aleatório (EQMa), então esse é tido como adequado, ou seja, o erro sistemático (EQMs) deve ser minimizado para que o modelo possa predizer uma variável com máxima acurácia.

Na Tabela 11 verifica-se que, com exceção da estimativa de $\mathrm{CE}_{\text {s-est1:2, }}$ todas as estimativas apresentaram a maior parte do EQM composta pelo erro aleatório, indicando que os erros não podem ser eliminados apenas pelo ajuste do modelo. Estes erros podem estar relacionados à metodologia utilizada, a qual sofre influência de 
diversos fatores como: (i) intensidade do vácuo aplicada aos extratores, com conseqüente variação na zona de influência da cápsula, (ii) precipitação e diluição de sais com a variação de umidade do solo, (iii) variabilidade espacial da solução do solo, e de outros fatores já expostos anteriormente.

Tabela 11. Valores do erro quadrado médio (EQM) e das razões entre o erro quadrado médio sistemático (EQMs) e o erro quadrado médio aleatório (EQMa) e EQM, para cada variável estimada a partir dos valores medidos no extrato de saturação (ES) e na solução 1:2 (1:2)

\begin{tabular}{lccc}
\hline \multicolumn{1}{c}{ Variável estimada } & EQM & EQMs/EQM & EQMa/EQM \\
\hline $\mathrm{CE}_{\text {s-estES }}$ & 19 & 0,31 & 0,69 \\
$\mathrm{CE}_{\text {s-est1:2 }}$ & 228 & 0,66 & 0,34 \\
$\mathrm{NO}_{3 \text { s-estES }}$ & 1069279 & 0,38 & 0,62 \\
$\mathrm{~K}_{\text {s-estES }}$ & 48244 & 0,04 & 0,96 \\
$\mathrm{Na}_{\text {s-estES }}$ & 159683 & 0,03 & 0,97 \\
$\mathrm{Ca}_{\text {s-estES }}$ & 519568 & 0,25 & 0,75 \\
\hline
\end{tabular}

A maior representatividade do erro sistemático para $\mathrm{CE}_{\text {s-est1:2 }}$ pode estar relacionada à metodologia envolvida nas análises da solução 1:2. Em comparação com as determinações realizadas a partir do extrato de saturação, na solução 1:2 uma quantidade preestabelecida de água é adicionada à amostra de solo, fazendo com que todas as análises sejam realizadas com o solo a uma umidade constante, diferentemente das análises pelo extrato de saturação onde o ponto de saturação é obtido para cada amostra individualmente. Isso poderia levar a um erro mais constante no cálculo da

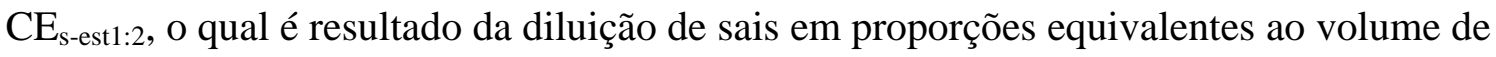
água adicionado à amostra.

Portanto, os resultados obtidos no presente trabalho demonstram que apenas a correção de umidade não é suficiente para se estimar a CE e as concentrações de $\mathrm{NO}_{3}$ e Ca na solução do solo a partir dos valores medidos no extrato de saturação, apresentando estimativas satisfatórias para $\mathrm{K}$ e Na até as concentrações de $500 \mathrm{mg} \mathrm{L}^{-1} \mathrm{e}$ $700 \mathrm{mg} \mathrm{L}^{-1}$, respectivamente. Estudos demonstrando os efeitos da precipitação de sais na 
solução do solo são necessários para a melhor compreensão dos fenômenos envolvidos, principalmente sob condições de fertirrigação, na qual a concentração iônica da solução do solo geralmente atinge níveis significativamente mais elevados do que em condições de adubação pelos métodos convencionais.

\subsection{Variáveis relacionadas à cultura do tomateiro}

\subsubsection{Concentração iônica na seiva do pecíolo}

As concentrações de $\mathrm{NO}_{3}$ e $\mathrm{K}$ na seiva do pecíolo das folhas não variaram proporcionalmente às doses de N e K aplicadas via fertirrigação (Tabela 12).

Tabela 12. Valores médios da concentração de nitrato, potássio e sódio na seiva do pecíolo do tomateiro $\left(\mathrm{NO}_{3 \text { seiva }}, \mathrm{K}_{\text {seiva }}\right.$ e $\mathrm{Na}_{\text {seiva }}$, respectivamente) por ocasião do florescimento do terceiro e quinto cachos, para cada nível de $\mathrm{N}$ e $\mathrm{K}$ aplicado via fertirrigação

\begin{tabular}{lcccccc}
\hline \multicolumn{1}{c}{$\begin{array}{c}\text { Causa da } \\
\text { variação }\end{array}$} & $\mathrm{NO}_{\text {3seiva }}$ & $\begin{array}{c}\text { Cacho 3 } \\
\mathrm{K}_{\text {seiva }}\end{array}$ & $\begin{array}{c}\mathrm{Na}_{\text {seiva }} \\
\mathrm{mg} \mathrm{L}^{-1}\end{array}$ & $\mathrm{NO}_{3 \text { seiva }}$ & $\mathrm{K}_{\text {seiva }}$ & $\mathrm{Na}_{\text {seiva }}$ \\
\hline Nitrogênio (N) & & & & & & \\
N1 & 1030 & 6822 & 623 & 1563 & 9633 & 1141 \\
N2 & 1011 & 6194 & 759 & 1704 & 9455 & 1407 \\
N3 & 1045 & 6892 & 631 & 1719 & 9869 & 1043 \\
Potássio (K) & & & & & & \\
K1 & 879 & 6512 & 695 & 1700 & 9933 & 1203 \\
K2 & 1299 & 6108 & 650 & 1715 & 9615 & 1212 \\
K3 & 917 & 7567 & 676 & 1558 & 9350 & 1141 \\
\hline
\end{tabular}

Não houve efeito dos tratamentos sobre as concentrações de $\mathrm{NO}_{3}, \mathrm{~K}$ e $\mathrm{Na}$ na seiva das plantas, com exceção da concentração de K por ocasião do florescimento do quinto cacho, a qual foi influenciada pelos níveis de K na água de irrigação (Tabela 13). Entretanto, a relação foi inversamente proporcional, ocorrendo redução na concentração 
de K na seiva do pecíolo com o aumento das doses de K aplicadas na fertirrigação, o que não era esperado.

Tabela 13. Resumo da análise de variância para concentração de nitrato, potássio e sódio na seiva do pecíolo do tomateiro $\left(\mathrm{NO}_{3 \text { seiva }}, \mathrm{K}_{\text {seiva }}\right.$ e $\mathrm{Na}_{\text {seiva }}$, respectivamente) por ocasião do florescimento do terceiro e quinto cachos, em função dos níveis de $\mathrm{N}$ e K aplicados via fertirrigação

\begin{tabular}{lcccccc}
\hline \multicolumn{1}{c}{$\begin{array}{c}\text { Causa da } \\
\text { variação }\end{array}$} & $\mathrm{NO}_{\text {3seiva }}$ & $\begin{array}{c}\text { Cacho 3 } \\
\mathrm{K}_{\text {seiva }}\end{array}$ & $\mathrm{Na}_{\text {seiva }}$ & $\mathrm{NO}_{\text {3seiva }}$ & $\begin{array}{c}\text { K } \\
\text { seiva }\end{array}$ & $\mathrm{Na}_{\text {seiva }}$ \\
\hline Nitrogênio & 0,02 & 0,02 & 0,20 & 0,06 & 2,03 & 0,47 \\
Potássio (K) & 0,98 & 1,23 & 0,05 & 0,35 & $5,37 *$ & 0,78 \\
Linear & - & - & - & - & $11,39 * *$ & - \\
Quadr. & - & - & - & - & 0,02 & - \\
Interação NxK & 0,87 & 0,58 & 0,85 & 1,38 & 0,62 & 1,21 \\
\hline *, ** Significativo a 0,05 e 0,01 de probabilidade pelo teste F, respectivamente.
\end{tabular}

As diferenças entre as concentrações de $K$ na seiva foram pequenas, sendo esta de apenas 6\% entre K1 e K3. A equação de ajuste é apresentada na Figura 22.

Hochmuth (1994) recomenda que, no período compreendido entre a emissão do segundo e quinto cachos, as concentrações de $\mathrm{NO}_{3}$ e $\mathrm{K}$ na seiva do pecíolo sejam mantidas entre 3500-4500 mg L ${ }^{-1}$ e 4000-5000 mg L ${ }^{-1}$, respectivamente. Portanto, as concentrações de $\mathrm{NO}_{3}$ e $\mathrm{K}$ na seiva foram, respectivamente, abaixo e acima dos níveis recomendados para o tomateiro em ambiente protegido. 


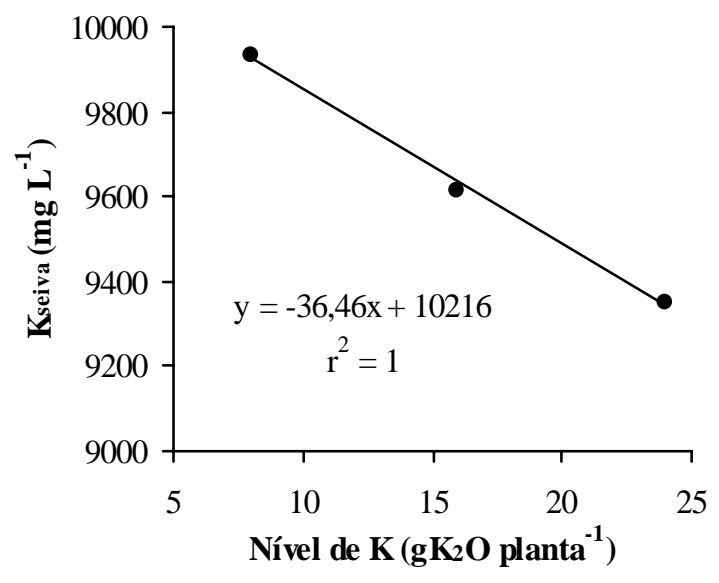

Figura 22 - Relação entre o teor de potássio medido na seiva do pecíolo do tomateiro ( $\mathrm{K}_{\text {seiva }}$ ) por ocasião do florescimento do quinto cacho e os níveis de $\mathrm{K}$ aplicados via fertirrigação

$\mathrm{O}$ estresse salino geralmente resulta na redução da quantidade de $\mathrm{N}$ absorvida pelo tomateiro, o que é mais facilmente verificado quando se analisa a concentração deste nutriente nas folhas mais novas (Rendig \& Broadbent, 1985; Pessarakli \& Tucker, 1988). Com relação ao K, trabalhos têm sugerido que seu teor na matéria seca da parte aérea da planta não é influenciado pela salinidade em cultivares de tomateiro que apresentam certa tolerância à salinidade, mesmo quando esta é promovida pelo $\mathrm{NaCl}$ (Alfocea et al., 1993; Alpaslan \& Gunes, 2001).

\subsubsection{Teor de nutrientes e de prolina nas folhas}

Os teores foliares dos nutrientes e de Na determinados (Tabela 14) foram similares àqueles obtidos por outros autores (Gargantini \& Blanco, 1963; Fernandes et al., 1975; Maher, 1976; Castro, 1976; Haag et al., 1978).

Dechen (1980) verificou que altas concentrações de Ca na solução nutritiva promoveram a redução dos teores de N, P, K, B, Zn e aumento nos teores de $\mathrm{Ca}, \mathrm{Mg}, \mathrm{S}$ e $\mathrm{Cu}$ nas folhas inferiores do tomateiro. Portanto, os baixos teores de boro 
obtidos podem ser devido à grande quantidade de Ca aplicada pelo cloreto de cálcio, utilizado para elevar a $\mathrm{CE}_{\mathrm{a}}$.

Tabela 14. Valores médios dos teores de macro e micronutrientes e teor de prolina nas folhas do tomateiro, para cada nível de $\mathrm{N}$ e K aplicado via fertirrigação

\begin{tabular}{lccccccc}
\hline \multicolumn{1}{c}{ Causa da } \\
variação
\end{tabular}

A relação inversa entre os teores de $\mathrm{N}$ e Ca nas folhas, embora nãosignificativa, provavelmente foi devida à aplicação de nitrogênio na forma amoniacal pelo nitrato de amônio, sendo que o $\mathrm{NH}_{4}$ apresenta relação antagônica com o Ca em termos de absorção pelo tomateiro (Barke \& Menary, 1971; Wilcox et al., 1973; Saxena 
et al., 1975; Pill et al., 1978; Dechen, 1980). Entretanto, em condições de clima quente, a aplicação de $\mathrm{N}$ na forma de amônio geralmente não acarreta efeitos adversos para o tomateiro devido à rápida transformação do amônio em nitrato e ao crescimento vigoroso das plantas (Adams, 1986). No presente estudo, a alta freqüência de aplicação de fertilizantes pela fertirrigação pode ter contribuído para manter a concentração de $\mathrm{NH}_{4}$ na solução do solo em níveis mais elevados do que pela adubação convencional, favorecendo a ocorrência de antagonismo entre $\mathrm{NH}_{4}$ e Ca.

Os teores de N, P, S e B foram afetados pelas doses de $\mathrm{N}$ aplicadas via fertirrigação, enquanto que as doses de K tiveram efeito apenas sobre os teores de K e de prolina nas folhas (Tabela 15).

Não foram observados efeitos nos teores de $\mathrm{Na}$ e $\mathrm{Cl}$ com o aumento das doses de $\mathrm{K}$ e $\mathrm{N}$, respectivamente, como era esperado. A concentração de nutrientes nas folhas do tomateiro pode variar bastante quando as plantas são submetidas à salinidade. Alian et al. (2000) cultivaram quatro cultivares de tomateiro em solução nutritiva contendo $\mathrm{NaCl}$ e verificaram grande aumento nos teores de $\mathrm{Na}$ e $\mathrm{Cl}$ nas folhas, não havendo diferenças para o teor de K. Em outro trabalho, a irrigação com água de até 9,5 dS m ${ }^{-1}$ obtida pela adição de $\mathrm{NaCl}$ aumentou os teores foliares de $\mathrm{Na}, \mathrm{Cl}$, Ca e $\mathrm{Mg}$, reduziu o teor de $\mathrm{K}$ e não teve efeito sobre os de $\mathrm{NO}_{3}$ e $\mathrm{N}$ total (Martinez et al., 1987).

$\mathrm{O}$ aumento na dose de $\mathrm{N}$ resultou no aumento linear dos teores de $\mathrm{N}$ e $\mathrm{B}$ (Figuras 23A e 23D), apresentando relação quadrática com os teores de P e S (Figuras 23B e 23C). 
Tabela 15. Resumo da análise de variância para teores de macro e micronutrientes e teor de prolina nas folhas do tomateiro, em função dos níveis de $\mathrm{N}$ e K aplicados via fertirrigação

\begin{tabular}{|c|c|c|c|c|c|c|c|}
\hline \multirow[t]{3}{*}{$\begin{array}{l}\text { Causa da } \\
\text { variação }\end{array}$} & \multicolumn{7}{|c|}{$\mathrm{F}$} \\
\hline & \multicolumn{6}{|c|}{ Macronutrientes } & Teor de \\
\hline & $\mathrm{N}$ & $\mathrm{P}$ & $\mathrm{K}$ & $\mathrm{Ca}$ & $\mathrm{Mg}$ & $\mathrm{S}$ & prolina \\
\hline Nitrogênio (N) & $7,62^{* *}$ & $7,41 * *$ & 0,77 & 2,52 & 0,57 & $3,78^{*}$ & 1,47 \\
\hline Linear & $14,68^{* *}$ & 2,26 & - & - & - & 0,51 & - \\
\hline Quad & 0,56 & $12,57 * *$ & - & - & - & $7,04 *$ & - \\
\hline Potássio (K) & 0,30 & 0,05 & $15,50^{* *}$ & 0,25 & 0,02 & 0,36 & $3,55^{*}$ \\
\hline Linear & - & - & $28,10^{* *}$ & - & - & - & $5,01 *$ \\
\hline Quad & - & - & 2,91 & - & - & - & 0,08 \\
\hline \multirow[t]{3}{*}{ Interação NxK } & 1,37 & 0,79 & 1,85 & 1,94 & 1,19 & 1,54 & 1,65 \\
\hline & \multicolumn{7}{|c|}{ Micronutrientes } \\
\hline & $\mathrm{Fe}$ & Mn & $\mathrm{Cu}$ & $\mathrm{Zn}$ & B & $\mathrm{Na}$ & $\mathrm{Cl}$ \\
\hline Nitrogênio (N) & 0,07 & 0,29 & 0,83 & 0,57 & $3,68^{*}$ & 1,96 & 1,46 \\
\hline Linear & - & - & - & - & $7,32 *$ & - & - \\
\hline Quad & - & - & - & - & 0,04 & - & - \\
\hline Potássio (K) & 0,03 & 0,11 & 0,66 & 0,50 & 0,29 & 0,25 & 0,93 \\
\hline Interação NxK & 0,05 & 0,50 & 1,97 & 0,87 & 2,02 & 0,27 & $3,46^{*}$ \\
\hline
\end{tabular}

**** Significativo a 0,05 e 0,01 de probabilidade pelo teste $\mathrm{F}$, respectivamente. 
(A)

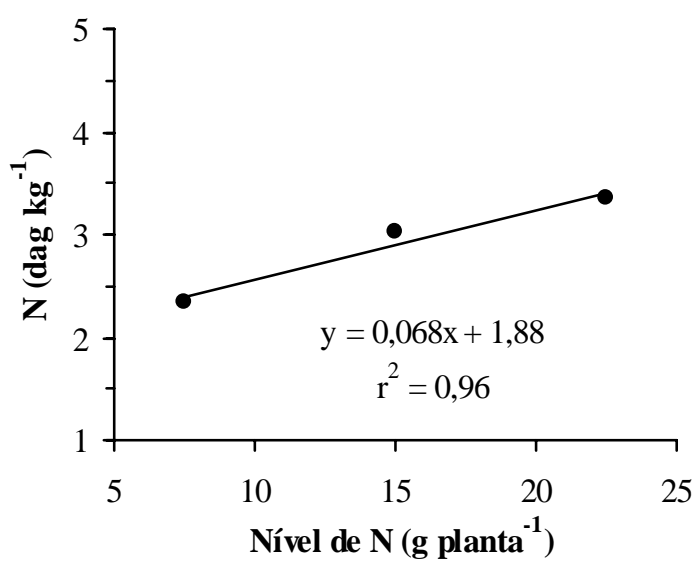

(C)

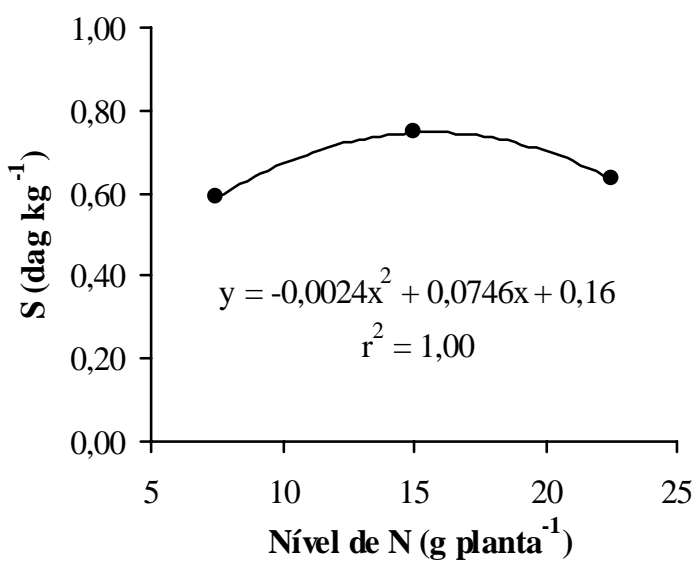

(B)

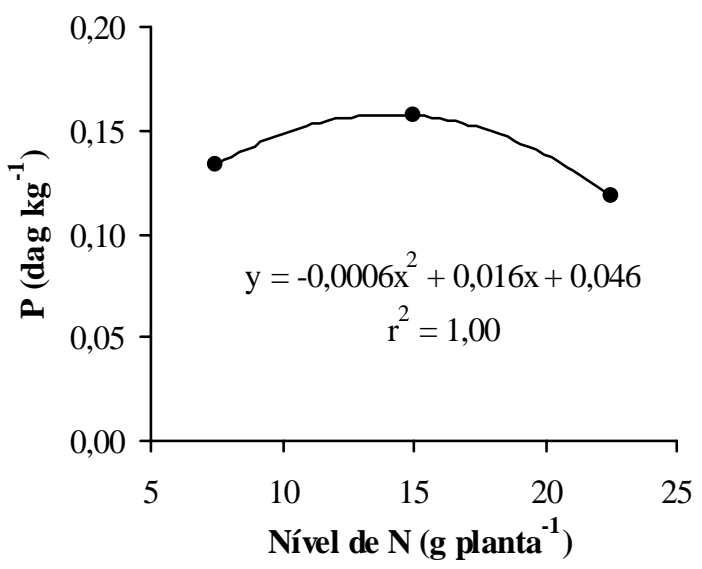

(D)

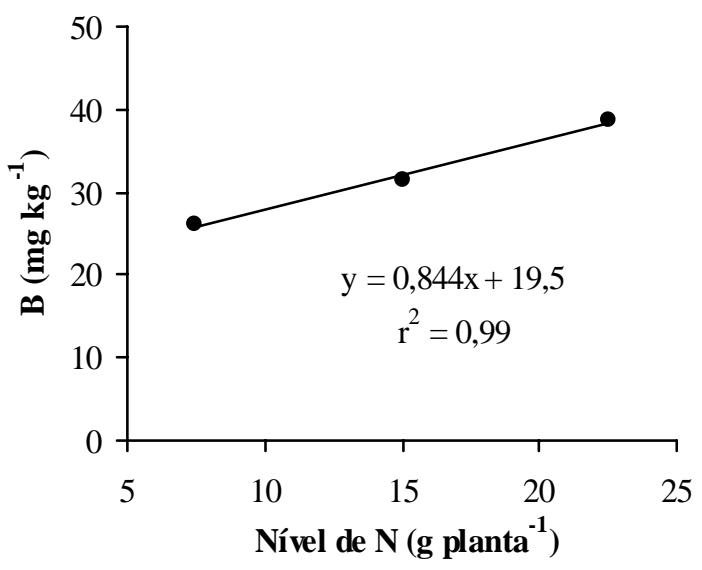

Figura 23 - Relação entre os teores de nitrogênio (A), fósforo (B), enxofre (C) e boro (D) nas folhas do tomateiro ao final do período de cultivo e os níveis de $\mathrm{N}$ aplicados via fertirrigação

Os teores de $\mathrm{K}$ e de prolina nas folhas aumentaram linearmente com o nível de K (Figura 24). 
(A)

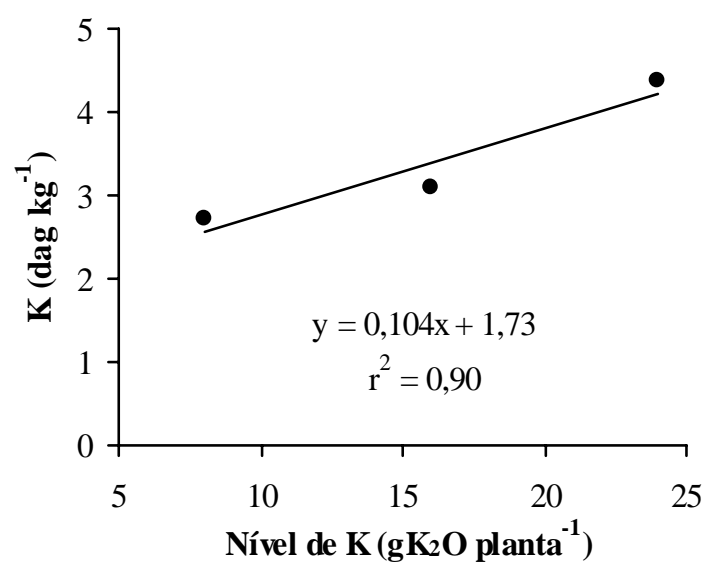

(B)

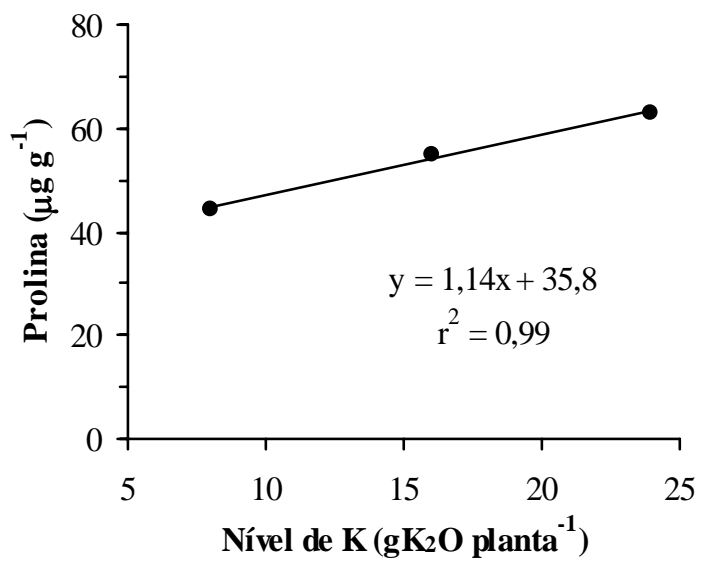

Figura 24 - Relação entre os teores de potássio (A) e prolina (B) nas folhas do tomateiro e os níveis de K aplicados via fertirrigação

Altas concentrações de Na geralmente inibem a absorção de $\mathrm{K}$ pelas plantas e tem-se sugerido que o acúmulo de putrescina nas folhas ocorre em resposta à deficiência de K em plantas sob estresse salino (Harborne, 1977). Uma vez que tanto a putrescina quanto a prolina são formadas a partir do glutamato (Thompson, 1980), então, talvez a redução na síntese de putrescina possa favorecer a síntese de prolina, o que explicaria o aumento no teor de prolina nas folhas com as maiores doses de $\mathrm{K}$.

Pelos resultados obtidos no presente estudo, o aumento da dose de $\mathrm{K}$ aplicada resultou no aumento do teor de $\mathrm{K}$ e de prolina nas folhas do tomateiro, sendo este um possível mecanismo de adaptação da planta à salinidade.

\subsubsection{Altura das plantas e diâmetro da haste}

As plantas apresentaram crescimento acelerado até o $56^{0} \mathrm{DAT}$, reduzindo a taxa de crescimento após essa data (Figura 25). Pode-se notar que, para os níveis mais baixos de $\mathrm{N}$ e $\mathrm{K}$, a altura das plantas foi ligeiramente superior quando comparada à altura das plantas submetidas aos níveis mais elevados. O diâmetro da haste das plantas teve rápido aumento inicial, sendo que na medição realizada aos 43 DAT o diâmetro já era correspondente a aproximadamente $80 \%$ do diâmetro final para todos os tratamentos. 
(A)

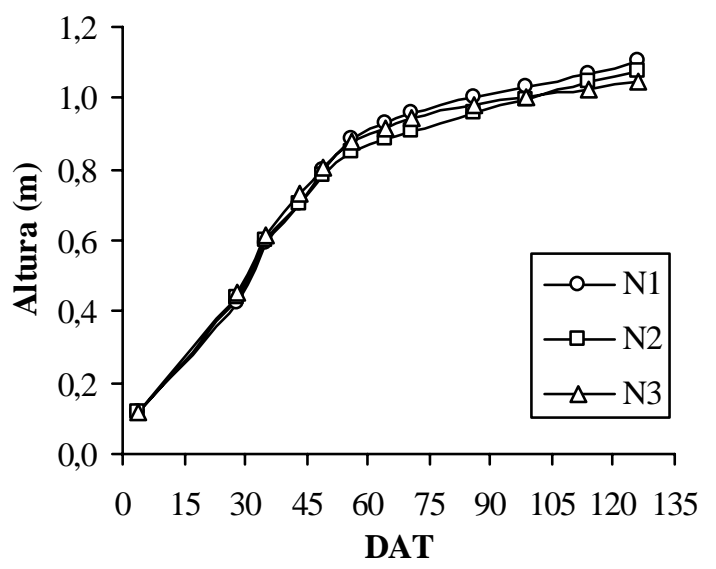

(C)

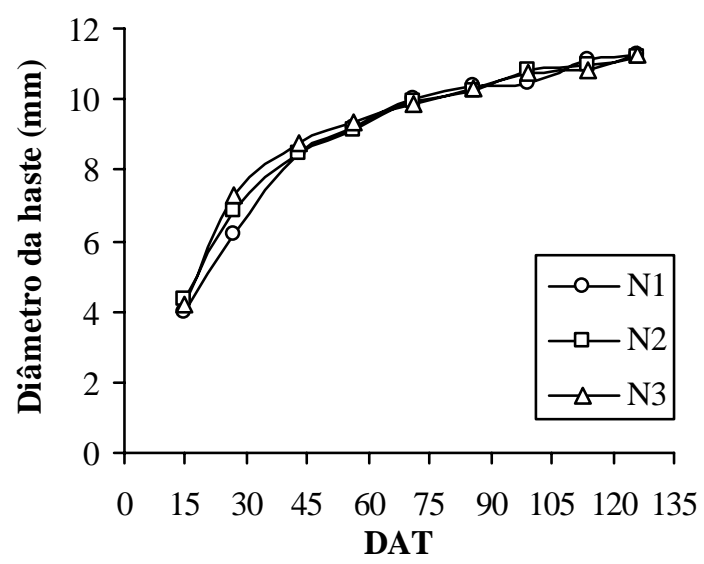

(B)

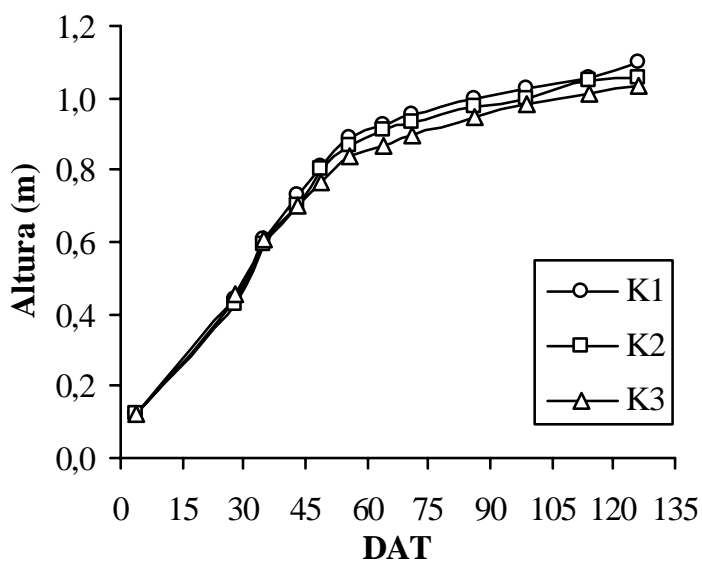

(D)

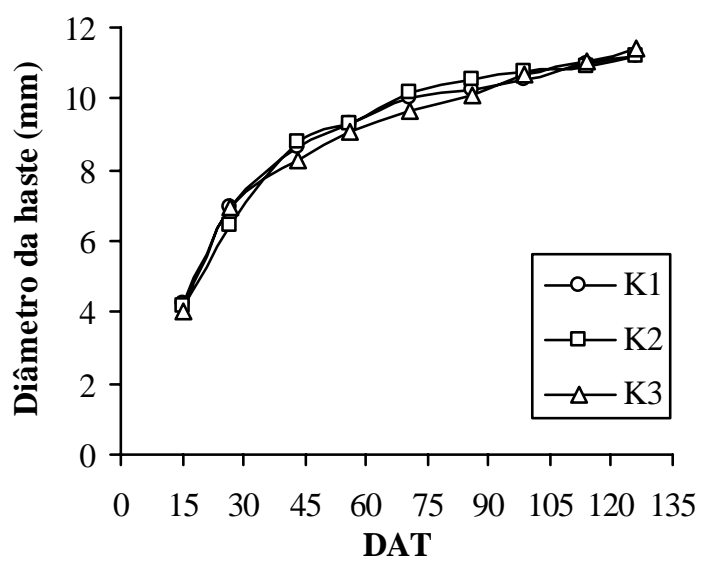

Figura 25 - Variação da altura (A e B) e diâmetro da haste (C e D) das plantas de tomate ao longo do período de cultivo, para cada nível de $\mathrm{N}$ e $\mathrm{K}$ aplicado via fertirrigação. DAT = dias após o transplantio

As diferenças de altura das plantas observadas para os diferentes tratamentos não foram estatisticamente significativas pela análise multivariada, enquanto que para o diâmetro da haste, apenas os níveis de nitrogênio resultaram em diferenças significativas ao longo do tempo (Tabela 16); porém, a análise univariada (Tabela 17) demonstrou haver efeito significativo do N apenas na segunda medição, aos 27 DAT, o que foi devido apenas aos erros cometidos na leitura devido ao formato irregular da haste, haja vista que esta leitura foi realizada no dia em que os tratamentos foram 
iniciados e, portanto, as diferenças observadas não podem ser atribuídas às diferentes doses de fertilizantes.

Tabela 16. Resumo da análise multivariada para altura e diâmetro da haste das plantas de tomate, em função do tempo (T) e dos níveis de $\mathrm{N}$ e $\mathrm{K}$ aplicados via fertirrigação

\begin{tabular}{lcccccc}
\hline & \multicolumn{3}{c}{ Altura da planta } & \multicolumn{3}{c}{ Diâmetro da haste } \\
$\begin{array}{l}\text { Causa da } \\
\text { variação }\end{array}$ & Wilks & Pillai & $\begin{array}{c}\text { Hotelling- } \\
\text { Lawley }\end{array}$ & Wilks & Pillai & $\begin{array}{c}\text { Hotelling- } \\
\text { Lawley }\end{array}$ \\
\hline $\mathrm{T}$ & $290,98^{* *}$ & $290,98^{* *}$ & $290,98^{* *}$ & $143,83^{* *}$ & $143,83^{* *}$ & $143,83^{* *}$ \\
$\mathrm{~T}$ x N & 1,44 & 1,42 & 1,46 & $2,79^{* *}$ & $2,45^{* *}$ & $3,13^{* *}$ \\
T x K & 1,25 & 1,25 & 1,25 & 1,34 & 1,30 & 1,37 \\
TxNxK & 1,34 & 1,31 & 1,34 & 1,23 & 1,24 & 1,20 \\
\hline
\end{tabular}

** Significativo a 0,01 de probabilidade pelo teste $\mathrm{F}$.

Tabela 17. Resumo da análise de variância para diâmetro da haste das plantas de tomate, para cada medição realizada ao longo do período de cultivo, em função dos níveis de $\mathrm{N}$ aplicados via fertirrigação

\begin{tabular}{lccccccccc}
\hline \multirow{2}{*}{$\begin{array}{c}\text { Causa da } \\
\text { Variação }\end{array}$} & \multirow{2}{*}{27} & 43 & 56 & 71 & 86 & 99 & 114 & 126 \\
& & \multicolumn{7}{c}{ Dias após o transplantio } \\
\hline Nitrogênio & $5,71^{* *}$ & 0,55 & 0,30 & 0,24 & 0,12 & 0,60 & 0,35 & 0,00 \\
Linear & $8,19 * *$ & - & - & - & - & - & - & - \\
Quad. & 0,33 & - & - & - & - & - & - & - \\
\hline
\end{tabular}

** Significativo a 0,01 de probabilidade pelo teste $\mathrm{F}$.

O N geralmente promove aumento do vigor da planta (Adams, 1986; Papadopoulos, 1991), o qual está associado à altura da planta e ao diâmetro da haste (Navarrete et al., 1997). No presente trabalho, as doses de $\mathrm{N}$ não tiveram efeito sobre 
estas variáveis, provavelmente devido ao efeito do excesso de sais, o que impediu que a cultura exibisse maior vigor vegetativo mesmo sob altas doses de $\mathrm{N}$.

Ausência de resposta ao $\mathrm{K}$ no desenvolvimento da cultura também foi observada por Macêdo (2002). De fato, o K não está associado ao aumento do vigor vegetativo das culturas e, para o tomateiro, Papadopoulos (1991) afirma que o K atua como "regulador" de crescimento, inibindo o crescimento excessivo quando a disponibilidade de $\mathrm{N}$ é alta.

\subsection{4 Área foliar}

A relação entre a área foliar medida e o produto entre a largura e o comprimento máximo da folha foi ajustada a uma função quadrática, a qual apresentou $\mathrm{r}^{2}$ de 0,99 (Figura 26). Com isso, o padrão de distribuição de área foliar (PDAF) foi determinado (Figura 27) e revelou que as folhas localizadas nas alturas relativas de 0,25 e 0,72 poderiam ser utilizadas para representar a área foliar média das plantas.

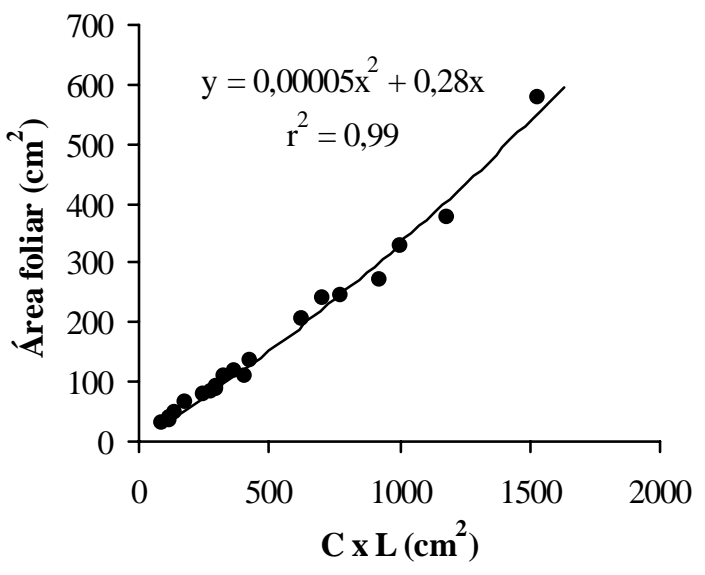

Figura 26 - Relação entre a área foliar medida e o produto do comprimento (C) pela largura (L) de vinte folhas do tomateiro 


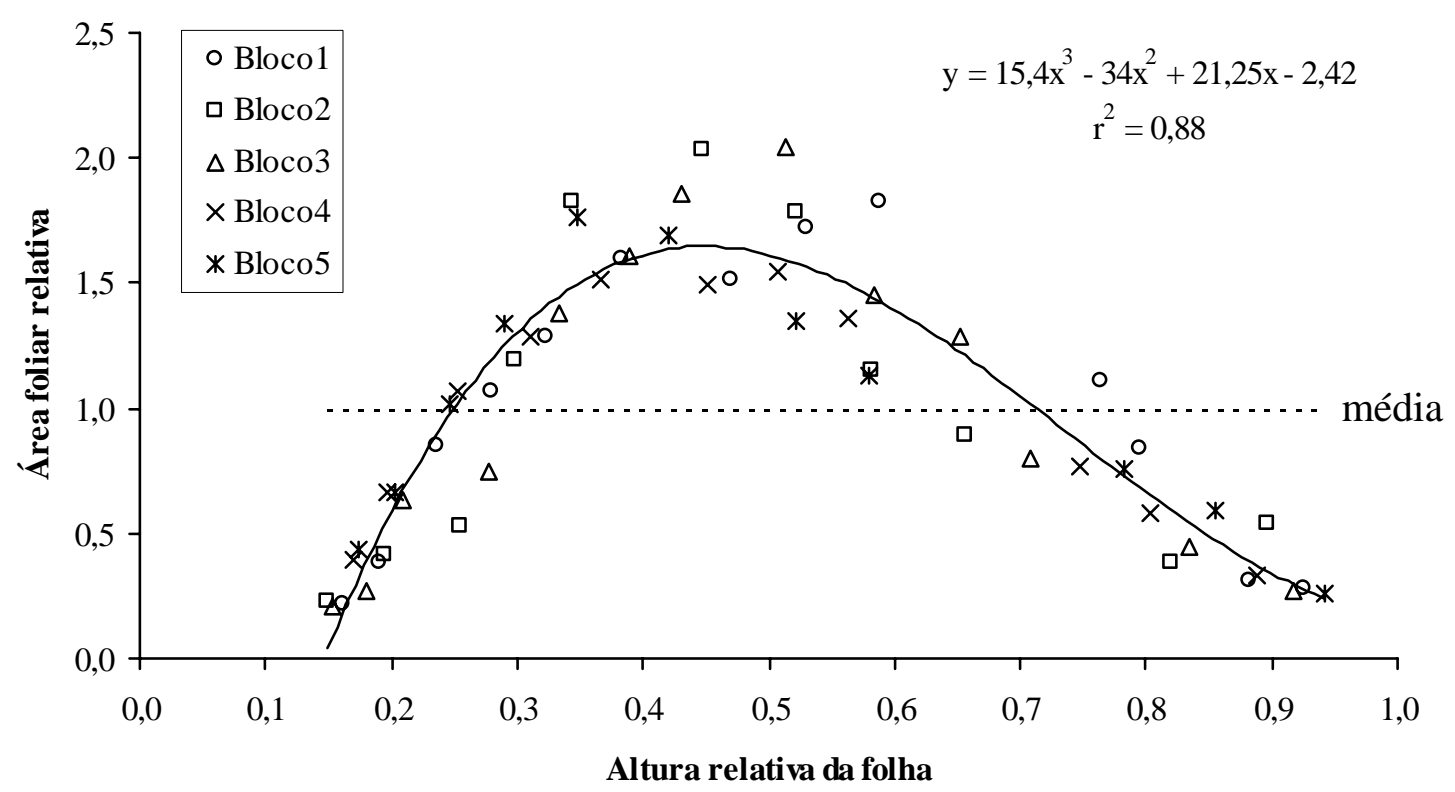

Figura 27 - Padrão de distribuição de área foliar das plantas de tomate para as plantas do tratamento N2K2 de cada bloco experimental

A área foliar média e total das plantas aos 43 DAT foram, em média, $177 \mathrm{~cm}^{2}$ e $1949 \mathrm{~cm}^{2}$, respectivamente, sendo que cada planta apresentava 11 folhas com pequena variação entre os tratamentos (Tabela 18). Verifica-se uma ligeira tendência de aumento da área foliar média com os níveis de $\mathrm{K}$ e da área foliar total com os níveis de $\mathrm{N}$; entretanto, as diferenças observadas não foram significativas pela análise de variância, não havendo efeito das doses de fertilizantes sobre as variáveis analisadas (Tabela 19).

Incrementos significativos de área foliar têm sido observados com o aumento da quantidade de $\mathrm{N}$ aplicada (Ronchi et al., 2001, Tei et al., 2002). Por outro lado, para concentrações de $\mathrm{N}$ na água de irrigação variando de 28 a $224 \mathrm{mg} \mathrm{L}^{-1}$, Nicola \& Basoccu (1994) não verificaram efeitos sobre a área foliar de mudas de tomateiro. Para muitas espécies de plantas, a relação entre a área foliar e o teor de N não é linear mas, sim, hiperbólica, havendo uma estabilização da curva a partir de certo teor de $\mathrm{N}$ (Le Bot et al., 1998). Portanto, apesar das maiores concentrações de $\mathrm{NO}_{3}$ verificadas na solução do solo e dos maiores teores de $\mathrm{N}$ nas folhas com o aumento da dose de $\mathrm{N}$ 
aplicada, a ausência de efeito significativo sobre AFM, AFT e NF indicam que o N não teve efeito sobre a tolerância da cultura à salinidade com relação a estas variáveis.

Tabela 18. Valores médios da área foliar média, área foliar total e número de folhas (NF) do tomateiro aos 43 dias após o transplantio, para cada nível de $\mathrm{N}$ e $\mathrm{K}$ aplicado via fertirrigação

\begin{tabular}{lccc}
\hline \multicolumn{1}{c}{ Causa da variação } & Média & Área foliar & NF \\
& \multicolumn{2}{c}{${\text { cm } \text { planta }^{-1}}^{\text {Total }}$} & folhas planta $^{-1}$ \\
\hline Nitrogênio (N) & 178 & 1891 & 10,7 \\
N1 & 172 & 1925 & 11,3 \\
N2 & 180 & 2030 & 11,2 \\
N3 & & & \\
Potássio (K) & 168 & 1863 & 11,1 \\
K1 & 180 & 2086 & 11,5 \\
K2 & 182 & 1897 & 10,5 \\
K3 & & & \\
\hline
\end{tabular}

Tabela 19. Resumo da análise de variância para área foliar média (AFM), área foliar total (AFT) e número de folhas por planta (NF) de tomateiro aos 43 dias após o transplantio, em função dos níveis de N e K aplicados via fertirrigação

\begin{tabular}{lccc}
\hline \multicolumn{1}{c}{ Causa da variação } & AFM & AFT & NF \\
\hline Nitrogênio (N) & & F & \\
Potássio (K) & 0,10 & 0,22 & 0,95 \\
Interação NxK & 0,31 & 0,60 & 2,86 \\
\hline
\end{tabular}

* Significativo a 0,05 de probabilidade pelo teste $\mathrm{F}$.

\subsubsection{Florescimento}

Cada planta de tomate produziu, em média, de 6 a 7 cachos e o número de dias para o florescimento de cada cacho apresentou certa variação (Tabela 20). 
Tabela 20. Valores médios do número de cachos produzidos por planta de tomate e número de dias para o florescimento de cada cacho, para cada nível de $\mathrm{N}$ e $\mathrm{K}$ aplicado via fertirrigação

\begin{tabular}{lccccccc}
\hline \multicolumn{1}{c}{$\begin{array}{c}\text { Causa da } \\
\text { variação }\end{array}$} & $\begin{array}{c}\text { Número } \\
\text { de cachos } \\
\text { cachos planta }^{-1}\end{array}$ & \multicolumn{6}{c}{$\begin{array}{c}\text { Florescimento } \\
\text { Cacho 1 Cacho 2 }\end{array}$} \\
\hline Nitrogênio (N) & & \multicolumn{7}{c}{$\begin{array}{c}\text { Cacho 3 Cacho 4 Cacho } 5 \text { Cacho } 6 \\
\text { Dias }\end{array}$} \\
N1 & 6,7 & 30,6 & 36,5 & 42,3 & 50,0 & 62,6 & 89,0 \\
N2 & 6,9 & 27,5 & 34,4 & 39,1 & 48,2 & 62,9 & 82,2 \\
N3 & 6,5 & 27,6 & 33,2 & 38,4 & 45,7 & 58,3 & 78,9 \\
Potássio (K) & & & & & & & \\
K1 & 6,9 & 28,9 & 35,1 & 40,3 & 47,8 & 58,6 & 83,0 \\
K2 & 6,7 & 28,9 & 34,7 & 40,1 & 47,1 & 59,6 & 82,7 \\
K3 & 6,5 & 27,9 & 34,3 & 39,5 & 49,1 & 65,5 & 83,5 \\
\hline
\end{tabular}

Apenas o número de dias para o florescimento do primeiro cacho foi afetado pelos tratamentos empregados (Tabela 21); porém, à semelhança do ocorrido com o diâmetro da haste das plantas, o florescimento do primeiro cacho deu-se entre o $27^{\circ}$ e o $31^{\circ}$ DAT e, uma vez que os tratamentos foram iniciados aos 27 DAT, então as diferenças observadas foram devidas, provavelmente, à variabilidade genética do material utilizado e/ou às variações micrometeorológicas no interior do ambiente protegido, não podendo estar relacionadas aos diferentes tratamentos empregados. 
Tabela 21. Resumo da análise de variância para número de cachos produzidos por planta de tomate e número de dias para o florescimento de cada cacho, em função dos níveis de $\mathrm{N}$ e K aplicados via fertirrigação

\begin{tabular}{lcccccc}
\hline \multicolumn{1}{c}{$\begin{array}{c}\text { Causa da } \\
\text { variação }\end{array}$} & $\begin{array}{c}\text { Número } \\
\text { de cachos }\end{array}$ & Cacho 1 & Cacho 2 & Cacho 3 & Cacho 4 & Cacho 5 \\
\hline Nitrogênio (N) & 0,59 & $4,96^{*}$ & 2,73 & 2,66 & 1,83 & 0,60 \\
Linear & - & $5,71^{*}$ & - & - & - & - \\
Quad & - & $4,21^{*}$ & - & - & - & - \\
Potássio (K) & 0,78 & 0,50 & 1,04 & 0,81 & 0,23 & 1,04 \\
Interação NxK & 1,59 & 0,92 & 0,57 & 0,21 & 1,03 & 1,23 \\
\hline
\end{tabular}

* Significativo a 0,05 de probabilidade pelo teste $\mathrm{F}$.

\subsubsection{Produtividade e características dos frutos}

A produtividade total não apresentou grandes variações entre os tratamentos empregados, apresentando média de 266 g planta, sendo que de cada planta foram colhidos em torno de 14 a 16 frutos. Cada fruto teve peso médio de 18,2 g e diâmetro de 3,1 cm (Tabela 22).

Trabalhos têm demonstrado aumento de produtividade do tomateiro com o aumento da dose de N aplicada (Winsor et al., 1967; Adams et al., 1978; Ferreira et al., 2003), embora a ausência de resposta a este nutriente também tenha sido verificada (Pill et al., 1978; Bojórquez et al., 2001).

Apesar do K ser geralmente associado ao aumento de produção (Saxena et al., 1975; Sampaio, 1996; Churata-Masca et al., 2001), neste trabalho não foi observado efeito desse nutriente sobre a produtividade e característica dos frutos, concordando com resultados obtidos por outros autores (Bojórquez et al., 2001; Macêdo, 2002). 
Tabela 22. Valores médios de produtividade, número de frutos por planta, diâmetro médio e peso médio dos frutos de tomate, para cada nível de N e K aplicado via fertirrigação

\begin{tabular}{lcccc}
\hline $\begin{array}{c}\text { Causa da } \\
\text { variação }\end{array}$ & $\begin{array}{c}\text { Produtividade } \\
\text { g planta }^{-1}\end{array}$ & $\begin{array}{c}\text { Frutos } \\
\text { por planta } \\
\text { frutos planta }^{-1}\end{array}$ & $\begin{array}{c}\text { Diâmetro } \\
\text { do fruto } \\
\text { cm }\end{array}$ & $\begin{array}{c}\text { Peso médio } \\
\text { do fruto } \\
\text { g fruto }^{-1}\end{array}$ \\
\hline Nitrogênio (N) & & & & \\
N1 & 267 & 15,3 & 3,10 & 18,1 \\
N2 & 262 & 14,5 & 3,20 & 19,3 \\
N3 & 268 & 16,4 & 3,07 & 17,3 \\
Potássio (K) & & & & \\
K1 & 267 & 15,7 & 3,13 & 18,3 \\
K2 & 282 & 14,8 & 3,24 & 19,7 \\
K3 & 248 & 15,6 & 2,98 & 16,7 \\
\hline
\end{tabular}

Na análise de variância não foram verificadas diferenças significativas para nenhuma das variáveis analisadas (Tabela 23).

Tabela 23. Resumo da análise de variância para produtividade, número de frutos por planta, diâmetro médio e peso médio dos frutos de tomate, em função dos níveis de $\mathrm{N}$ e K aplicados via fertirrigação

\begin{tabular}{lcccc}
\hline $\begin{array}{c}\text { Causa da } \\
\text { variação }\end{array}$ & Produtividade & $\begin{array}{c}\text { Frutos } \\
\text { por planta }\end{array}$ & $\begin{array}{c}\text { Diâmetro } \\
\text { do fruto }\end{array}$ & $\begin{array}{c}\text { Peso médio } \\
\text { do fruto }\end{array}$ \\
\hline Nitrogênio (N) & 0,02 & 1,99 & 0,82 & 0,81 \\
Potássio (K) & 1,36 & 0,54 & 2,87 & 1,69 \\
Interação NxK & 1,67 & 0,28 & 0,96 & 1,02 \\
\hline
\end{tabular}

Uma vez que as concentrações de $\mathrm{NO}_{3}$ e $\mathrm{K}$ na solução do solo foram altas para todos os níveis de $\mathrm{N}$, então o aumento de produtividade só seria esperado se a cultura apresentasse um mecanismo de tolerância à salinidade pelo qual a maior disponibilidade desses nutrientes na solução, com conseqüente aumento das quantidades 
absorvidas, resultasse em menor absorção de $\mathrm{Na}$ e $\mathrm{Cl}$, reduzindo os efeitos osmótico e de toxidez promovidos por estes íons.

Os baixos valores de peso médio e diâmetro dos frutos são decorrentes do efeito da exposição prolongada à salinidade. Pela Figura 28 verifica-se declínio acentuado do peso médio dos frutos ao longo das colheitas, o que é devido não apenas ao efeito da salinidade, mas, também, às características intrínsecas da cultura, haja vista que o tamanho e, conseqüentemente, o peso médio dos frutos tendem a reduzir ao longo do período produtivo (Ho \& Hewitt, 1986).

(A)

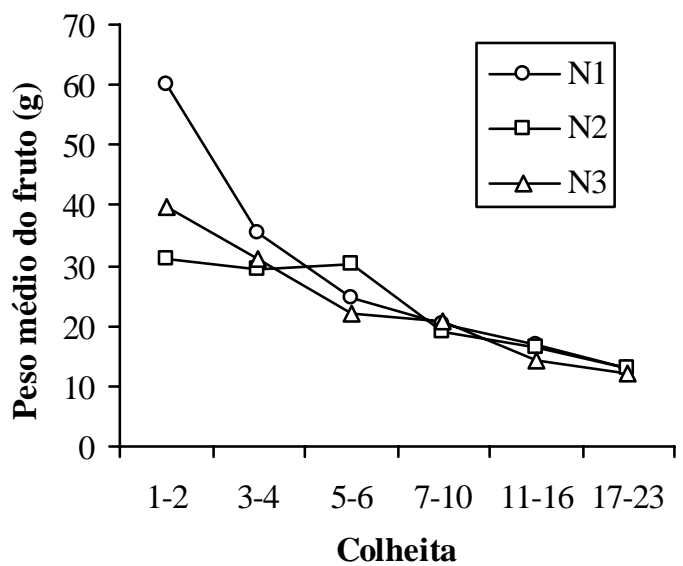

(B)

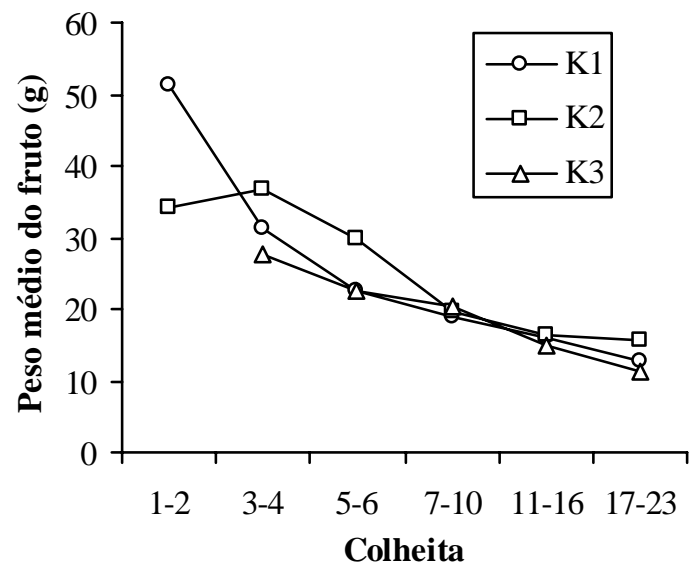

Figura 28 - Peso médio dos frutos de tomate ao longo do período produtivo, para cada nível de N (A) e K (B) aplicado via fertirrigação

\subsubsection{Produção de matéria seca}

A produção de matéria seca nas diferentes partes da planta variou entre os níveis dos fatores empregados (Tabela 24). Na Tabela 25 são apresentados os resultados da análise de variância para cada variável. Os níveis de nitrogênio não tiveram efeito na produção de matéria seca, enquanto que os níveis de potássio afetaram apenas a MSHC e MST, sendo a interação NxK também significativa para estas variáveis. 
Tabela 24. Valores médios da massa seca de frutos (MSF), folhas (MSFo), haste+cachos (MSHC) e total (MST) do tomateiro, para cada nível de $\mathrm{N}$ e K aplicado via fertirrigação

\begin{tabular}{lcccc}
\hline \multicolumn{1}{c}{ Causa da variação } & MSF & MSFo & $\begin{array}{c}\text { MSHC } \\
\text { g planta }^{-1}\end{array}$ \\
\hline Nitrogênio (N) & \multicolumn{4}{c}{ MST } \\
N1 & 33,4 & 27,9 & 22,8 & 96,7 \\
N2 & 34,0 & 26,1 & 22,6 & 96,7 \\
N3 & 34,0 & 25,7 & 21,2 & 93,7 \\
Potássio (K) & & & & \\
K1 & 34,3 & 27,7 & 22,1 & 94,1 \\
K2 & 35,1 & 25,3 & 23,9 & 100,9 \\
K3 & 31,9 & 26,7 & 21,0 & 92,2 \\
\hline
\end{tabular}

Tabela 25. Resumo da análise de variância para massa seca de frutos (MSF), folhas (MSFo), haste+cachos (MSHC) e total (MST) do tomateiro, em função dos níveis de $\mathrm{N}$ e K aplicados via fertirrigação

\begin{tabular}{lcccc}
\hline \multicolumn{1}{c}{ Causa da variação } & MSF & MSFo & MSHC & MST \\
\hline Nitrogênio (N) & 0,05 & 0,45 & 2,77 & 1,05 \\
Potássio (K) & 0,87 & 0,40 & $3,65^{*}$ & $8,33^{* *}$ \\
Linear & - & - & 0,92 & 0,53 \\
Quad. & - & - & $6,39^{*}$ & $16,13^{* *}$ \\
Interação NxK & 1,35 & 0,70 & $3,53^{*}$ & $7,64^{* *}$ \\
\hline
\end{tabular}

*,** Significativo a 0,05 e 0,01 de probabilidade pelo teste $\mathrm{F}$, respectivamente.

MST e MSHC aumentaram para K2 em relação a K1 e diminuíram novamente para K3 (Figura 29). Provavelmente, estes resultados não expressam os reais efeitos de $\mathrm{K}$, uma vez que a concentração de $\mathrm{K}$ nas folhas aumentou linearmente com a dose aplicada na fertirrigação (Figura 24A). Era esperado que o teor de Na nas folhas diminuísse com o aumento da dose de $\mathrm{K}$ aplicada, mas a relação K/Na nas folhas foi 4,7, 
3,6 e 5,7 para K1, K2 e K3, respectivamente, o que torna difícil explicar a maior produção de matéria seca obtida para K2.

(A)

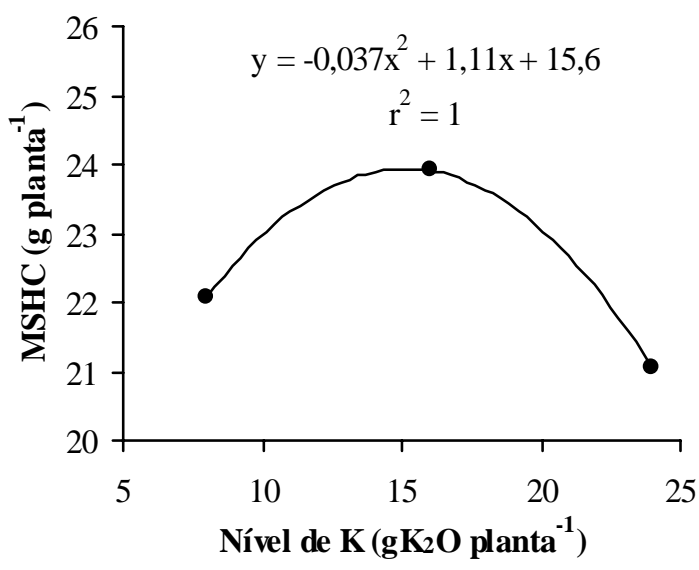

(B)

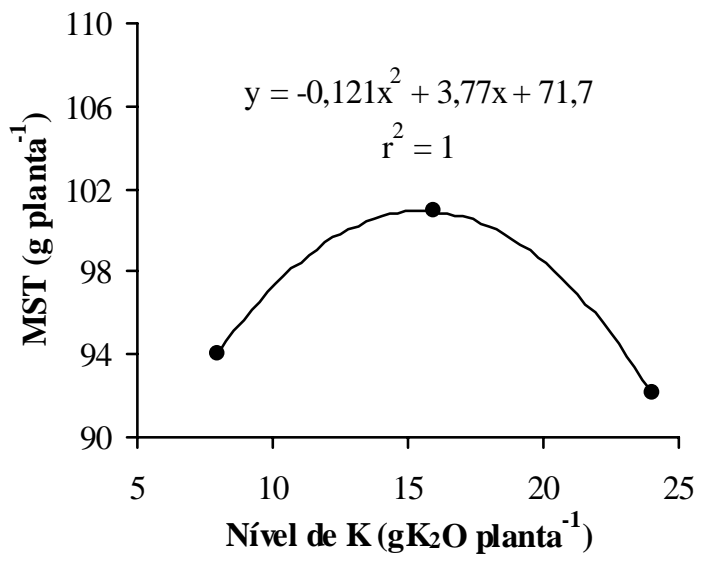

Figura 29 - Relação entre massa seca de haste+cachos, MSHC (A), e massa seca total, MST (B), e os níveis de K aplicados via fertirrigação

Pelo desdobramento da interação NxK, verifica-se que o efeito do potássio em MSHC e MST só foi observado para os valores mais baixos de N (Tabela 26).

Resultados semelhantes foram obtidos por Botrini et al. (2000), embora o nível intermediário de $\mathrm{K}$ tenha resultado nos valores mais baixos de $\mathrm{Na}$ em folhas da cultivar "Edkawi”, com aumento linear do teor de Na para a cultivar "UC 82B". A produção de matéria seca de brotos, como também sua porcentagem em relação ao peso fresco, diminuiu com o aumento os níveis de $\mathrm{K}$ na solução nutritiva, apesar dos resultados não terem sido significativos. 
Tabela 26. Resumo da análise de variância para massa seca de haste+cachos (MSHC) e massa seca total (MST) das plantas de tomate, em função dos níveis de K dentro dos níveis de $\mathrm{N}$

\begin{tabular}{lccc}
\hline \multicolumn{1}{c}{ Causa da variação } & N1 & N2 & N3 \\
& & MSHC & \\
Nível de K & $6,36^{* *}$ & 2,18 & 2,09 \\
Linear & 1,04 & - & - \\
Quad. & $11,48^{* *}$ & - & - \\
& & MST & \\
Nível de K & $16,77^{* *}$ & $6,21^{*}$ & 0,80 \\
Linear & $8,59^{*}$ & 1,79 & - \\
Quad. & $24,96^{* *}$ & $10,63^{*}$ & - \\
$*, * *$ Significativo a 0,05 e 0,01 de probabilidade pelo teste F, respectivamente.
\end{tabular}

As porcentagens de matéria seca nas diferentes partes da planta apresentaram certa variação para os diferentes níveis de N e K (Tabela 27), porém os resultados não diferiram significativamente pelo teste F (Tabela 28).

Tabela 27. Valores médios da porcentagem de matéria seca de haste+cachos (PMSHC), folhas (PMSFo) e frutos no início $\left(\mathrm{PMSF}_{\mathrm{I}}\right)$ e no final $\left(\mathrm{PMSF}_{\mathrm{F}}\right)$ do período de colheita do tomateiro, para cada nível de $\mathrm{N}$ e K aplicado via fertirrigação

\begin{tabular}{lcccc}
\hline \multicolumn{1}{c}{ Causa da variação } & PMSHC & PMSFo & PMSF $_{\mathrm{I}}$ & PMSF $_{\mathrm{F}}$ \\
\hline Nitrogênio & & & & \\
N1 & & & & \\
N2 & 21,7 & 22,3 & 12,3 & 13,2 \\
N3 & 20,9 & 20,6 & 13,6 & 12,8 \\
Potássio (K) & 20,7 & 22,8 & 13,2 & 12,4 \\
K1 & & & & \\
K2 & 21,2 & 21,0 & 13,2 & 12,7 \\
K3 & 21,6 & 20,8 & 12,6 & 12,6 \\
\hline
\end{tabular}


Tabela 28. Resumo da análise de variância para porcentagem de matéria seca de haste+cachos (PMSHC), folhas (PMSFo) e frutos no início $\left(\mathrm{PMSF}_{\mathrm{I}}\right)$ e no final $\left(\mathrm{PMSF}_{\mathrm{F}}\right)$ do período de colheita do tomateiro, em função dos níveis de N e K aplicados via fertirrigação

\begin{tabular}{lcccc}
\hline \multicolumn{1}{c}{ Causa da variação } & PMSHC & PMSFo & PMSF $_{\text {I }}$ & PMSF F \\
& & \multicolumn{2}{c}{ F } & \\
\hline Nitrogênio (N) & 1,49 & 0,65 & 2,18 & 0,84 \\
Potássio (K) & 1,55 & 0,83 & 0,92 & 0,37 \\
Interação NxK & 1,38 & 0,84 & 2,60 & 0,11 \\
\hline
\end{tabular}

\subsubsection{Qualidade dos frutos}

Os valores médios observados para as variáveis relacionadas à qualidade dos frutos são apresentados na Tabela 29, os quais encontram-se dentro das faixas observadas por outros autores (Gargantini \& Blanco, 1963; Fernandes et al., 1975; Maher, 1976; Castro, 1976; Haag et al., 1978; Dechen, 1980).

Tabela 29. Valores médios dos teores de macro e micronutrientes, brix e acidez dos frutos do tomateiro, para cada nível de $\mathrm{N}$ e K aplicado via fertirrigação

\begin{tabular}{lcccccccccc}
\hline \multicolumn{1}{c}{$\begin{array}{c}\text { Causa da } \\
\text { variação }\end{array}$} & $\mathrm{N}$ & $\mathrm{P}$ & $\mathrm{K}$ & $\begin{array}{c}\mathrm{Ca} \\
\mathrm{dag} \mathrm{kg}^{-1}\end{array}$ & $\mathrm{Mg}$ & $\mathrm{S}$ & $\mathrm{Cl}$ & $\begin{array}{c}\mathrm{Na} \\
\mathrm{mg} \mathrm{kg}^{-1}\end{array}$ & $\begin{array}{c}\text { Brix } \\
{ }^{\circ} \mathrm{Brix}\end{array}$ & $\begin{array}{c}\text { Acidez }^{\#} \\
\%\end{array}$ \\
\hline Nitrogênio (N) & & & & & & & & & & \\
N1 & 3,2 & 0,19 & 3,3 & 0,23 & 0,13 & 0,25 & 5,3 & 855 & 10,0 & 1,01 \\
N2 & 3,2 & 0,20 & 3,2 & 0,24 & 0,13 & 0,26 & 5,3 & 922 & 9,6 & 0,94 \\
N3 & 3,2 & 0,22 & 3,3 & 0,23 & 0,13 & 0,29 & 5,5 & 982 & 9,6 & 0,91 \\
Potássio (K) & & & & & & & & & & \\
K1 & 3,2 & 0,20 & 3,1 & 0,25 & 0,13 & 0,26 & 5,0 & 1122 & 9,7 & 0,97 \\
K2 & 2,8 & 0,19 & 3,2 & 0,22 & 0,13 & 0,27 & 5,7 & 930 & 9,8 & 0,94 \\
K3 & 3,5 & 0,22 & 3,5 & 0,23 & 0,13 & 0,28 & 5,4 & 692 & 9,8 & 0,95 \\
\hline \#
\end{tabular}

\# Valores em porcentagem de ácido cítrico 
Os níveis de $\mathrm{N}$ não tiveram efeito sobre nenhuma das variáveis analisadas, enquanto que os teores de $\mathrm{N}$ e $\mathrm{K}$ nos frutos foram afetados pelos níveis de $\mathrm{K}$ (Tabela 30).

Tabela 30. Resumo da análise de variância para teores de macro e micronutrientes, brix e acidez dos frutos do tomateiro, em função dos níveis de $\mathrm{N}$ e K aplicados via fertirrigação

\begin{tabular}{lcccccccccc}
\hline \multicolumn{1}{c}{$\begin{array}{c}\text { Causa da } \\
\text { variação }\end{array}$} & $\mathrm{N}$ & $\mathrm{P}$ & $\mathrm{K}$ & $\mathrm{Ca}$ & $\mathrm{Mg}$ & $\mathrm{S}$ & $\mathrm{Cl}$ & $\mathrm{Na}$ & Brix & Acidez \\
\hline Nitrogênio (N) & 0,05 & 2,58 & 0,03 & 0,12 & 0,94 & 3,10 & 0,07 & 0,44 & 0,64 & 2,14 \\
Potássio (K) & $5,55^{* *}$ & 2,01 & $3,54^{*}$ & 0,74 & 0,43 & 0,33 & 0,71 & 2,49 & 0,39 & 0,29 \\
Linear & 1,54 & - & $6,49^{*}$ & - & - & - & - & - & - & - \\
Quad. & $9,39 * *$ & - & 0,06 & - & - & - & - & - & - & - \\
Interação NxK & 0,56 & 0,10 & 0,08 & 1,06 & 0,37 & 1,19 & 0,63 & 0,80 & 0,40 & 0,22 \\
\hline *,** Significativo a 0,05 e 0,01 de probabilidade pelo teste F, respectivamente.
\end{tabular}

Com relação ao brix e à acidez, apenas esta última apresentou tendência de redução com o aumento do nível de N; porém, concordando com resultados obtidos por outros autores (Hobson \& Davies, 1971; Sampaio, 1996; Macêdo, 2002), os níveis de $\mathrm{N}$ e K não tiveram efeito significativo sobre estas variáveis.

$\mathrm{O}$ teor de $\mathrm{N}$ nos frutos variou de forma quadrática e o de $\mathrm{K}$ variou linearmente com os níveis de K aplicados via fertirrigação (Figura 30).

Os valores médios comumente obtidos para brix e acidez de frutos de tomateiro situam-se na faixa de 4 a 6 para brix e 0,3 a 0,4 para acidez titulável (Picha \& Hall, 1982; Wolk et al., 1983; Mitchell et al., 1991; Alcántar et al., 1999). Como o brix e a acidez são fatores que apresentam alta correlação com o sabor e aroma do fruto do tomateiro (Auerswald et al., 1999), a aplicação de sais na água de irrigação como meio utilizado para obtenção de frutos de alta qualidade comercial pode elevar o brix e a acidez para valores acima de $8^{\circ}$ e 1\%, respectivamente (Sakamoto et al., 1999; Pascale et al., 2001), valores estes bem acima daqueles geralmente observados em cultivos convencionais, o que explica os altos valores observados no presente estudo. 
(A)

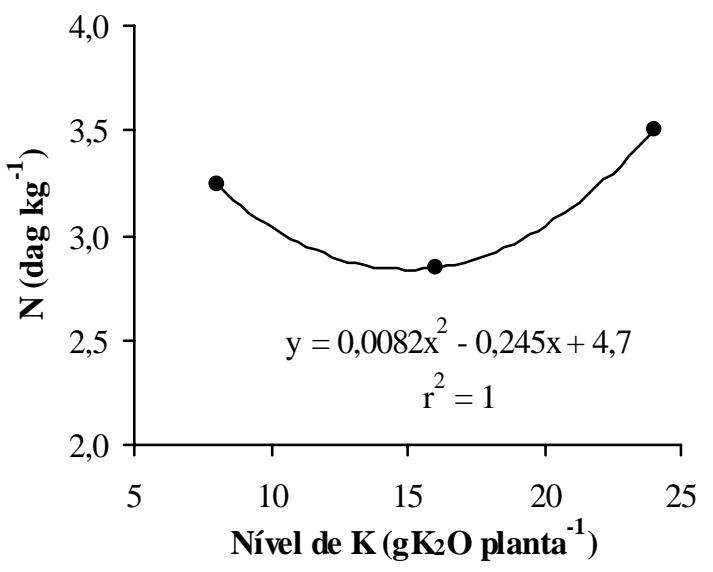

(B)

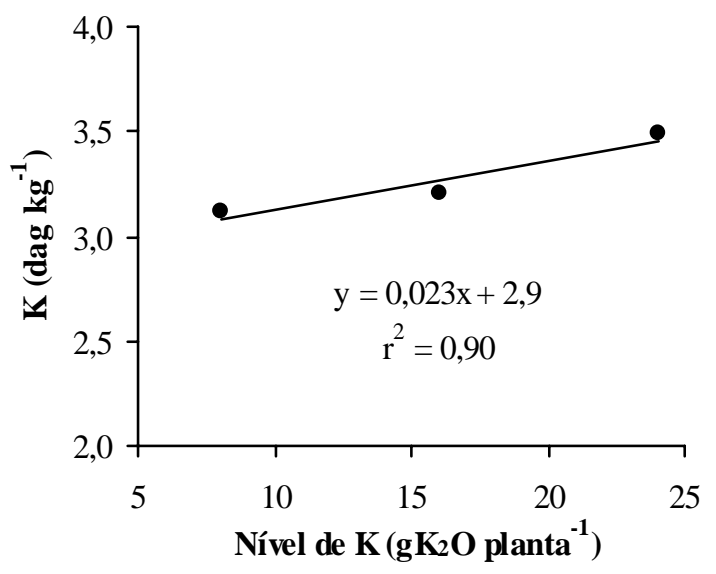

Figura 30 - Relação entre os teores de nitrogênio (A) e potássio (B) nos frutos do tomateiro ao final do período de cultivo e os níveis de $\mathrm{K}$ aplicados via fertirrigação 


\section{CONCLUSÕES}

Com base nos resultados obtidos e nas condições em que o trabalho foi conduzido, puderam-se estabelecer as seguintes conclusões:

- As concentrações de $\mathrm{NO}_{3}$ e $\mathrm{K}$ na solução do solo obtida com extratores de cápsula porosa foram proporcionais às doses de $\mathrm{N}$ e K aplicadas via fertirrigação, indicando que este equipamento é adequado para o monitoramento do nível de nutrientes no solo;

- Os medidores de íons específicos foram adequados para determinar as concentrações de $\mathrm{NO}_{3}$, K e Na no solo e na seiva do pecíolo do tomateiro, apresentando correlações satisfatórias com as determinações realizadas em laboratório pelos métodos-padrões;

- Os valores de condutividade elétrica no extrato de saturação e na solução 1:2 e concentrações de $\mathrm{NO}_{3}$ e Ca no extrato de saturação não podem ser utilizados para estimar os valores destas variáveis na solução do solo apenas pela correção da umidade;

- As concentrações de K e Na na solução do solo podem ser estimadas a partir dos valores no extrato de saturação pela correção de umidade, porém com baixa precisão para concentrações acima de $500 \mathrm{mg} \mathrm{L}^{-1}$ para $\mathrm{K}$ e $700 \mathrm{mg} \mathrm{L}^{-1}$ para Na;

- O aumento das doses aplicadas de $\mathrm{N}$ e K não resultou em aumento da tolerância do tomateiro à salinidade, não havendo efeito sobre o desenvolvimento e a produção da cultura; 
- Os teores de $\mathrm{N}$ e K na matéria seca das folhas aumentaram com a dose aplicada destes nutrientes e não apresentaram efeito sobre os teores de $\mathrm{Cl}$ e Na;

- Os maiores teores de $\mathrm{K}$ e de prolina nas folhas observados com o aumento da dose de $\mathrm{K}$ aplicada via fertirrigação indicaram que a cultura apresenta um mecanismo de tolerância à salinidade, o qual deve ser mais bem estudado sob condições de salinidade moderada;

- O teor de $\mathrm{K}$ nos frutos aumentou com a dose aplicada deste nutriente, não havendo efeito do $\mathrm{N}$ e do $\mathrm{K}$ para as demais características dos frutos. 


\section{REFERÊNCIAS BIBLIOGRÁFICAS}

ADAMS, P. Mineral nutrition. In: ATHERTON, J.G.; RUDICH, J. (Ed.). The tomato crop: a scientific basis for improvement. London/New York: Chapman and Hall, 1986. cap.7, p.281-334.

ADAMS, P.; GRAVES, C.J.; WINSOR, G.W. Tomato yields in relations to the nitrogen, potassium and magnesium status of the plants and of the peat substrate. Plant and Soil, v.49, n.1, p.137-148, 1978.

ALCÁNTAR G., G.; VILlARREAL R., M.; AGUILAR S., A. Tomato growth (Lycopersicon esculentum Mill), and nutrient utilisation in response to varying fertigation programs. Acta Horticulturae, n.481, p.385-391, 1999.

ALFOCEA, F.P.; ESTAN, M.T.; CARO, M. et al. Response of tomato cultivars to salinity. Plant and Soil, v.150, n.2, p.203-211, 1993.

ALIAN, A.; ALTMAN, A.; HEUER, B. Genotypic difference in salinity and water stress tolerance of fresh market tomato cultivars. Plant Science, v.152, n.1, p.59-65, 2000.

ALPASLAN, M.; GUNES, A. Interactive effects of boron and salinity stress on the growth, membrane permeability and mineral composition of tomato and cucumber plants. Plant and Soil, v.236, n.1, p.123-128, 2001.

AMBRÓSIO, L.A.; NAGAI, H. Sazonalização dos preços das classes de tomate, no atacado, em São Paulo, nos períodos de 1983/1986 e 1987/1990. Horticultura Brasileira, v.9, n.1, p.30, 1991. /Apresentado ao 31o. Congresso Brasileiro de Olericultura, Belo Horizonte, 1991 - Resumo/ 
ANDRIOLO, J.L.; FALCÃO, L.L. Efeito da poda de folhas sobre a acumulação de matéria seca e sua repartição para os frutos do tomateiro cultivado em ambiente protegido. Revista Brasileira de Agrometeorologia, v.8, n.1, p.75-83, 2000.

ASPINALL, D. Metabolic effects of water and salinity stress in relation to expansion of the leaf surface. Australian Journal of Plant Physiology, v.13, n.1, p.59-73, 1986.

AUERSWALD, H.; SCHWARZ, D.; KORNELSON, C. et al. Sensory analysis, sugar and acid content of tomato at different EC values of the nutrient solution. Scientia Horticulturae, v.82, n.3/4, p.227-242, 1999.

AZEVEDO, H.M. Irrigação localizada. Informe Agropecuário, v.12, n.139, p.40-53, 1986.

AZIZ, A.; TANGUY, J.M.; LARHER, F. Salt stress-induced proline accumulation and changes in tyramine and polyamine levels are linked to ionic adjustment in tomato leaf discs. Plant Science, v.145, n.2, p.83-91, 1999.

BAR-YOUSEF, B. Fertilization under drip irrigation. In: PALGRAVE, D.A. (Ed.) Fluid fertilizer: science and technology. New York: Marcel Dekker, 1991. cap.14, p.285-329.

BARKE, R.E.; MENARY, R.C. Calcium nutrition of the tomato as influenced by total salts and ammonium nutrition. Australian Journal of Experimental Agriculture and Animal Husbandry, v.11, n.52, p.562-569, 1971.

BATES, L.S.; WALDREN, R.P.; TEARE, I.D. Rapid determination of free proline for water-stress studies. Plant and Soil, v.39, p.205-207, 1973.

BERNSTEIN, L.; FRANCOIS, L.E. Effects of Sprinkling with saline waters compared with daily drip irrigation. Agronomy Journal, v.67, n.2, p.185-190, 1975.

BIDDINGTON, N. The effect of mechanically induced stress in plants - a review. Plant Growth Regulation, v.4, n.2, p.103-123, 1986.

BLANCO, F.F. Tolerância do pepino enxertado à salinidade em ambiente protegido e controle da salinização do solo. Piracicaba, 1999. 104p. Dissertação (Mestrado) Escola Superior de Agricultura “Luiz de Queiroz”, Universidade de São Paulo. 
BLANCO, F.F.; FOLEGATTI, M.V. Salt accumulation and distribution in a greenhouse soil as affected by salinity of irrigation water and leaching management. Revista Brasileira de Engenharia Agrícola e Ambiental, v.6, n.3, p.414-419, 2002.

BLANCO, F.F.; MEDEIROS, J.F.; FOLEGATTI, M.V. Produção da alface (Lactuca sativa L.) em ambiente protegido sob condições salinas (compact disc). In: CONGRESSO BRASILEIRO DE ENGENHARIA AGRÍCOLA, 28., Pelotas, 1999. Anais. Pelotas: SBEA, 1999.

BOJÓRQUEZ, A.D.A.; CASTILLO, G.A.B.; GONZÁLEZ, G.A. et al. Nitrate and potassium ratios in a drip fertigation system on production, quality and nutrient uptake in tomato. Revista Chapingo Serie Horticultura, v.7, n.1, p.61-75, 2001.

BOTRINI, L.; PAOLA, M.L.; GRAIFENBERG, A. Potassium affects sodium content in tomato plants grown in hydroponic cultivation under saline-sodic stress. HortScience, v.35, n.7, p.1220-1222, 2000.

BOUMA, D. Diagnosis of mineral deficiencies using plant tests. In: LÄUCHLI, A.; BIELESKI, R.L. (Ed.). Inorganic plant nutrition. Berlin: Springer-Verlag, 1983. cap.1, p.120-146.

BOUYOUCOS, G.J. The hydrometer as a new method for the mechanical analysis of soils. Soil Science, v.23, n.5, p.343-353, 1927.

BOUYOUCOS, G.J. A recalibration of the hydrometer method for making mechanical analysis of soils. Agronomy Journal, v.43, n.9, p.434-438, 1951.

BRADFORD, K.J.; YANG, S.F. Physiological responses of plants to waterlogging. HortScience, v.16, n.1, p.25-30, 1981.

BREMNER, J.M. Inorganic forms of nitrogen. In: BLACK, C.A.; EVANS, D.D.; WHITE, J.L.; ENSMINGER, L.E.; CLARK, F.E. (Ed.). Methods of soil analysis: chemical and microbiological properties. part 2. Madison: ASA, 1965. cap. 84, p.1179-1237. (ASA. Agronomy, 9). 
BRESLER, E. Two-dimensional transport of solutes during non-steady infiltration from a trickle source. Soil Science Society of America Proceedings, v.39, n.4, p.604613, 1975.

BURGUEÑO, H. La fertirrigacion en cultivos hortícolas com acolchado plástico. Culiacan: O autor, 1994. v.1. 45p.

BURT, C.; O’CONNOR, K.; RUEHR, T. Fertigation. San Luis Obispo: The Irrigation Training \& Research Center, 1998. 295p.

BUTTERS, G.L.; CARDON, G.E. Temperature effects on air-pocket tensiometers. Soil Science, v.163, n.9, p.677-685, 1998.

CAMERON, F.K. The soil solution: the nutrient medium for plant growth. Easton: The Chemical Publishing, 1911. 136p.

CÁPSULAS porosas para tensiômetro. Boletim Informativo da Sociedade Brasileira de Ciências do Solo, v.10, n.3, p.64, 1985.

CASSEL, D.K.; KLUTE, A. Water potential: tensiometry. In: KLUTE, A. (Ed.). Methods of soil analysis: physical and mineralogical methods. part 1. Madison: ASA/SSSA, 1986. cap.23, p.563-596. (Agronomy, 9).

CASTELLANE, P.D. Nutrição mineral da cultura do tomateiro (Lycopersicon esculentum Mill). I. Efeitos do nutrientes na qualidade dos frutos. In: MULLER, J.J.V.; CASALI, V.W.D. (Ed.). Seminários de olericultura. Viçosa: UFV, 1982. v.3, p.113-157.

CASTRO, P.R.C. Efeitos de reguladores de crescimento em tomateiro (Lycopersicon esculentum Mill.). Piracicaba, 1976. 148p. Tese (Doutorado) - Escola Superior de Agricultura “Luiz de Queiroz”, Universidade de São Paulo.

CHOW, W.S.; BALL, M.C.; ANDERSON, J.M. Growth and photosynthetic responses of spinach to salinity: implications of $\mathrm{K}^{+}$nutrition for salt tolerance. Australian Journal of Plant Physiology, v.17, n.5, p.563-578, 1990.

CHURATA-MASCA, M.G.C.; BONOMO, R.; GONÇALVES, V.S.; OLIVEIRA, A.B. Resposta de híbridos de tomate industrial a diferentes níveis de potássio aplicado em 
fertirrigação (compact disc). Horticultura Brasileira, v.19, n.2, 2001. Suplemento. /Apresentado ao 41o. Congresso Brasileiro de Olericultura, Brasília, 2001 - Resumo/

COCKSHULL, K.E.; HO, L.C. Regulation of tomato fruit size by plant density and truss thinning. Journal of Horticultural Science, v.70, n.3, p.395-407, 1995.

COCKSHULL, K.E.; GRAVES, C.J.; CAVE, C.R.J. The influence of shading on yield of glasshouse tomatoes. Journal of Horticultural Science, v.67, n.1, p.11-24, 1992.

COLTMAN, R.R. Sampling considerations for nitrate quick tests of greenhouse-grown tomatoes. Journal of the American Society for Horticultural Science, v.112, n.6, p.922-927, 1987.

COLTMAN, R.R. Yields of greenhouse tomatoes managed to maintain specific petiole sap nitrate levels. HortScience, v.23, n.1, p.148-151, 1988.

CRAM, W.J. Chloride accumulation as a homeostatic system: set points and perturbation. Journal of Experimental Botany, v.34, n.148, p.1484-1502, 1983.

CRUZ, A.S.; ALFOCEA, F.P.; CARO, M.; ACOSTA, M. Polyamines as short-term salt tolerante traits in tomato. Plant Science, v.138, n.1, p.9-16, 1998.

CUARTERO, J.; MUÑOZ, R.F. Tomato and salinity. Scientia Horticulturae, v.78, n.1/4, p.83-125, 1999.

CUMMINGS, Earle (earlec@water.ca.gov). Clippings on salt-tolerant crop. 31 jul. 2001. E-mail para: SALINITY-L (salinity-1@crcvms.unl.edu).

DECHEN, A.R. Cálcio no desenvolvimento do tomateiro (Lycopersicum esculentum, Mill). Piracicaba, 1980. 91p. Tese (Doutorado) - Escola Superior de Agricultura “Luiz de Queiroz”, Universidade de São Paulo.

DOORENBOS, J.; KASSAM, A.H. Yield response to water. Rome: FAO, 1979. 193p. (FAO. Irrigation and Drainage Paper, 33).

FAYAD, J.A. Absorção de nutrientes, crescimento e produção do tomateiro cultivado em condições de campo e estufa. Viçosa, 1998. 81p. Dissertação (Mestrado) Universidade Federal de Viçosa.

FERNANDES, P.D.; CHURRATA-MASCA, M.G.C.; OLIVEIRA, G.D.; HAAG, H.P. Nutrição mineral de hortaliças. XXVII. Absorção de nutrientes pelo tomateiro 
(Lycopersicon esculentum Mill.), em cultivo rasteiro. Anais da Escola Superior de Agricultura “Luiz de Queiroz”, v.32, p.595-608, 1975.

FERREIRA, M.M.M.; FERREIRA, G.B.; FONTES, P.C.R. et al. Produção do tomateiro em função de doses de nitrogênio e da adubação orgânica em duas épocas de cultivo. Horticultura Brasileira, v.21, n.3, p.468-473, 2003.

FERREYRA E., R. Efecto de diferentes alturas de agua sobre el cultivo del tomate (Lycopersicon esculentum Mill.). I. Relación evapotranspiración-rendimiento. Agricultura Tecnica, v.47, n.3, p.254-259, 1987.

FERREYRA E., R.; TOSSO T., J.; RUIZ S., R. Efectos de diferentes alturas de agua sobre el cultivo del tomate (Lycopersicon esculentum Mill.) II. Relación evapotranspiración-crescimiento-nutrición. Agricultura Tecnica, v.49, n.3, p.211215, 1989.

FLOWERS, T.J.; YEO, A.R. Ion relations of plants under drought and salinity. Australian Journal of Plant Physiology, v.13, n.1, p.75-91, 1986.

FNP CONSULTORIA E COMÉRCIO. Agrianual 2004: anuário da agricultura brasileira. São Paulo: Argos Comunicação, 2003. p.476.

FOLEGATTI, M.V.; CASARINI, E.; BLANCO, F.F. Greenhouse irrigation water depths in relation to rose stem and bud qualities. Scientia Agricola, v.58, n.3, p.465468, 2001.

FREIRE, F.M.; MONNERAT, P.H.; MARTINS FILHO, C.A.S. Nutrição mineral e adubação do tomateiro. Informe Agropecuário, v.6, n.66, p.13-20, 1980.

FROMMER, W.B.; LUDEWIG, U.; RENTSCH, D. Taking transgenic plants with a pinch of salt. Science, v.285, n.5431, p.1222-1223, 1999.

GARCIA, N.F.; MARTÍNEZ, V.; CERDÁ, A.; CARVAJAL, M. Water and nutrient uptake of grafted tomato plants grown under saline conditions. Journal of Plant Physiology, v.159, n.8, p.899-905, 2002.

GARGANTINI, H.; BLANCO, H.G. Marcha de absorção de nutrientes pelo tomateiro. Bragantia, v.22, n.56, p.693-714, 1963. 
GERTSSON, U.E. Nutrient uptake by tomatoes grown in hydroponics. Acta Horticulturae, n.401, p.351-356, 1995.

GILLMAN, G.P.; BELL, L.C. Soil solution studies on wheathered soils from tropical north Queensland. Australian Journal of Soil Research, v.16, n.1, p.67-77, 1978.

GOLDBERG, D.; SHMUELI, M. Drip irrigation - a method used under arid and desert conditions of high water and soil salinity. Transactions of the ASAE, v.13, n.1, p.38-41, 1970.

GORHAM, J. Sodium content of agricultural crops. In: PHILLIPS, C.J.C.; CHIY, P.C.

(Ed.) Sodium in agriculture. Canterbury: Chalcombe Publications, 1995. cap.2, p.17-32.

GRACE, J.; THOMPSON, J.R. The after-effect of wind on the photosynthesis and transpiration of Festuca arundinacea. Physiologia Plantarum, v.28, n.3, p.541-547, 1973.

GRATTAN, S.R.; GRIEVE, C.M. Salinity-mineral nutrient relations in horticultural crops. Scientia Horticulturae, v.78, n.1/4, p.127-157, 1999.

GROSSMANN, J.; UDLUFT, P. The extraction of soil water by the suction-cup method: a review. Journal of Soil Science, v.42, n.1, p.83-93, 1991.

GRUMET, R.; HANSON, A.D. Genetic evidence for an osmoregulatory function of glycinebetaine accumulation in barley. Australian Journal of Plant Physiology, v.13, n.3, p.353-364, 1986.

GUIMARÃES, T.G.; FONTES, P.C.R.; PEREIRA, P.R.G. et al. Determinação dos teores de nitrogênio na seiva do tomateiro por meio de medidor portátil. Horticultura Brasileira, v.16, n.2, p.144-151, 1998.

HAAG, H.P., OLIVEIRA, G.D.; BARBOSA, V.; SILVA NETO, J.M. Nutrição mineral de hortaliças. XXXII. Marcha de absorção de nutrientes pelo tomateiro (Lycopersicon esculentum Mill.) destinado ao processamento industrial. Anais da Escola Superior de Agricultura “Luiz de Queiroz”, v.35, p.243-269, 1978. 
HALBROOK, M.C.; WILCOX, G.E. Tomato plant development and elemental accumulation. Journal of the American Society for Horticultural Science, v.105, n.6, p.826-828, 1980.

HANSEN, E.A.; HARRIS, A.R. Validity of soil-water samples collected with porous ceramic cups. Soil Science Society of America Proceedings, v.39, n.3, p.528-536, 1975.

HARBORNE, J.B. Introduction to ecological biochemistry. New York: Academic Press, 1977. 243p.

HAWKINS, H.J.; LEWIS, O.A.M. Effect of NaCl salinity, nitrogen form, calcium and potassium concentration on nitrogen uptake and kinetics in Triticum aestivum L. cv. Gametoos. The New Phytologist, v.124, n.1, p.171-177, 1993.

HO, L.C.; HEWITT, J.D. Fruit development. In: ATHERTON, J.G.; RUDICH, J. (Ed.). The tomato crop: a scientific basis for improvement. London/New York: Chapman and Hall, 1986. cap.5, p.201-239.

HOAGLAND, D.R.; MARTIN, J.C.; STEWART, G.R. Relation of the soil solution to the soil extract. Journal of Agricultural Research, v.20, n.5, p.381-395, 1920.

HOBSON, G.E.; DAVIES, U.N. The tomato. In: HULME, A.C. (Ed.). The biochemistry of fruits and their products. London: Academic Press, 1971. v.2, cap.3, p.437-482.

HOCKMUTH, G. Plant petiole sap-testing for vegetable crops. Gainesville: University of Florida, 1994. 6p. (Circular, 1144).

INSTITUTO INTERNACIONAL DE LA POTASA. Dinámica del potasio en el suelo. Worblaufen-Bern: IIP, 1977. 11p. (Guia de extensión).

JUAN, J.A.M.S. Riego por goteo. 3.ed. Madrid: Mundi-Prensa, 1993. 256p.

KAFKAFI, U.; VALORAS, N.; LETEY, J. Chloride interaction with nitrate and phosphate nutrition in tomato (Lycopersicon esculentum L.). Journal of Plant Nutrition, v.5, n.12, p.1369-1385, 1982.

KARDOS, L.T. Soil fixation of plant nutrients. In: BEAR, F.E. (Ed.) Chemistry of the soil. 2.ed. New York: Reinhold Publishing, 1964. cap.9, p.369-394. 
KIEHL, E.J. Manual de edafologia. São Paulo: Editora Agronômica Ceres, 1979. 262p.

KRONE, R.B.; LUDWIG, H.F.; THOMAS, J.F. Porous tube device for sampling soil solutions during water-spreading operations. Soil Science, v.73, n.3, p.211-219, 1952.

LE BOT, J.; ADAMOWICZ, S.; ROBIN, P. Modelling plant nutrition of horticultural crops: a review. Scientia Horticulturae, v.74, n.1/2, p.47-82, 1998.

LIANG, Y.; SHEN, Q.; SHEN, Z. et al. Effects of silicon on salinity tolerance of two barley cultivars. Journal of Plant Nutrition, v.19, n.1, p.173-183, 1996.

LIMA, C.G. Análise de dados longitudinais proveniente de experimentos em blocos casualisados. Piracicaba, 1996. 126p. Tese (Doutorado) - Escola Superior de Agricultura “Luiz de Queiroz”, Universidade de São Paulo.

LIPTAY, A.; AREVALO, A.E. Plant mineral accumulation, use and transport during the life cycle of plants: a review. Canadian Journal of Plant Science, v.80, n.1, p.29-38, 2000.

LOCASCIO, S.J.; HOCHMUTH, G.J.; RHOADS, F.M. et al. Nitrogen and potassium application scheduling effects on drip-irrigated tomato yield and leaf tissue analysis. HortScience, v.32, n.2, p.230-235, 1997.

LOPES, M.C.; STRIPARI, P.C. A cultura do tomateiro. In: GOTO, R.; TIVELLI, S.W. (Org.) Produção de hortaliças em ambiente protegido: condições subtropicais. São Paulo: UNESP, 1998. cap.9, p.257-319.

LÓPEZ, C.C. Cálculo e preparo de soluções fertilizantes. In: FOLEGATTI, M.V.; CASARINI, E.; BLANCO, F.F. et al. (Coord.) Fertirrigação: flores, frutas e hortaliças. Guaíba: Agropecuária, 2001. cap.4, p.145-162.

MAAS, E.V.; HOFFMAN, G.J. Crop salt tolerance - Current assessment. Journal of Irrigation and Drainage Division, v.103, IR2, p.115-134, 1977.

MACÊDO, L.S. Lâminas de água e fertirrigação potássica sobre o crescimento, produção e qualidade de frutos do tomateiro (Lycopersicon esculentum Mill.) em 
ambiente protegido. Lavras, 2002. 101p. Tese (Doutorado) - Universidade Federal de Lavras.

MAHER, M.J. Growth and nutrient content of glasshouse tomato crop grown in peat. Scientia Horticulturae, v.4, n.1, p.23-26, 1976.

MALAVOLTA, E.; VITTI, G.C.; OLIVEIRA, S.A. Avaliação do estado nutricional das plantas: princípios e aplicações. 2.ed. Piracicaba: POTAFOS, 1997. 201p.

MANZAN, R.J. Irrigação do tomateiro. Informe Agropecuário, v.6, n.66, p.20-21, 1980.

MARIANO, Z.F. Variação temporal do balanço hídrico e do clima, de acordo com os critérios de Köppen (1918) e Thornthwaite (1948), na região de Piracicaba - SP. Piracicaba, 1998. 90p. Dissertação (Mestrado) - Escola Superior de Agricultura “Luiz de Queiroz”, Universidade de São Paulo.

MARIN, F.R.; ANGELOCCI, L.R.; COELHO FILHO, M.A.; VILLA NOVA, N.A. Construção e avaliação de psicrômetro aspirado de termopar. Scientia Agrícola, v.58, n.4, p.839-844, 2001.

MARQUES, F.C.; TIBOLA, A.J.; PRIEBE, A.J. Cultivo protegido de cultivares de tomateiro submetidas ou não à desbrota. Horticultura Brasileira, v.18, p.190-191, 2000. Suplemento. /Apresentado ao 40o. Congresso Brasileiro de Olericultura, São Pedro, 2000 - Resumo/

MARTHALER, H.P.; VOGELSNGER, W.; RICHAR, F.; WIERENGA, P.J. A pressure transducer for field tensiometers. Soil Science Society of America Journal, v.47, n.4, p.624-627, 1983.

MARTINEZ, V.; CERDA, A.; FERNANDEZ, F.G. Salt tolerance of four tomato hybrids. Plant and Soil, v.97, n.2, p.233-242, 1987.

MARTINS, G. Produção de tomate em ambiente protegido. In: ENCONTRO NACIONAL DE PRODUÇÃO E ABASTECIMENTO DE TOMATE, 2., Jaboticabal, 1991. Anais. Jaboticabal: FUNEP, 1991. p.219-230. 
MARTINS, G. Uso de casa-de-vegetação com cobertura plástica na tomaticultura de verão. Jaboticabal, 1992. 65p. Tese (Doutorado) - Faculdade de Ciências Agrárias e Veterinárias, Universidade Estadual Paulista "Júlio de Mesquita Fo".

MOTOH, T.; KAIRUSMEE, P.; TAKAHASHI, E. Salt-induced damage to rice plants and alleviation effect of silicate. Soil Science and Plant Nutrition, v.32, n.2, p.295304, 1986.

MEDEIROS, J.F. Manejo da água de irrigação salina em estufa cultivada com pimentão. Piracicaba, 1998. 152p. Tese (Doutorado) - Escola Superior de Agricultura “Luiz de Queiroz”, Universidade de São Paulo.

MENGEL, K.; KIRKBY, E.A. Principles of plant nutrition. 4.ed. Switzerland: International Potash Institute, 1987. 687p.

MENK, J.R.F.; IGUE, T. Relacionamento de dados de solos entre métodos analíticos: o caso da análise granulométrica. Revista Brasileira de Ciência do Solo, v.16, n.2, p.143-152, 1992.

MIRANDA, J. Caracterização da solução do solo e das propriedades físicas e químicas de um latossolo vermelho-amarelo sob diferentes coberturas vegetais. Viçosa, 1993. 65p. Dissertação (Mestrado) - Universidade Federal de Viçosa.

MIRANDA, J.R.P.; CARVALHO, J.G.; SANTOS, D.R. et al. Silício e cloreto de sódio na nutrição mineral e produção de matéria seca de plantas de moringa (Moringa oleifera LAM.). Revista Brasileira de Ciência do Solo, v.26, n.4, p.957-965, 2002.

MITCHELL, J.P.; SHENNAN, C.; GRATTAN, S.R.; MAY, D.M. Tomato fruit yields and quality under water deficit and salinity. Journal of the American Society for Horticultural Science, v.116, n.2, p.215-221, 1991.

MOFTAH, A.E.; MICHEL, B.E. The effect of sodium chloride on solute potential and proline accumulation in soybean leaves. Plant Physiology, v.83, n.2, p.238-243, 1987.

MORAES, J.F.V. Movimento de nutrientes em latossolo vermelho-escuro. Pesquisa Agropecuária Brasileira, v.26, n.1, p.85-97, 1991. 
MORAES, J.F.V.; DYNIA, J.F. Uso de cápsulas porosas para extrair solução do solo. Pesquisa Agropecuária Brasileira, v.25, n.10, p.1523-1528, 1990.

MORRISON, D.F. Multivariate statistical methods. 3.ed. New York: McGraw-Hill, 1990. 414p.

MORRISON, R.; SZECSODY, J. Sleeve and casing lysimeters for soil pore water sampling. Soil Science, v.139, n5, p.446-451, 1985.

MOSS, P. Some aspects of the cation status of soil moisture. Part I: The ratio law and soil moisture content. Plant and Soil, v.18, n.1, p.99-113, 1963.

MUSICK, J.T.; DUSEK, D.A. Limited irrigation of grain sorghum in alternating strips with wheat. Transactions of the ASAE, v.18, n.3, p.544-548, 1975.

NAGAI, H. Avanços obtidos com o melhoramento genético do tomate no Brasil. In: ENCONTRO NACIONAL DE PRODUÇÃO E ABASTECIMENTO DE TOMATE, 1., Viçosa, 1989. Anais. Viçosa: UFV 1989. p.88-107.

NAVARRETE, M.; JEANNEQUIN, B. Effect of frequency of axillary bud pruning on vegetative growth and fruit yield in greenhouse tomato crops. Scientia Horticulturae, v.86, n.3, p.197-210, 2000.

NAVARRETE, M.; JEANNEQUIN, B.; SEBILLOTTE, M. Vigour of greenhouse tomato plants (Lycopersicon esculentum Mill.): analysis of the criteria used by growers and search for objective criteria. Journal of Horticultural Science, v.72, n.5, p.821-829, 1997.

NELSON, P.V.; FABER, W.R. Bulk solution displacement. HortScience, v.21, n.2, p.225-227, 1986.

NICOLA, S.; BASOCCU, L. Nitrogen and N, P, K relation affect tomato seedling growth, yield and earliness. Acta Horticulturae, n.357, p.95-102, 1994.

NOGUEIRA, M.C.S. Estatística experimental aplicada à experimentação agronômica. Piracicaba: ESALQ, 1997. 250p.

OLITTA, A.F.; MINAMI, K. Irrigação por gotejo em morango. Anais da Escola Superior de Agricultura “Luiz de Queiroz”, v.31, p.713-720, 1974. 
OLIVEIRA, A.S.; SALATI, E. Um estudo sobre as águas subterrâneas da região de Piracicaba. Anais da Escola Superior de Agricultura “Luiz de Queiroz”, v.38, p.885-907, 1981.

PALEG, L.G.; STEWART, G.R.; BRADBEER, J.W. Proline and glycine betaine influence protein solvation. Plant Physiology, v.75, n.4, p.974-978, 1984.

PAPADOPOULOS, A.P. Growing greenhouse tomatoes in soil and in soilless media. Ottawa: Agriculture Canada Publication, 1991. 79p.

PAPADOPOULOS, I. Constant feeding of field-grown tomatoes irrigated with sulphate water. Plant and Soil, v.88, n.2, p.231-236, 1985.

PAPADOPOULOS, I. Effects of residual soil salinity resulting from sulphate waters on lettuce. Plant and Soil, v.97, n.2, p.171-177, 1987.

PASCALE, S.; MAGGIO, A.; FOGLIANO, V. et al. Irrigation with saline water improves carotenoids content and antioxidant activity of tomato. Journal of Horticultural Science \& Biotechnology, v.76, n.4, p.447-453, 2001.

PESSARAKLI, M.; TUCKER, T.C. Dry matter yield and nitrogen-15 uptake by tomatoes under sodium chloride stress. Soil Science Society of America Journal, v.52, n.3, p.698-700, 1988.

PHILLS, B.R.; PECK, N.H.; MACDONALD, G.E. et al. Differential response of Lycopersicon and Solanum species to salinity. Journal of the American Society for Horticultural Science, v.104, n.3, p.349-352, 1979.

PICHA, D.H.; HALL, C.B. Effect of potassium fertilization and season on fresh market tomato quality characters. HortScience, v.17, n.4, p.634-635, 1982.

PILL, W.G.; LAMBETH, V.N.; HINCKLEY, T.M. Effects of nitrogen form and level on ion concentrations, water stress, and blossom-end rot incidence in tomato. Journal of the American Society for Horticultural Science, v.103, n.2, p.265-268, 1978.

PINTO, J.M.; SOARES, J.M.; NASCIMENTO, T. Análise de coeficientes de uniformidade de distribuição de água em sistema de irrigação localizada. 
Petrolina: EMBRAPA-CPATSA, 1991. 24p. (EMBRAPA-CPATSA. Boletim de Pesquisa, 41).

PRASAD, M.; SPIERS, T.M. A rapid nitrate sap test for outdoor tomatoes. Scientia Horticulturae, v.25, n.3, p.211-215, 1985.

PRASHAR, C.R.K.; PEARL, R.; HAGAN, R.M. Review on water and crop quality. Scientia Horticulturae, v.5, n.3, p.193-205, 1976.

PREGNOLATTO, W.; PREGNOLATTO, N.P. Normas analíticas do Instituto Adolfo

Lutz: métodos químicos e físicos para análise de alimentos. 3.ed. São Paulo: Instituto Adolfo Lutz, 1985. v.1, 533p.

PRINCE, A.B. Absorption spectrophotometry. In: BLACK, C.A.; EVANS, D.D.; WHITE, J.L. et al. (Ed.). Methods of soil analysis: chemical and microbiological properties. part 2. Madison: ASA, 1965. cap.55, p.866-878. (ASA. Agronomy, 9).

QIAN, P.; WOLT, J.D. Effects of drying and time of incubation on the composition of displaced soil solution. Soil Science, v.149, n.6, p.367-374, 1990.

RAINS, D.W. Plant tissue and protoplast culture: applications to stress physiology and biochemistry. In: JONES, H.G.; FLOWERS, T.J.; JONES, M.B.(Ed.). Plants under stress. Cambridge: Cambridge University Press, 1989. cap.10, p.181-196.

RAJASEKARAN, L.R.; ASPINALL, D.; PALEG, L.G. Physiological mechanism of tolerance of Lycopersicon spp. exposed to salt stress. Canadian Journal of Plant Science, v.80, n.1, p.151-159, 2000.

REEVE, R.C.; DOERING, E.J. Sampling the soil solution for salinity appraisal. Soil Science, v.99, n.5, p.339-344, 1965.

RENDIG, V.V.; BROADBENT, F.E. Plant physiological responses to interactions between salt and water stress and $\mathrm{N}$ utilization. In: LETEY, J. (Ed.). Soil and plant interactions with salinity: Kearney foundation five-year report 1980-1985. Berkeley: University of California, 1985. cap.9, p.39-43.

RHOADES, J.D. Quality of water for irrigation. Soil Science, v.113, n.4, p.277-284, 1974. 
RHOADES, J.D.; KANDIAH, A.M.; MASHALI, A.M. Uso de águas salinas para produção agrícola. Trad. de H.R. Gheyi, J.R. de Sousa, J.E. Queiroz. Campina Grande: UFPB, 2000. 117p. (Estudos FAO: Irrigação e Drenagem, 48).

RHOADES, J.D.; MANTEGHI, N.A.; SHOUSE, P.J. et al. Soil electrical conductivity and soil salinity: new formulations and calibrations. Soil Science Society of America Journal, v.53, n.2, p.433-439, 1989.

RICH, C.I. Elemental analysis by flame photometry. In: BLACK, C.A.; EVANS, D.D.; WHITE, J.L. et al. (Ed.). Methods of soil analysis: chemical and microbiological properties. part 2. Madison: ASA, 1965. cap. 54, p.849-865. (ASA. Agronomy, 9).

RICHARDS, L.A. A pressure-membrane extraction apparatus for soil solution. Soil Science, v.51, n.5, p.377-386, 1941.

RICHARDS, L.A. Diagnosis and improvement of saline and alkali soils. Washington: United States Salinity Laboratory, 1954. 160p. (USDA. Agriculture Handbook, 60).

RONCHI, C.P.; FONTES, P.C.R.; PEREIRA, P.R.G. et al. Índices de nitrogênio e de crescimento do tomateiro em solo e em solução nutritiva. Revista Ceres, v.48, n.278, p.469-484, 2001.

ROSSI, C.; LIMA, G.P.P.; HAKVOORT, D.M.R. Atividade de peroxidases (EC 1.11.1.7) e teor de prolina em feijoeiro Phaseolus vulgaris L. cultivado em condições de salinidade. Scientia Agrícola, v.54, n.3, p.123-127, 1997.

RUSH, D.W.; EPSTEIN, E. Genotypic responses to salinity: diferences between saltsensitive and salt-tolerant genotypes of the tomato. Plant Physiology, v.57, n.2, p.162-166, 1976.

SAGLAM, N.; YAZGAN, A. Effect of fruit number per truss on yield and quality in tomato. Acta Horticulturae, n.491, p.261-264, 1999.

SAKAMOTO, Y.; WATANABE, S.; NAKASHIMA, T. et al. Effects of salinity at two ripening stages on the fruit quality of single-truss tomato grown in hydroponics. Journal of Horticultural Science \& Biotechnology, v.74, n.6, p.690-693, 1999. 
SAMPAIO, R.A. Produção, qualidade dos frutos e teores de nutrientes no solo e no pecíolo do tomateiro, em função da fertirrigação potássica e da cobertura plástica do solo. Viçosa, 1996. 117p. Tese (Doutorado) - Universidade Federal de Viçosa.

SASAKI, J.L.S.; SENO, S. Importância da adubação na qualidade de algumas olerícolas (alho, cebola, couve-flor, pimentão e tomate). In: SÁ, M.E.; BUZZETI, S. (Coord.) Importância da adubação na qualidade dos produtos agrícolas. São Paulo: Ícone, 1994. cap.19, p.331-343.

SAXENA, G.K.; LOCASCIO, S.J.; LUCAS, J.B. Effect of N, P and K rates on response of cabbage and tomato grown on a coasted clay soil of Guyana. Tropical Agriculture, v.52, n.2, p.149-156, 1975.

SCAIFE, A.; STEVENS, K.L. Monitoring sap nitrate in vegetable crops: comparison of test strips with electrode methods, and effects of time of day and leaf position. Communications in Soil Science and Plant Analysis, v.14, n.9, p.761-771, 1983.

SCHACHTMAN, D.P.; SCHROEDER, J.I. Structure and transport mechanism of a high-affinity potassium uptake transporter from higher plants. Nature, v.370, n.6491, p.655-658, 1994.

SHIMSHI, D. Use of ceramic points for the sampling of soil solution. Soil Science, v.101, n.2, p.98-103, 1966.

SILKWORTH, D.R.; GRIGAL, D.F. Field comparison of soil solution samplers. Soil Science Society of America Proceedings, v.45, n.2, p.440-442, 1981.

SILVA, E.F.F. Manejo da fertirrigação e controle da salinidade na cultura do pimentão utilizando extratores de solução do solo. Piracicaba, 2002. 136p. Tese (Doutorado) - Escola Superior de Agricultura “Luiz de Queiroz”, Universidade de São Paulo.

SMETHURST, P.J. Soil solution and other soil analyses as indicators of nutrient supply: a review. Forest Ecology and Management, v.138, n.1/3, p.397-411, 2000.

SMITH, J.H.; SILVERTOOTH, J.C.; NORTON, E.R. Comparison of the two methods for the analysis of petiole nitrate nitrogen concentration in irrigated cotton. http://ag.arizona,edu/pubs/crops/az1006/az10068c. html. (08 Jan. 2000). 
SOARES, J.M.; FARIA, C.M.B. Métodos de irrigação e adubação na cultura do tomate industrial. Pesquisa Agropecuária Brasileira, v.18, n.3, p.281-286, 1983.

SOUSA, E.F.; BERNARDO, S.; CARVALHO, J.A. Função de produção da cana-deaçúcar em relação à água para três variedades, em Campos dos Goytacazes, RJ. Engenharia Agrícola, v.19, n.1, p.28-42, 1999.

SPARKS, D.L.; HUANG, P.M. Physical chemistry of soil potassium. In: MUNSON, R.D. (Ed.). Potassium in agriculture. Madison: ASA/CSSA/SSSA, 1985. cap.9, p.201-276.

STANLEY, C.D.; MAYNARD, D.N. Vegetables. In: STEWART, B.A.; NIELSEN, D.R. (Ed.). Irrigation of agricultural crops. Madison: ASA/CSSA/SSSA, 1990. cap.31, p.921-950.

STEEL, R.G.D.; TORRIE, J.H. Principles and procedures of statistics: a biometrical approach. 2.ed. New York: McGraw-Hill, 1980. 633p.

STEGMAN, E.C.; MUSICK, J.T.; STEWART, J.I. Irrigation water management. In: JENSEN, M.E. (Ed.) Design and operation of farm irrigation systems. St. Joseph: ASAE, 1980. cap.18, p.763-816.

STEVENS, M.A.; RICK, C.M. Genetics and breeding. In: ATHERTON, J.G.; RUDICH, J. (Ed.). The tomato crop: a scientific basis for improvement. London/New York: Chapman and Hall, 1986. cap.2, p.35-109.

SUAREZ, D.L. Prediction of $\mathrm{pH}$ errors in soil-water extractors due to degassing. Soil Science Society of America Journal, v.51, n.1, p.64-67, 1987.

SUHAYDA, C.G.; GIANNINI, J.L.; BRISKIN, D.P. et al. Eletrostatic changes in Lycopersicon esculentum root plasma membrane resulting from salt stress. Plant Physiology, v.93, n.2, p.471-478, 1990.

TANAKA, A.; FUJITA, K. Nutrio-physiological studies on the tomato plant: IV. source-sink relationships and the structure of the source-sink unit. Soil Science and Plant Nutrition, v.20, n.3, p.305-315, 1974.

TEI, F.; BENINCASA, P.; GUIDUCCI, M. Critical nitrogen concentration in processing tomato. European Journal of Agronomy, v.18, n.1/2, p.45-55, 2002. 
THOMPSON, J.F. Arginine synthesis, praline synthesis, and related processes. In: MIFLIN, B.J. (Ed.). Amino acids and derivatives. New York: Academic Press, 1980. cap.10, p.375-402. (Biochemistry of Plants, v.5).

TISDALE, S.L.; NELSON, W.L.; BEATON, J.D.; HAVLIN, J.L. Soil fertility and fertilizers. 5.ed. New York: Macmillan Publishing, 1993. 634p.

TORELLO, W.A.; RICE, L.A. Effects of $\mathrm{NaCl}$ stress on proline and cation accumulation in salt sensitive and tolerant turfgrasses. Plant and Soil, v.93, n.2, p.241-247, 1986.

TORRECILLAS, A.; GUILLAUME, C.; ALARCÓN, J.J.; RUIZ-SÁNCHEZ, M.C. Water relations of two tomato species under water stress and recovery. Plant Science, v.105, n.2, p.169-176, 1995.

TRANI, P.E. Fertirrigação para hortaliças no Estado de São Paulo. In: WORKSHOP DE FERTIRRIGAÇÃO, 1., Piracicaba, 1999. Resumos. Piracicaba: DER/ESALQ/USP, 1999. p.35-36.

TRANI, P.E.; NUCCI, T.A.; MINAMI, K.; HAAG, H.P. Nutrição mineral e adubação do tomateiro. Campinas: IAC, 1994. 67p. (IAC. Boletim técnico, 151).

TRAVIS, J. Gene makes tomato tolerate salts. Science News, v.160, n.5, p.68, 2001. van den ENDE, J.; KOORNNEEF, P.; SONNEVELD, C. Osmotic pressure of the soil solution: determination and effects on some glasshouse crops. Netherlands Journal of Agricultural Science, v.23, n.3, p.181-190, 1975.

van SCHILFGAARDE, J.; BERNSTEIN, L.; RHOADES, J.D.; RAWLINS, S.L. Irrigation management for salt control. Journal of the Irrigation and Drainage Division, v.100, IR3, p.321-338, 1974.

VIEIRA, D.B.; MANFRINATO, H.A. A irrigação por gotejamento em berinjela. Anais da Escola Superior de Agricultura “Luiz de Queiroz”, v.31, p.73-90, 1974.

VILLAS BÔAS, R.L.; ANTUNES, C.L.; BOARETTO, A.E. et al. Perfil da pesquisa e emprego da fertirrigação no Brasil. In: FOLEGATTI, M.V.; CASARINI, E.; BLANCO, F.F. et al. (Coord.) Fertirrigação: flores, frutas e hortaliças. Guaíba: Agropecuária, 2001. cap.2, p.71-103. 
VIVANCOS, A.D. Fertirrigacion. Madri: Mundi-Prensa, 1993. 217p.

VOOGT, W. Nutrient uptake of year round tomato crops. Acta Horticulturae, n.339, p.99-112, 1993.

YARON, B.; SHALHEVET, J.; SHIMSHI, D. Patterns of salt distribution under trickle irrigation. In: HADA, A.; SWARTZENDRUBER, D.; RIJTEMA, P.E.; FUCHS, M.; YARON, B. (Ed.). Physical aspects of soil water and salts in ecosystems. Berlin: Springer-Verlag, 1973. p.389-394. (Ecological Studies, 4).

YEO, A.R.; FLOWERS, T.J. Selection for physiological characters - examples from breeding for salt tolerance. In: JONES, H.G.; FLOWERS, T.J.; JONES, M.B. (Ed.). Plants under stress. Cambridge: Cambridge University Press, 1989. cap.12, p.217-234.

YOHANNES, F.; TADESSE, T. Effect of drip and furrow irrigation and plant spacing on yield of tomato at Dire Dawa, Ethiopia. Agricultural Water Management, v.35, n.3, p.201-207, 1998.

WAGNER, G.H. Use of porous ceramic cups to sample soil water within the profile. Soil Science, v.94, p.379-387, 1962.

WARD, G.M. Growth and nutrient absorption in greenhouse tomato and cucumber. Proceedings of the American Society for Horticultural Science, v.90, p.335-341, 1967.

WARRICK, A.W.; AMOOZEGAR-FARD, A. Soil water regimes near porous cup water samplers. Water Resources Research, v.13, n.1, p.203-207, 1977.

WILCOX, G.E.; HOFF, J.E.; JONES, C.M. Amonium reduction of calcium and magnesium content of tomato and sweet corn leaf tissue and influence of incidence of blossom-end rot of tomato fruit. Journal of the American Society for Horticultural Science, v.98, n.1, p.86-89, 1973.

WILLMOTT, C.J. On the validation of models. Physical Geography, v.2, n.2, p.184194, 1981.

WINSOR, G.; ADAMS, P. Diagnosis of mineral disorders in plants: glasshouse crops. v.3. London: MAFF/AFRC, 1987. 168p. 
WINSOR, G.W.; DAVIES, J.N.; LONG, M.I.E. The effects of nitrogen, phosphorus, potassium, magnesium and lime in factorial combination on the yields of glasshouse tomatoes. Journal of Horticultural Science, v.42, n.3, p.277-288, 1967.

WOLK, J.O.; KRETCHMAN, D.W.; ORTEGA JUNIOR., D.G. Response of tomato to defoliation. Journal of the American Society for Horticultural Science, v.108, n.4, p.536-540, 1983.

WOLT, J.D. Soil solution chemistry: applications to environmental science and agriculture. New York: Wiley, 1994. 345p.

WOOD, A.L.; WILSON, J.T.; COSBY, R.L.; et al. Apparatus and procedure for sampling soil profiles for volatile organic compounds. Soil Science Society of America Journal, v.45, n.2, p.442-444, 1981. 